\title{
MEASUREMENTS VERSUS PREDICTIONS FOR A HYBRID (HYDROSTATIC PLUS HYDRODYNAMIC) THRUST BEARING FOR A RANGE OF ORIFICE DIAMETERS
}

\author{
A Thesis \\ by \\ PAUL ROBERT ESSER \\ Submitted to the Office of Graduate Studies of \\ Texas A\&M University \\ in partial fulfillment of the requirements for the degree of \\ MASTER OF SCIENCE
}

May 2010

Major Subject: Mechanical Engineering 


\title{
MEASUREMENTS VERSUS PREDICTIONS FOR A HYBRID (HYDROSTATIC PLUS HYDRODYNAMIC) THRUST BEARING FOR A RANGE OF ORIFICE DIAMETERS
}

\author{
A Thesis \\ by \\ PAUL ROBERT ESSER
}

\begin{abstract}
Submitted to the Office of Graduate Studies of
Texas A\&M University

in partial fulfillment of the requirements for the degree of

MASTER OF SCIENCE
\end{abstract}

\begin{abstract}
Approved by:
Chair of Committee, Dara W. Childs

Committee Members, Gerald Morrison

James R. Morgan

Head of Department, Dennis L. O’Neal
\end{abstract}

May 2010

Major Subject: Mechanical Engineering 


\begin{abstract}
Measurements versus Predictions for a Hybrid (Hydrostatic plus Hydrodynamic)

Thrust Bearing for a Range of Orifice Diameters. (May 2010)

Paul Robert Esser, B.S., Texas Christian University

Chair of Advisory Committee: Dr. Dara W. Childs
\end{abstract}

A fixed geometry hybrid thrust bearing is investigated with three different supply orifice diameters. The test rig uses a face-to-face thrust bearing design, with the test bearing acting as the rotor loading mechanism. A hydraulic shaker applies the static axial load, which is reacted by a second thrust bearing. The rotor is supported radially by two water-lubricated fluid film journal bearings and is attached to a $30,600 \mathrm{rpm}$ motor via a high speed coupling with very low axial stiffness. Thrust bearings with three different orifice diameters $(1.63,1.80$, and $1.93 \mathrm{~mm})$ are tested for a range of supply pressures, fluid film thicknesses, and rotational speeds. The water-lubricated test bearings have eight pockets, with feed orifices located centrally in each pocket. Experimental results are comparted to predictions found using bulk flow model HYDROTHRUST®.

Analysis of the data reveals generally good agreements between predictions and measurements. Thrust-bearing inlet supply and inner radius flow rates all decreased with decreasing orifice diameters and bearing axial clearances. In most cases, the bearings with larger orifice diameters exhibit higher recess pressure ratios, operating 
clearances, and flow rates. The largest orifice diameter configuration does not display higher recess pressure ratios or operating clearances at high speeds for some supply pressures, but it does continue to require additional lubricant flow rate compared to the smaller orifice bearings. In these cases, the results are not reflected in predictions, which otherwise correlate very well with experimental measurements. Estimations of static loading axial stiffness are obtained using experimental results.

An optimum hybrid thrust bearing orifice diameter will depend on the conditions of individual applications. Larger orifices generally provide larger operating clearances and higher stiffnesses, but also require higher flow rates. For most applications, a compromise of bearing performance parameters will be desired. The test results and comparisons presented will aid in sizing orifice diameters for future hybrid thrust bearing designs. 


\section{DEDICATION}

To my family, who have always supported me. 


\section{ACKNOWLEDGEMENTS}

I would like to thank my committee chair, Dr. Childs, for providing me with the opportunity to work on this project, and for is continued guidance and support over the course of this research.

Thanks also to Mike Forsberg and Fernando Ramirez for their prior effort on the test rig. I also thank David Klooster, Scott Wilson, and the rest of my coworkers at the Turbomachinery Laboratory. I would also like to thank Stephen Phillips and Eddie Denk for all the support and assistance.

Finally, I would like to thank my parents for their love and ongoing patience. 


\section{NOMENCLATURE}

$A_{0}$

$C_{d}$

$D_{o}$

$E_{d F / d Z}$

$E_{N}$

$F_{Z}$

$K_{m n}$

$M_{1}$

$M_{2}$

$P_{e}, P_{r}, P_{s}$

$p_{\text {ratio }}$

$Q_{0}$

$V_{o}$

$Z_{1}, Z_{2}, Z_{3}$

$z$

$\Phi_{b}$

$\rho$

$\mu$ $\rho$
Orifice cross-sectional area

$\left[\mathrm{mm}^{2}\right]$

Orifice discharge coefficient

Orifice diameter

$[\mathrm{mm}]$

Overall uncertainty

Uncertainty associated with term "N"

Load on the bearing face

$[\mathrm{N}]$

Stiffness coefficient for " $\mathrm{m}$ " direction from the " $\mathrm{n}$ " variable $[\mathrm{N} / \mathrm{m}]$

Thrust bearing horizontal misalignment

$[\mathrm{mm} / \mathrm{mm}]$

Thrust bearing vertical misalignment

$[\mathrm{mm} / \mathrm{mm}]$

Exhaust, recess, and supply pressures

[bar]

Recess pressure ratio

Flow rate through an orifice

[LPM]

Fluid velocity through the orifice

$[\mathrm{m} / \mathrm{s}]$
Gap reading from proximity probes 1,2 , and 3 , respectively[mm]

Thrust bearing clearance

Misalignment angle about axis " $b$ "

[radians]

Fluid density

$\left[\mathrm{kg} / \mathrm{m}^{3}\right]$

Fluid dynamic viscosity
$\left[\mathrm{N}^{*} \mathrm{~s} / \mathrm{m}^{3}\right]$ 


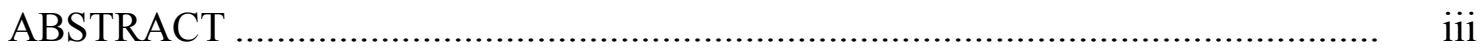

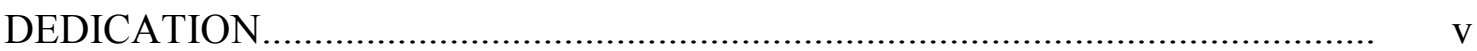

ACKNOWLEDGEMENTS........................................................................ vi

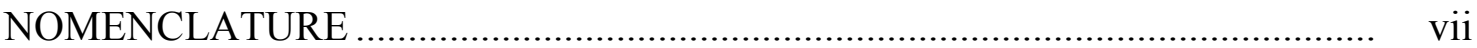

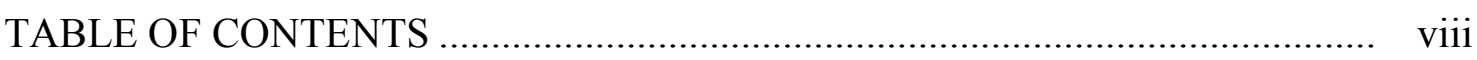

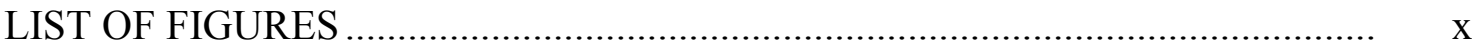

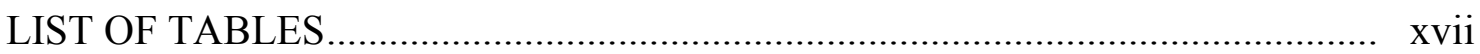

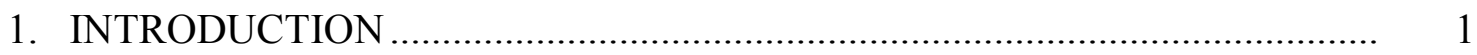

2. PREVIOUS THRUST BEARING TEST RIGS AND RESEARCH ................... 4

3. TEST RIG DESCRIPTION AND INSTRUMENTATION …………………...... 6

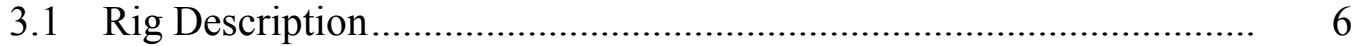

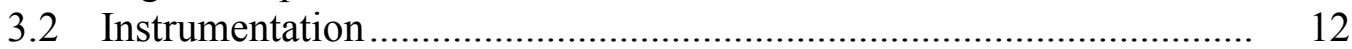

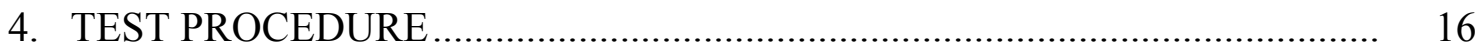

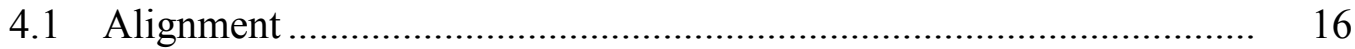

4.2 Test Procedure ….......................................................................... 19

5. TEST RESULTS AND PREDICTIONS ......................................................... 22

$5.1 \quad$ Inlet Flow Rate ........................................................................... 27

5.2 Recess Pressure Ratios ...................................................................... 30

5.3 Inner Radius Exhaust Flow Rate ......................................................... 36

5.4 Operating Center Clearance............................................................... 39

5.5 Estimation of Axial Stiffness........................................................... 45

6. SUMMARY AND CONCLUSIONS ……………….................................... 51 


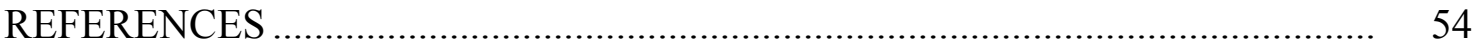

APPENDIX A - RADIAL AND AEROSTATIC BEARING DETAIL ................. 56 APPENDIX B - UNCERTAINTY ANALYSIS OF EXPERIMENTAL MEASUREMENTS ..................................................................... 58

APPENDIX C - LABVIEW FRONT PANEL AND INSTRUMENTATION

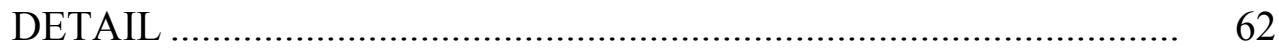

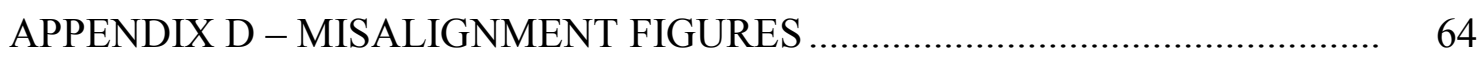

APPENDIX E - INLET FLOW RATE FIGURES …....................................... 70

APPENDIX F - RECESS PRESSURE RATIO FIGURES ................................. 76

APPENDIX G - INNER RADIUS EXHAUST FLOW RATE FIGURES ............. 82

APPENDIX H - CENTER CLEARANCE FIGURES ..................................... 88

APPENDIX I - ESTIMATED AXIAL STIFFNESS FIGURES .......................... 95

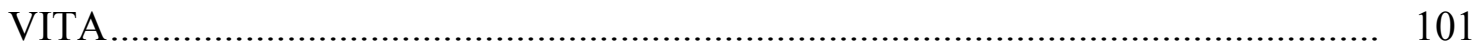




\section{LIST OF FIGURES}

Page

Figure 1: $\quad$ Test thrust bearing front and back .............................................. 2

Figure 2: $\quad$ Test rig schematic .................................................................

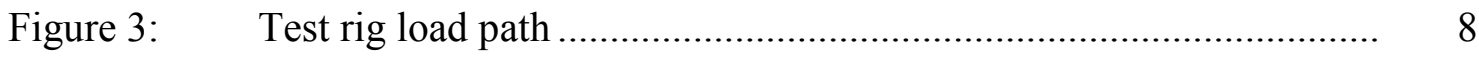

Figure 4: $\quad$ Test thrust bearing support pedestal and loading shaft.................... 9

Figure 5: $\quad$ Test thrust bearing water and air flow ....................................... 10

Figure 6: $\quad$ Test thrust bearing instrumentation [16] ................................... 13

Figure 7: Misalignment illustration and proximity probe locations on the

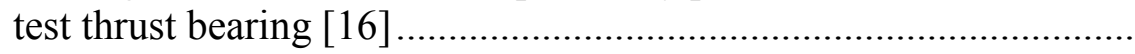

Figure 8: $\quad$ Misalignment over the bearing face about the $\mathrm{x}$ and $\mathrm{y}$ axes versus center clearance at 17.24 bar supply and $17.5 \mathrm{krpm}$. Lines note desired misalignment limits $( \pm 0.013 \mathrm{~mm})$

Figure 9: $\quad$ Measured and predicted [3] inlet flow rate versus center clearance at 10.34 bar supply and $12.5 \mathrm{krpm}$ 28

Figure 10: $\quad$ Measured and predicted [3] inlet flow rate versus clearance at 17.24 bar supply and $7.5 \mathrm{krpm}$

Figure 11: $\quad$ Measured and predicted [3] inlet flow rate versus center clearance at 5.17 bar supply and $0 \mathrm{rpm}$

Figure 12: $\quad$ Measured and predicted [3] recess pressure ratio versus clearance at 10.34 bar supply and $12.5 \mathrm{krpm}$

Figure 13: $\quad$ Measured and predicted [3] recess pressure ratio versus clearance at 17.24 bar supply and $7.5 \mathrm{krpm}$

Figure 14: $\quad$ Measured and predicted [3] recess pressure ratio versus clearance at 5.17 bar supply and $0 \mathrm{rpm}$

Figure 15: $\quad$ Measured and predicted [3] recess pressure ratio versus clearance at 5.17 bar supply and $17.5 \mathrm{krpm}$. 
Figure 16: Measured and predicted [3] recess pressure ratio versus clearance at 17.24 bar supply and $12.5 \mathrm{krpm}$

Figure 17: $\quad$ Measured and predicted [3] inner radius exhaust flow rate versus center clearance at 17.24 bar supply and $12.5 \mathrm{krpm}$.

Figure 18: $\quad$ Measured and predicted [3] inner radius exhaust flow rate versus center clearance at 10.34 bar supply and $12.5 \mathrm{krpm}$.

Figure 19: $\quad$ Measured and predicted [3] inner radius exhaust flow rate versus center clearance at 5.17 bar supply and $0 \mathrm{rpm}$

Figure 20: $\quad$ Measured and predicted [3] inner radius exhaust flow rate versus center clearance at 5.17 bar and $17.5 \mathrm{krpm}$.

Figure 21: $\quad$ Measured and predicted [3] center clearance versus load for $1.63 \mathrm{~mm}$ orifice bearing at 17.24 bar supply and $7.5 \mathrm{krpm}$.

Figure 22: $\quad$ Measured and predicted [3] center clearance versus load at 5.17 bar supply and $0 \mathrm{rpm}$

Figure 23: $\quad$ Measured and predicted [3] center clearance versus load at 10.34 bar supply and $7.5 \mathrm{krpm}$

Figure 24: $\quad$ Measured and predicted [3] center clearance versus load at 17.24 bar supply and $7.5 \mathrm{krpm}$

Figure 25: $\quad$ Measured and predicted [3] center clearance versus load at 10.34 bar supply and $1.63 \mathrm{~mm}$ orifice diameters for all speeds

Figure 26: Estimated axial stiffness versus clearance at 5.17 bar supply and $0 \mathrm{rpm}$

Figure 27: $\quad$ Estimated axial stiffness versus clearance at 10.34 bar supply and $7.5 \mathrm{krpm}$

Figure 28: $\quad$ Measured and predicted [3] load versus center clearance at 10.34 bar supply and $7.5 \mathrm{krpm}$

Figure 29: $\quad$ Estimated axial stiffness versus clearance at 17.24 bar supply and $7.5 \mathrm{krpm}$

Figure A-1: Depiction of radial hybrid bearings 
Figure A-2: $\quad$ View of aerostatic bearing ( $3 \mathrm{~d}$, side and front cross sections) .......... 58

Figure C-1: $\quad$ LabVIEW VI front panel ............................................................. 62

Figure D-1: Misalignment over the bearing face about the $\mathrm{x}$ and $\mathrm{y}$ axes versus center clearance at 5.17 bar supply and $0 \mathrm{rpm}$

Figure D-2: Misalignment over the bearing face about the $\mathrm{x}$ and $\mathrm{y}$ axes versus center clearance at 5.17 bar supply and $7.5 \mathrm{krpm}$

Figure D-3: Misalignment over the bearing face about the $\mathrm{x}$ and $\mathrm{y}$ axes versus center clearance at 5.17 bar supply and $12.5 \mathrm{krpm}$

Figure D-4: Misalignment over the bearing face about the $\mathrm{x}$ and $\mathrm{y}$ axes versus center clearance at 5.17 bar supply and $17.5 \mathrm{krpm}$

Figure D-5: Misalignment over the bearing face about the $\mathrm{x}$ and $\mathrm{y}$ axes versus center clearance at 10.34 bar supply and $0 \mathrm{rpm}$

Figure D-6: Misalignment over the bearing face about the $\mathrm{x}$ and $\mathrm{y}$ axes versus center clearance at 10.34 bar supply and $7.5 \mathrm{krpm}$

Figure D-7: Misalignment over the bearing face about the $\mathrm{x}$ and $\mathrm{y}$ axes versus center clearance at 10.34 bar supply and $12.5 \mathrm{krpm}$

Figure D-8: Misalignment over the bearing face about the $\mathrm{x}$ and $\mathrm{y}$ axes versus center clearance at 10.34 bar supply and $17.5 \mathrm{krpm}$

Figure D-9: Misalignment over the bearing face about the $\mathrm{x}$ and $\mathrm{y}$ axes versus center clearance at 17.24 bar supply and $0 \mathrm{rpm}$

Figure D-10: Misalignment over the bearing face about the $\mathrm{x}$ and $\mathrm{y}$ axes versus center clearance at 17.24 bar supply and $7.5 \mathrm{krpm}$

Figure D-11: Misalignment over the bearing face about the $\mathrm{x}$ and $\mathrm{y}$ axes versus center clearance at 17.24 bar supply and $12.5 \mathrm{krpm}$

Figure D-12: Misalignment over the bearing face about the $\mathrm{x}$ and $\mathrm{y}$ axes versus center clearance at 17.24 bar supply and $17.5 \mathrm{krpm}$ - repeated for reference

Figure E-1: $\quad$ Measured and predicted [3] inlet flow rate versus clearance at 5.17 bar supply and $0 \mathrm{rpm}$ - repeated for reference 
Figure E-2: $\quad$ Measured and predicted [3] inlet flow rate versus clearance at 5.17 bar supply and $7.5 \mathrm{rpm}$

Figure E-3: $\quad$ Measured and predicted [3] inlet flow rate versus clearance at 5.17 bar supply and $12.5 \mathrm{rpm}$......

Figure E-4: $\quad$ Measured and predicted [3] inlet flow rate versus clearance at 5.17 bar supply and $17.5 \mathrm{rpm}$

Figure E-5: $\quad$ Measured and predicted [3] inlet flow rate versus clearance at 10.34 bar supply and $0 \mathrm{rpm}$

Figure E-6: Measured and predicted [3] inlet flow rate versus clearance at 10.34 bar supply and $7.5 \mathrm{krpm}$

Figure E-7: $\quad$ Measured and predicted [3] inlet flow rate versus clearance at 10.34 bar supply and $12.5 \mathrm{krpm}$ - repeated for reference

Figure E-8: $\quad$ Measured and predicted [3] inlet flow rate versus clearance at 10.34 bar supply and $17.5 \mathrm{krpm}$.

Figure E-9: $\quad$ Measured and predicted [3] inlet flow rate versus clearance at 17.24 bar supply and $0 \mathrm{rpm}$

Figure E-10: Measured and predicted [3] inlet flow rate versus clearance at 17.24 bar supply and $7.5 \mathrm{krpm}$ - repeated for reference

Figure E-11: $\quad$ Measured and predicted [3] inlet flow rate versus clearance at 17.24 bar supply and $12.5 \mathrm{krpm}$

Figure E-12: Measured and predicted [3] inlet flow rate versus clearance at 17.24 bar supply and $17.5 \mathrm{krpm}$

Figure F-1: $\quad$ Measured and predicted [3] recess pressure ratio versus clearance at 5.17 bar supply and $0 \mathrm{rpm}$ - repeated for reference

Figure F-2: $\quad$ Measured and predicted [3] recess pressure ratio versus clearance at 5.17 bar supply and $7.5 \mathrm{krpm}$

Figure F-3: $\quad$ Measured and predicted [3] recess pressure ratio versus clearance at 5.17 bar supply and $12.5 \mathrm{krpm}$.

Figure F-4: $\quad$ Measured and predicted [3] recess pressure ratio versus clearance at 5.17 bar supply and $17.5 \mathrm{krpm}$ - repeated for reference 
Figure F-5: $\quad$ Measured and predicted [3] recess pressure ratio versus clearance at 10.34 bar supply and $0 \mathrm{rpm}$

Figure F-6: $\quad$ Measured and predicted [3] recess pressure ratio versus clearance at 10.34 bar supply and $7.5 \mathrm{krpm}$

Figure F-7: $\quad$ Measured and predicted [3] recess pressure ratio versus clearance at 10.34 bar supply and $12.5 \mathrm{krpm}$ - repeated for reference

Figure F-8: $\quad$ Measured and predicted [3] recess pressure ratio versus clearance at 10.34 bar supply and $17.5 \mathrm{krpm}$

Figure F-9: $\quad$ Measured and predicted [3] recess pressure ratio versus clearance at 17.24 bar supply and $0 \mathrm{rpm}$

Figure F-10: Measured and predicted [3] recess pressure ratio versus clearance at 17.24 bar supply and $7.5 \mathrm{krpm}$ - repeated for reference

Figure F-11: Measured and predicted [3] recess pressure ratio versus clearance at 17.24 bar supply and $12.5 \mathrm{krpm}$ - repeated for reference

Figure F-12: $\quad$ Measured and predicted [3] recess pressure ratio versus clearance at 17.24 bar supply and $17.5 \mathrm{krpm}$

Figure G-1: $\quad$ Measured and predicted [3] inner radius exhaust flow rate versus center clearance at 5.17 bar supply and $0 \mathrm{rpm}$ - repeated for reference.

Figure G-2: $\quad$ Measured and predicted [3] inner radius exhaust flow rate versus center clearance at 5.17 bar supply and $7.5 \mathrm{krpm}$

Figure G-3: $\quad$ Measured and predicted [3] inner radius exhaust flow rate versus center clearance at 5.17 bar supply and $12.5 \mathrm{krpm}$

Figure G-4: $\quad$ Measured and predicted [3] inner radius exhaust flow rate versus center clearance at 5.17 bar supply and $17.5 \mathrm{krpm}$ - repeated for reference

Figure G-5: $\quad$ Measured and predicted [3] inner radius exhaust flow rate versus center clearance at 10.34 bar supply and $0 \mathrm{rpm}$

Figure G-6: $\quad$ Measured and predicted [3] inner radius exhaust flow rate versus center clearance at 10.34 bar and $7.5 \mathrm{krpm}$ 
Figure G-7: $\quad$ Measured and predicted [3] inner radius exhaust flow rate versus center clearance at 10.34 bar supply and $12.5 \mathrm{krpm}$ - repeated for reference

Figure G-8: $\quad$ Measured and predicted [3] inner radius exhaust flow rate versus center clearance at 10.34 bar supply and $17.5 \mathrm{krpm}$

Figure G-9: $\quad$ Measured and predicted [3] inner radius exhaust flow rate versus center clearance at 17.24 bar supply and $0 \mathrm{rpm}$

Figure G-10: $\quad$ Measured and predicted [3] inner radius exhaust flow rate versus center clearance at 17.24 bar supply and $7.5 \mathrm{krpm}$.....

Figure G-11: Measured and predicted [3] inner radius exhaust flow rate versus center clearance at 17.24 bar supply and $12.5 \mathrm{krpm}$ - repeated for reference

Figure G-12: Measured and predicted [3] inner radius exhaust flow rate versus center clearance at 17.24 bar supply and $17.5 \mathrm{krpm}$

Figure H-1: $\quad$ Measured and predicted [3] center clearance versus load at 5.17 bar supply and $0 \mathrm{rpm}$ - repeated for reference

Figure H-2: $\quad$ Measured and predicted [3] center clearance versus load at 5.17 bar supply and $7.5 \mathrm{krpm}$

Figure H-3: $\quad$ Measured and predicted [3] center clearance versus load at 5.17 bar supply and $12.5 \mathrm{krpm}$

Figure H-4: $\quad$ Measured and predicted [3] center clearance versus load at 5.17 bar supply and $17.5 \mathrm{krpm}$

Figure H-5: $\quad$ Measured and predicted [3] center clearance versus load at 10.34 bar supply and $0 \mathrm{rpm}$

Figure H-6: $\quad$ Measured and predicted [3] center clearance versus load at 10.34 bar supply and $7.5 \mathrm{krpm}$ - repeated for reference .

Figure H-7: $\quad$ Measured and predicted [3] center clearance versus load at 10.34 bar supply and $12.5 \mathrm{krpm}$

Figure H-8: $\quad$ Measured and predicted [3] center clearance versus load at 10.34 bar supply and $17.5 \mathrm{krpm}$ 
Figure H-9: $\quad$ Measured and predicted [3] center clearance versus load at 17.24 bar supply and $0 \mathrm{rpm}$

Figure H-10: $\quad$ Measured and predicted [3] center clearance versus load at 17.24 bar supply and $7.5 \mathrm{krpm}$ - repeated for reference .

Figure H-11: Measured and predicted [3] center clearance versus load at 17.24 bar supply and $12.5 \mathrm{krpm}$.

Figure H-12: Measured and predicted [3] center clearance versus load at 17.24 bar supply and $17.5 \mathrm{krpm}$.

Figure H-13: Center clearance versus load at 10.34 bar supply and all speeds for all three orifice diameters

Figure H-14: Center clearance versus load at $7.5 \mathrm{krpm}$ and all supply pressures for all three orifice diameters.

Figure I-1: $\quad$ Estimated axial stiffness versus clearance at 5.17 bar supply and $0 \mathrm{rpm}$ - repeated for reference.

Figure I-2: $\quad$ Estimated axial stiffness versus clearance at 5.17 bar supply and $7.5 \mathrm{krpm}$

Figure I-3: $\quad$ Estimated axial stiffness versus clearance at 5.17 bar supply and $12.5 \mathrm{krpm}$

Figure I-4: $\quad$ Estimated axial stiffness versus clearance at 5.17 bar supply and $17.5 \mathrm{krpm}$

Figure I-5: $\quad$ Estimated axial stiffness versus clearance at 10.34 bar supply and $0 \mathrm{rpm}$

Figure I-6: $\quad$ Estimated axial stiffness versus clearance at 10.34 bar supply and $7.5 \mathrm{krpm}$ - repeated for reference

Figure I-7: $\quad$ Estimated axial stiffness versus clearance at 10.34 bar supply and $12.5 \mathrm{krpm}$

Figure I-8: $\quad$ Estimated axial stiffness versus clearance at 10.34 bar supply and $17.5 \mathrm{krpm}$.

Figure I-9: $\quad$ Estimated axial stiffness versus clearance at 17.24 bar supply and $0 \mathrm{rpm}$ 
Figure I-10: Estimated axial stiffness versus clearance at 17.24 bar supply

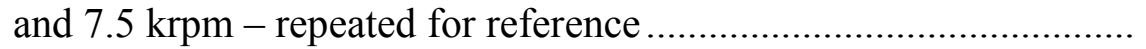

Figure I-11: $\quad$ Estimated axial stiffness versus clearance at 17.24 bar supply

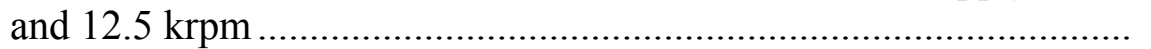

Figure I - 12: Estimated axial stiffness versus clearance at 17.24 bar supply and $17.5 \mathrm{krpm}$. 


\section{LIST OF TABLES}

Page

Table 1: $\quad$ Test thrust bearing dimensions and parameters.............................. 12

Table 2: $\quad$ PCI DAQ board specifications ................................................. 15

Table 3: $\quad$ Test conditions........................................................................ 16

Table 4: $\quad$ Input parameters used for HYDROTHRUST ${ }^{\circledR}$ predictions.............. 24

Table 5: $\quad$ Average orifice discharge coefficients used for HYDROTHRUST ${ }^{\circledR}$ predictions ......................................................................... 25

Table A-1: $\quad$ Dimensions and physical parameters of hybrid radial bearings (flexure pivot type and made of bearing bronze)........................... 57

Table A-2: $\quad$ Dimensions of aerostatic bearings, force coefficients and lateral natural frequencies of TB section and axial load shaft.................... 58

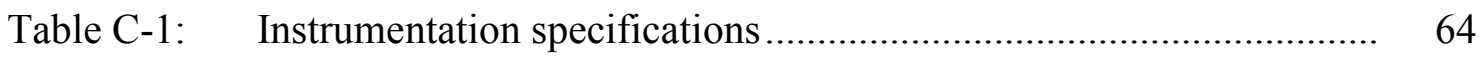




\section{INTRODUCTION}

Hybrid (combination hydrostatic and hydrodynamic) bearings are of particular interest in high speed cryogenic turbomachinery. These bearings utilize externally pressurized process fluids to develop reaction loads. Radial hybrid bearings provide exceedingly low wear and no DN (diameter times speed) life limit, high direct stiffness and damping coefficients, and accurate rotor position control. These features allow for smaller, lighter, and lower part count turbomachines with increased efficiency [1], [2], $[3]$.

Hydrostatic bearings rely on externally pressurized fluid for load capacity. This pressurized fluid flows first into an annulus at the back of the bearing before passing through an orifice into a pocket or recess on the bearing face. From the recesses, the fluid flows over the land regions to the edges of the bearing, where it exits to a lower ambient pressure. The orifice restrictor causes a pressure drop, which leads to a pressure ratio between the recess and the supply. The pressure developed in the recesses generates the force to counteract an applied load. For a thrust bearing, the reaction force is in the direction of the rotor's longitudinal axis. When the rotor is rotating, the bearing performance parameters may alter due to the hydrodynamic effects of the rotating fluid, especially at high rotational speeds. Therefore a bearing with significant rotational effects is referred to as a hybrid bearing due to the need to include both the hydrostatic and hydrodynamic effects for analysis and performance predictions. Thrust bearing

This thesis follows the style of ASME Journal of Tribology. 
performance is dependent on the size, number, and geometry of the recesses, the land area, supply orifices, bearing clearance, fluid properties, fluid supply pressure, and the rotational speed of the rotor. The test thrust bearing used here is depicted in Figure 1.

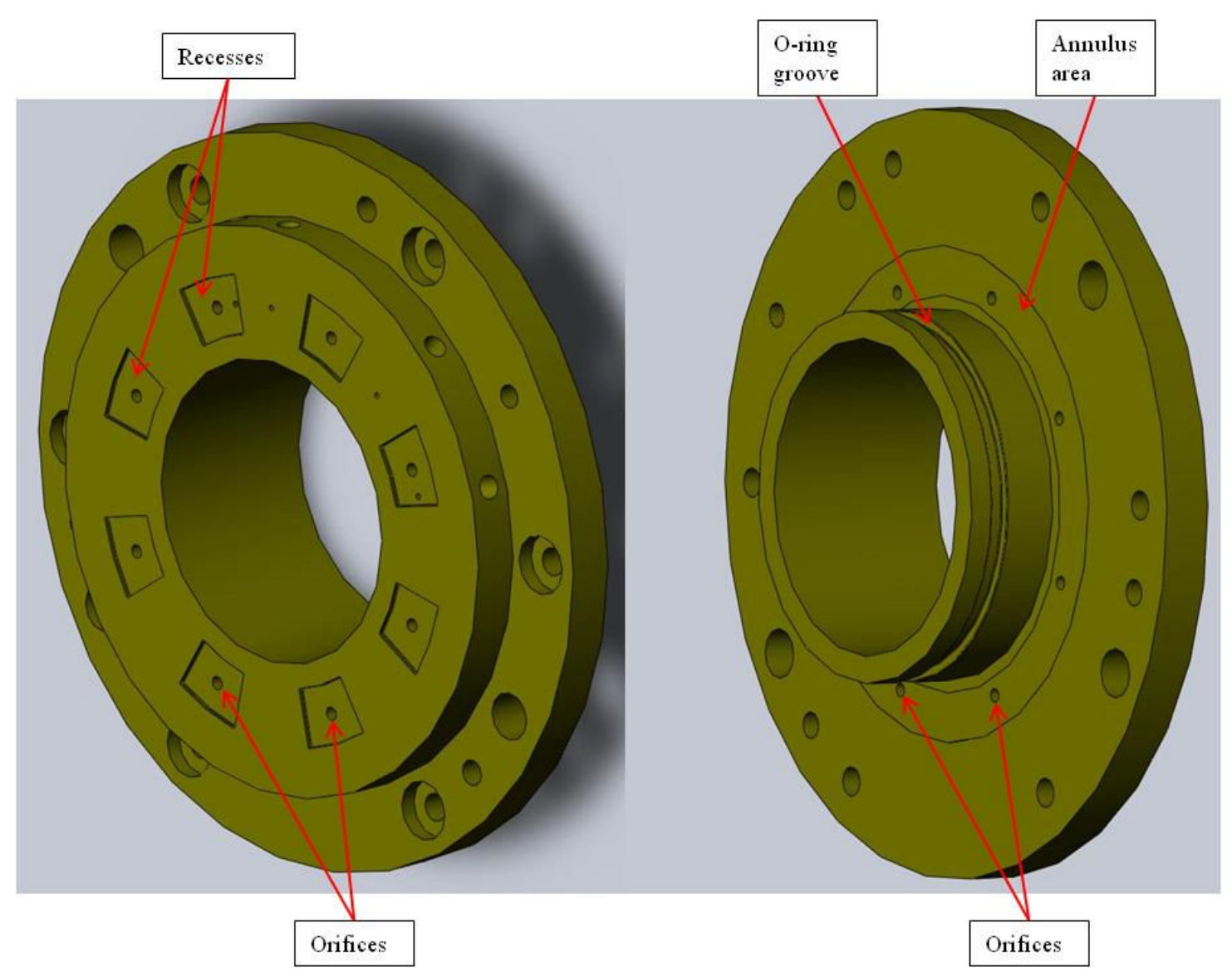

Figure 1: Test thrust bearing front and back 
Hybrid bearing performance also depends on the recess pressure ratio $P_{\text {ratio }}$ defined as the ratio of recess pressure to supply pressure at a given clearance,

$$
P_{\text {ratio }}=\frac{p_{r}-p_{e}}{p_{s}-p_{e}},
$$

where $p_{e}, p_{r}$, and $p_{s}$ are the exhaust, recess, and supply pressures, respectively. Sparse experimental data exists for hybrid thrust bearings and verification of analytical predictions. Mosher and Childs [4] investigated the effects of pressure ratio on the performance of a hybrid journal bearing for high speed, high pressure applications including theory and experimental data. The authors point out differences in optimum concentric recess pressure ratios in theory and experiments and from the typical value ( $\sim .5$ for radial bearings). To date, no such investigation exists for hybrid thrust bearings. This research comprises an experimental investigation of the influence of orifice diameters on recess pressure ratio and the performance parameters of orificecompensated, water-lubricated, hybrid thrust bearings. Comparisons of measured results are made at varying rotational speeds, supply pressures, and axial clearances using a thrust bearing with three different orifice diameters. 


\section{PREVIOUS THURST BEARING TEST RIGS AND RESEARCH}

Fluid film thrust bearings are not a new area of study in turbomachinery, but hybrid thrust bearings have had much more limited research, especially experimentally. Significant theoretical advancements have been made by a number of authors. The effects of centrifugal fluid inertia in hydrodynamic bearings are studied by Pinkus and Lund [5] and Hashimoto [6]. Additionally, Safar [7] provides a modified Reynolds number analysis on hydrostatic thrust bearing performance parameters including the effects of tilt. Finally, San Andrés [2] presents a computational bulk flow model, HYDROTHRUST ${ }^{\circledR}$, as a predictive tool for hybrid thrust bearing performance that includes fluid inertia, flow turbulence, and fluid compressibility. Predictions from this tool showed the possibility of "starvation" at high rotational speeds in hybrid thrust bearings due to large centrifugal fluid inertial forces of the fluid causing sub-ambient pressures at the inner radius of the thrust bearing. This outcome could result in a loss in load capacity and subsequent collapse of the bearing. San Andrés [3] further expands this study to include the effects of misalignment, which most notably impacts flow rate, damping, and stiffness.

Thrust bearing test rigs described in the literature are categorized by two types: single thrust bearing test rigs with the load applied by moving the rotor against a stationary thrust bearing, and multiple thrust bearing test rigs where a thrust bearing is used as loading device and is reacted by a second bearing. Most test rigs involving 
rotation cite a two-thrust-bearing test rig design, though the test bearings are generally hydrodynamic tilting pad type with mineral oil used as the lubricant. New [8] uses a test rig of this type, implementing a hydrostatic thrust bearing as the loading device, and Gregory [9], Neal [10], Horner et al. [11] describe similar rigs.

Harada et al. [12] present a multiple-thrust-bearing design, again using a hydrostatic thrust bearing as the loading device. The Harada test rig implements gas bearings to support the loading shaft and bearing with ball bearings used to react the load. The authors also use three eddy current proximity probes located $120^{\circ}$ apart on the test thrust bearing for detailed clearance measurements. Wang and Yamaguchi [13] use a similar hydrostatic thrust bearing test rig with a hydraulic loading mechanism and an additional thrust bearing to transfer the load to the test bearing to prevent misalignment and allow accurate torque measurements.

Gardner [14] and Glavatskih [15] use similar back-to-back style thrust bearing rigs which have thrust collars located on the outside of the thrust bearings. Glavatskih also utilizes the test thrust bearing as the loading device via hydraulic loading pistons. The load is then transmitted through the rotor before being reacted by the second bearing. These test rigs also provided hydrostatic support to allow for torque measurements on the test thrust bearing with the use of a load cell. Forsberg [16] and Ramirez [17] used the test rig employed in this study and provide further detailed descriptions of prior thrust bearing test rigs. 


\section{TEST RIG DESCRIPTION AND INSTRUMENTATION}

This research takes advantage of a preexisting test rig described in detail by Forsberg [16] and Ramirez [17]. The thrust bearing test rig is the identical structure and configuration described by Ramirez.

\subsection{Rig Description}

Figure 2 shows a schematic of the test rig, which is similar in layout to the backto-back designs of Gardner [14] and Glavatiskih [15], but locates the thrust bearings on the outside of the rotor thrust collars. This face-to-face configuration allows a singlepiece test thrust bearing design rather than split type and reduces the weight of the loading mechanism. On the non-drive-end of the test rig, a hydraulic loading cylinder generates the static load and is connected to the test thrust bearing via a shaft supported on two hydrostatic air bearings. The test bearing is then used to load the rotor axially, transmitting the load along its length before equally loading the opposing thrust bearing (slave bearing). The slave bearing reacts the applied load and is located at the drive end of the rotor housing, opposite from the test bearing. The test rig load path is illustrated in Figure 3. High pressure water is supplied from a single 6.89 MPa (1000 psig) pump to both journal bearings, slave thrust bearing, and test thrust bearing. Independent control valves individually throttle and control flow rates to each of the three sections. 
An electric motor drives the rotor through a FLEXXOR ${ }^{\circledR}$ coupling at the slave thrust bearing end of the test rig.

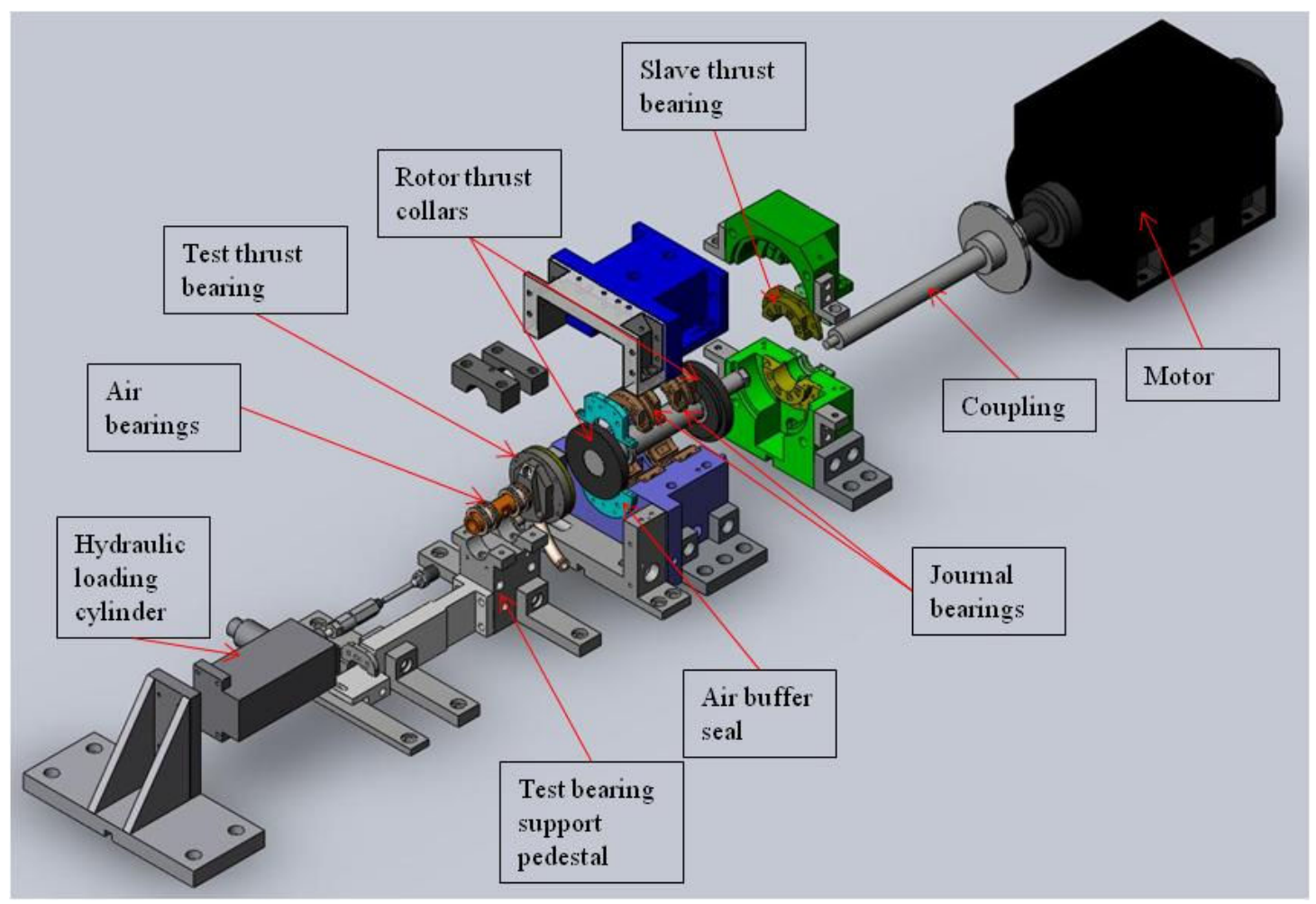

Figure 2: Test rig schematic 


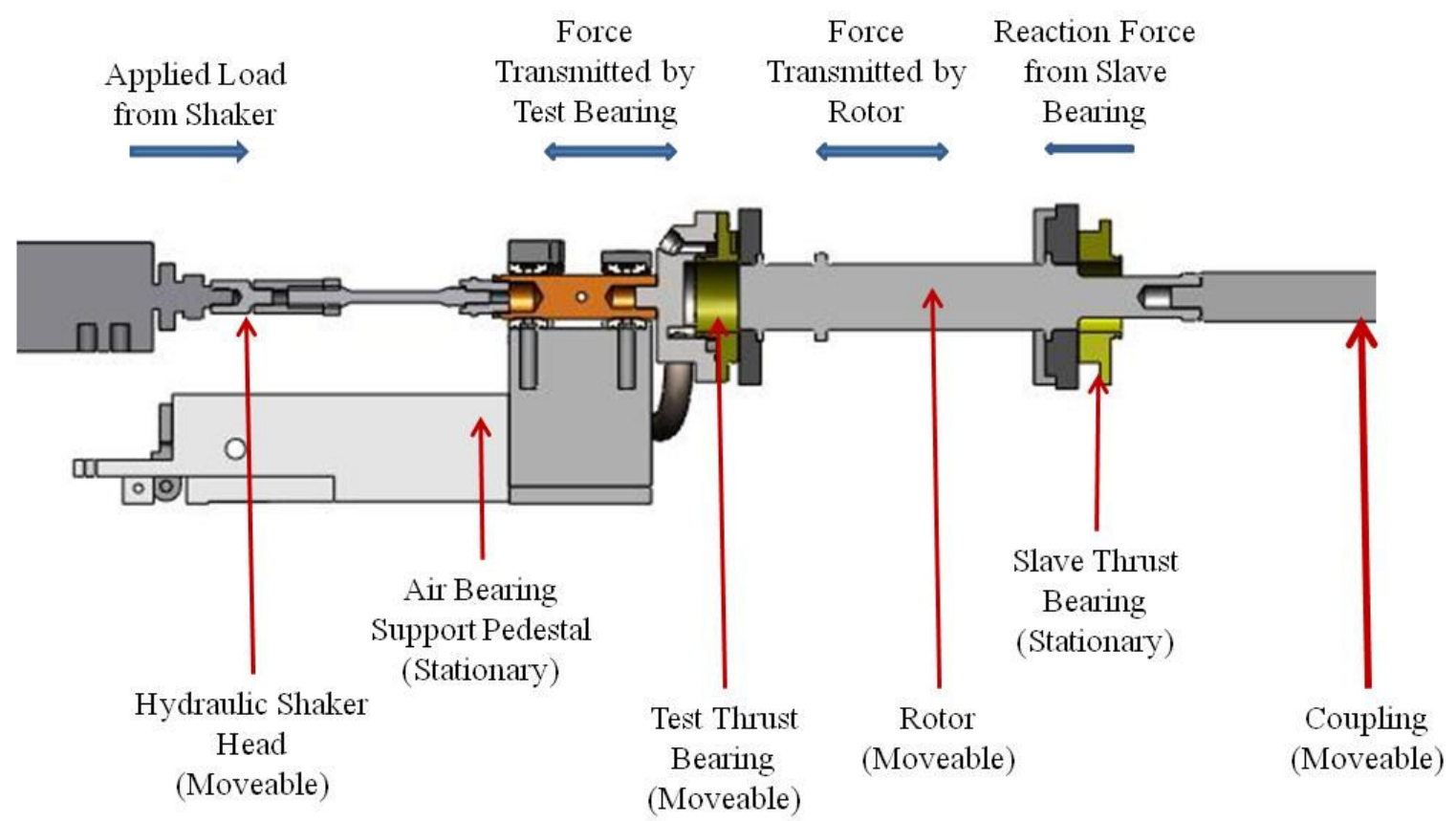

Figure 3: Test rig load path

The loading mechanism comprises a hydraulic loading cylinder connected to a shaft that is supported on two hydrostatic journal bearings. These aerostatic bearings are supplied with filtered 10.34 bar (shop) air. The test thrust bearing is then attached to the end of the support shaft opposite the hydraulic cylinder. This design allows free axial travel and rotation of the loading shaft, which provide accurate applied load measurements to the test thrust bearing. A moment arm attached to the support shaft between the air bearings acts on a strain gage load cell to allow measurement of test bearing frictional torque. The entire support is mounted on a pedestal that is designed to allow for horizontal adjustments of thrust bearing alignment to the rotor thrust face through the use of a micrometer and setscrew positioned on either side of the keyway in the test rig base. Figure 4 provides a detail view of the support pedestal with the 
hydraulic loader disconnected to show alignment adjusters and the load cell used for torque measurements.

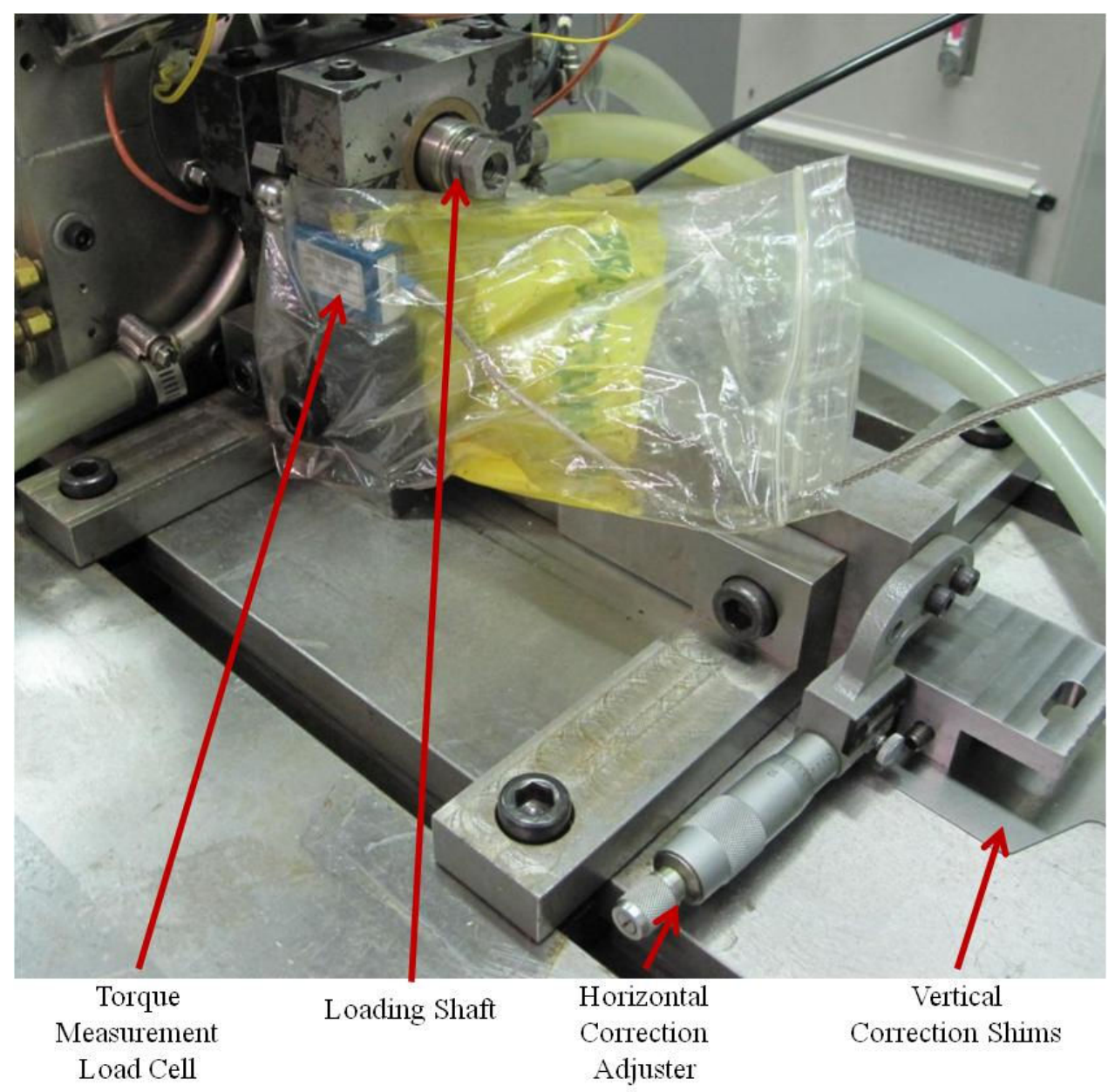

Figure 4: Test thrust bearing support pedestal and loading shaft

Test thrust bearing air seals and water flow paths are shown in Figure 5. Water is supplied to the top of an annulus at the back of the test thrust bearing before flowing through orifices and into the recesses. The water then flows radially across the land region of the bearing face to either the inner or outer radius where it is discharged. A 
pneumatic control valve provides precise control of the flow of water into the test bearing.

The large air seal isolates water in the test thrust bearing housing by preventing leakage contamination from the journal bearing section of the test rig. Additionally, the main air buffer seal prevents leakage out of the test rig from around the outer radius of the test bearing. This isolation ensures proper test lubricant measurements. A similar air buffer seal is located on the rotor shaft at the drive end of the test rig to prevent water leakage from the slave bearing.

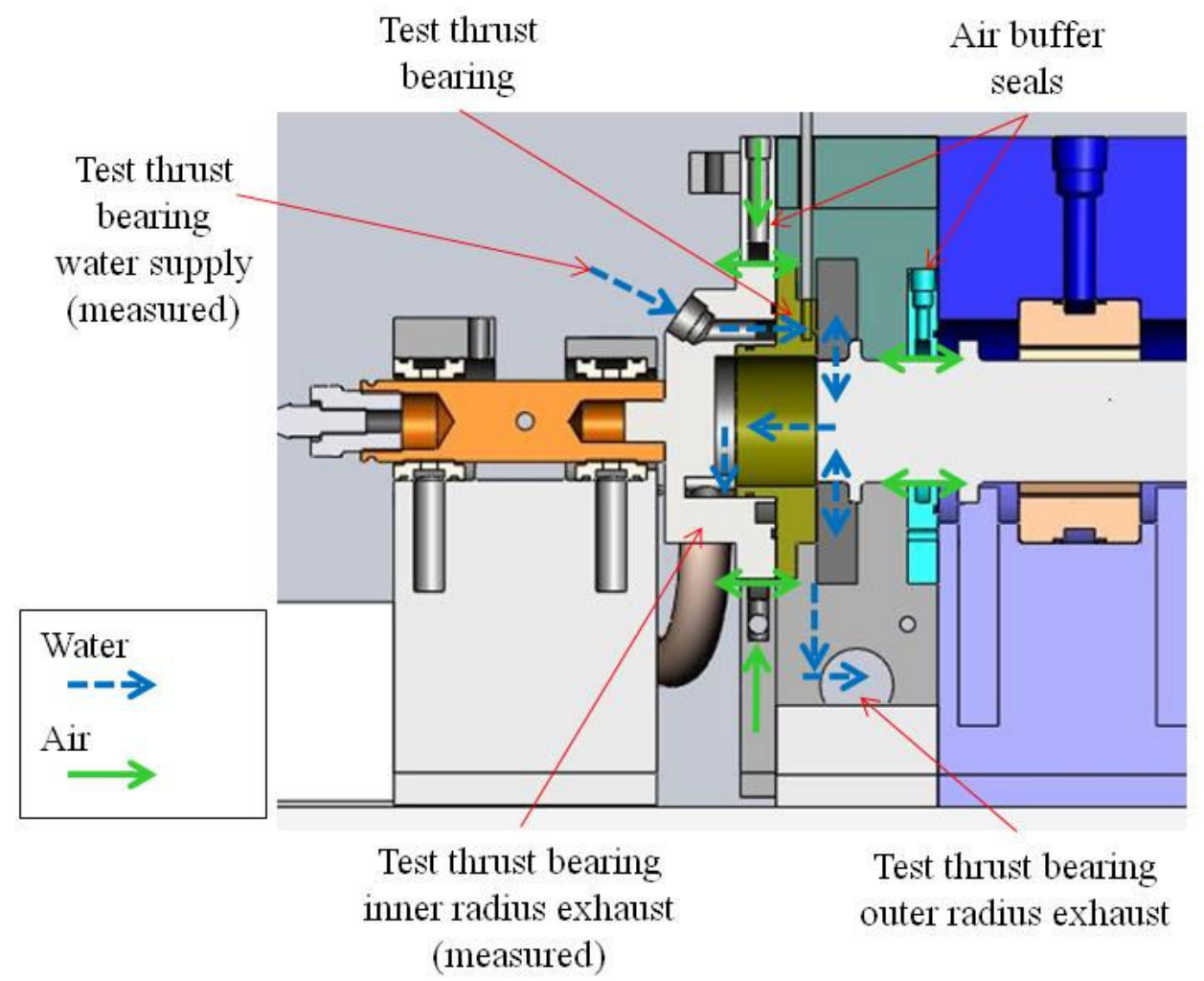

Figure 5: Test thrust bearing water and air flow 
In this research, an eight pocket orifice-compensated thrust bearing is tested. The only bearing parameter changed is the orifice diameters, which are varied to investigate the effects on hybrid thrust bearing performance. The bearing measures 76.2 $\mathrm{mm}(3 \mathrm{in})$ at the outer diameter and has an inner diameter of $40.64 \mathrm{~mm}$ (1 in). Additional relevant thrust bearing parameters are shown in Table 1.

The rotor is $268.30 \mathrm{~mm}$ (10.56 in) in length and is supported radially by two flexure-pivot-pad type hybrid journal bearings spaced $63.5 \mathrm{~mm}(2.5 \mathrm{in})$ apart between the two thrust collars. The rotor diameter is $38.10 \mathrm{~mm}(1.5 \mathrm{in})$ at the journal bearing locations, and the thrust collars are machined to $0.00508 \mathrm{~mm}(0.0002 \mathrm{in})$ flatness. The non-drive-end thrust collar is loaded by the test bearing while the drive-end collar loads the slave thrust bearing. The test rotor can be rotated at speeds up to $30,600 \mathrm{rpm}$ via a $22 \mathrm{~kW}$ variable frequency drive motor. The motor-to-shaft coupling is a FLEXXOR $®$ element and quill shaft providing very low axial stiffness $(3.5 \mathrm{~N} / \mathrm{mm})$ in addition to a permissible axial travel of 0.61 to $1.22 \mathrm{~mm}$. These properties allow isolation of the rotor and bearings from the motor to ensure good test measurements.

The slave thrust bearing is identical to the test bearing, with orifice diameters of $1.80 \mathrm{~mm}$, but is a split design. This feature allows for ease of installation due to the rotor passing through the bearing inner radius. The slave bearing also has a different flange design but still provides three proximity probes to monitor the bearing axial clearance. 
Table 1: Test thrust bearing dimensions and parameters

\begin{tabular}{|l|l|l|}
\hline Thrust Face & $\begin{array}{l}\text { Outer Diameter } \\
\text { Inner Diameter } \\
\text { Recesses }\end{array}$ & $76.2 \mathrm{~mm}(3 \mathrm{in})$ \\
& Machined Flatness & $0.00254 \mathrm{~mm}(1.6 \mathrm{in})$ \\
& Number of Recesses & 8 \\
Arc Length & $20^{\circ}$ \\
& Depth & $5.08 \mathrm{~mm}(0.020 \mathrm{in})$ \\
& Mean Diameter & $54.86 \mathrm{~mm}(2.16 \mathrm{~mm})$ \\
& Radial Length & $8.13 \mathrm{~mm}(0.32 \mathrm{in})$ \\
Recess/wetted land ratio & 0.19 \\
Orifices & Recess to land loss coefficient & 0.20 \\
& & $1.63,1.80,1.93 \mathrm{~mm}$ \\
One per recess & Diameters & $(0.064,0.071,0.0765 \mathrm{in})$ \\
& Radial Location & $27.43(1.08 \mathrm{in})$ \\
& Orifice Length & $12.7 \mathrm{~mm}(0.5 \mathrm{in})$ \\
\hline
\end{tabular}

\subsection{Instrumentation}

The thrust bearing test rig is fully instrumented for static measurements. Eddy current proximity probes verify clearance (fluid film thickness) and alignment of the thrust bearing face and rotor thrust collar. Three probes are used for each thrust bearing. The three on the test thrust bearing are displayed in Figure 6, labeled as "Probes." Two additional proximity probes are located radially $90^{\circ}$ apart at each rotor thrust collar to monitor radial movement of the rotor and its orbits. Ten proximity probes are used in all, providing exact positioning and alignment of the test thrust bearing and rotor both axially and radially. 
Five static pressure transducers are used to monitor lubricant pressure in the test bearing. One transducer measures water inlet pressure at the thrust bearing annulus, two measure pressures in two different recesses, and the final two transducers are used for measurements on the land region. The four pressure measurements on the test thrust bearing face are shown in Figure 6, and are labeled as "Pockets" and "Lands." The holes shown on the bearing face intersect with perpendicular holes drilled radially from the edge of the bearing. The transducers are connected to these pressure taps with flexible tubing. Four additional pressure transducers monitor inlet pressures to the two journal bearings and top and bottom inlet pressures of the split slave thrust bearing.

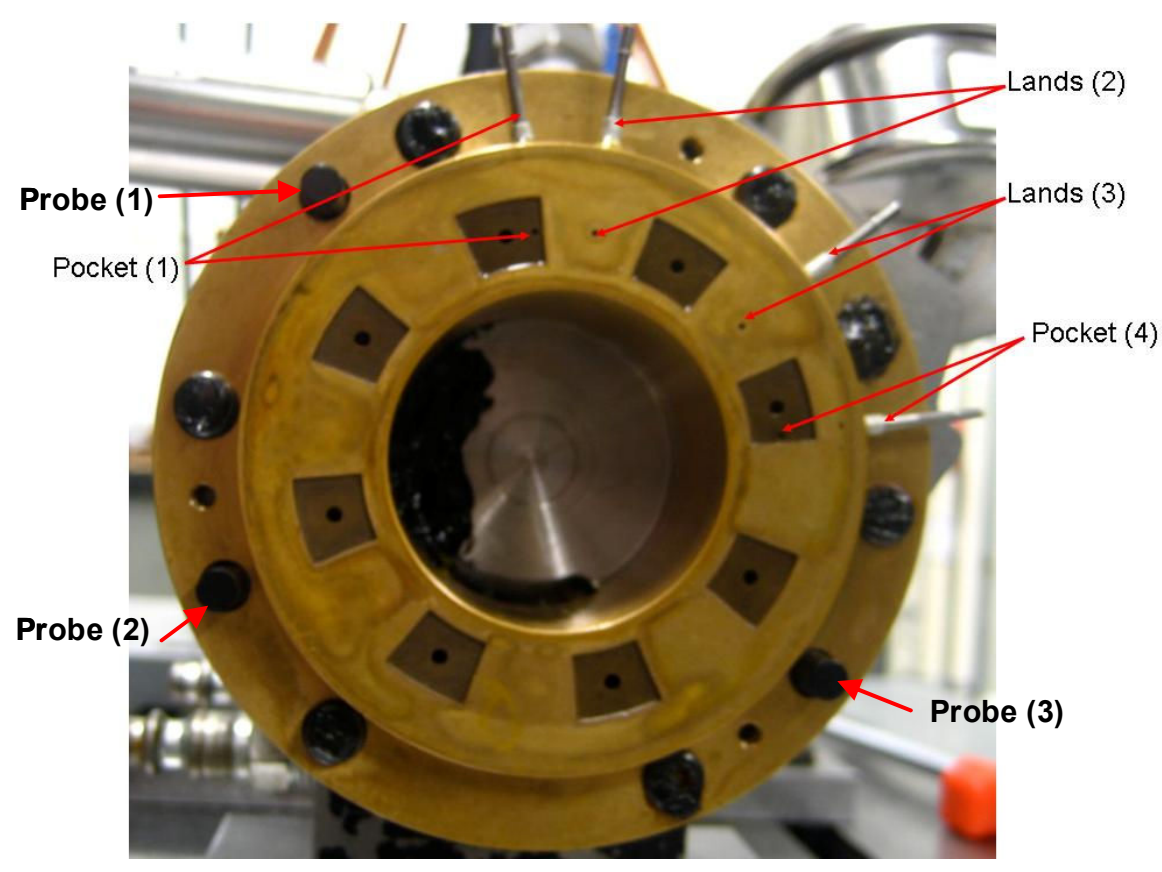

Figure 6: Test thrust bearing instrumentation [16] 
Two turbine flow meters monitor the water flow rate into the test bearing and the exhaust flow rate through its inner radius. Two additional turbine flow meters are used for the inlets of the slave thrust bearing and journal bearings. All four flow meter outputs are connected signal linearizers before being wired to the DAQ.

Three plug style type K thermocouples are used for temperature measurements at the test thrust, slave thrust, and journal bearing supply inlets. Two additional type $\mathrm{K}$ thermocouples are positioned at the inner and outer radii on the test thrust bearing for exhaust temperature measurements.

Static data collection is achieved using a National Instruments PCI-6225 DAQ board. Sensor outputs are displayed real time using a NI LabVIEW virtual instrument front panel previously used by Forsberg [16] and Ramirez [17]. Included in this front panel view are all proximity probe outputs, load cell, pressure transducer, flow meter, and thermocouple values, as well as the average axial clearance and minimum individual values of the axial proximity probes on the test thrust bearing. A summary of specifications for the PCI-6225 board is supplied in Table 2. The fully instrumented test rig allows precise control and monitoring during operation in addition to allowing quality test thrust bearing performance comparisons. Further details on the sensors and data acquisition system may be found in Appendix $\mathrm{C}$ and have been previously documented by Forsberg [16] and Ramirez [17]. 
Table 2: PCI DAQ board specifications

\begin{tabular}{ccccccc}
\hline $\begin{array}{c}\text { Board } \\
\text { Type }\end{array}$ & $\begin{array}{c}\text { Number } \\
\text { of } \\
\text { Channels }\end{array}$ & $\begin{array}{c}\text { Sampling } \\
\text { Rate [K } \\
\text { samples/s] }\end{array}$ & $\begin{array}{c}\text { Resolution } \\
{[\text { [bits] }}\end{array}$ & $\begin{array}{c}\text { Signal } \\
\text { Range } \\
{[\mathrm{V}]}\end{array}$ & Signal Type & Connection \\
\hline & & & & & $\begin{array}{c}\text { Analog/Digital } \\
\text { Input/Output }\end{array}$ & $\begin{array}{c}\text { 2 Pole wire } \\
\text { through SCB- }\end{array}$ \\
$\mathrm{PCl}-$ & & & & Analog Input & 68 Connector \\
6225 & 80 & 250 & 16 & \pm 10 & Used & Block \\
\hline
\end{tabular}




\section{TEST PROCEDURE}

Three hybrid thrust bearings with different orifice diameters $(1.63,1.80$, and 1.93 $\mathrm{mm}$ ) were individually tested at statically loaded, steady state conditions at three supply pressures (5.17 bar, 10.34 bar, and 17.24 bar) and four speeds ( $0 \mathrm{rpm}, 7500 \mathrm{rpm}, 12,500$ rpm, and 17,500 rpm) over a range of axial clearances. Table 3 provides an overview of the test matrix for each bearing.

Table 3: Test conditions

\begin{tabular}{|l|l|}
\hline Speed & $7500,12500,17500 \mathrm{rpm}$ \\
Supply (Annulus) Pressure & $5.17,10.34,17.24 \mathrm{bar}(75,150,250 \mathrm{psi})$ \\
Calculated Axial Clearance & 0.05 to $0.1 \mathrm{~mm}(0.002$ to $0.004 \mathrm{in})$ \\
\hline
\end{tabular}

\subsection{Alignment}

Thrust bearing face-to-rotor thrust collar alignment is of particular importance due to its influence on thrust bearing performance, but achieving adequate alignment presented difficulties throughout data collection. This problem was resolved vertically by using shims under the test thrust bearing support pedestal and shaker support and horizontally adjusted via micrometer and spring set screw in the thrust bearing support pedestal. Both horizontal and vertical adjustment mechanisms are shown on the thrust bearing support pedestal detailed previously in Figure 4. Shims under the shaker support 
ensured a directly horizontal loading action perpendicular to the vertical axis and were set at the beginning of alignment process and were not changed throughout testing.

Misalignment is quantified in this research by describing it as a slope of deviation from parallel over a radial length across the bearing face $[\mathrm{mm} / \mathrm{mm}]$. Alignment was systematically corrected before each test and checked for discrepancies immediately afterwards. Prior to each test, a baseline is conducted followed by an alignment assessment (both non-rotating). The baseline values of the proximity probes are taken as zero clearance and are subtracted from those found with the bearings pressurized resulting in calculated axial clearance and misalignment figures. Baseline readings are obtained by pressurizing the journal bearings to 17.24 bar to ensure a centered position and applying increasingly high loads to the non-pressurized thrust bearings. Without a fluid film between the thrust bearing faces and rotor thrust collar, the applied load forces flush mating between the two faces. After the baseline is established, an alignment assessment is conducted by pressurizing the thrust bearings to the desired test condition and applying a wide range of loads (exceeding the maximum and minimum for the test).

From the alignment tests, the misalignment across the bearing faces is obtained through evaluation of the three proximity probe values. Forsberg [16] derives Equations (2) and (3) which are used to quantify the misalignment for the test thrust bearing in the horizontal $\left(M_{1}\right)$ and vertical $\left(M_{2}\right)$ directions. These values are subsequently used to find the amount of shim required to correct it. The misalignments are calculated to be 


$$
\begin{gathered}
\mathrm{M}_{1}=0.00194\left(\mathrm{Z}_{2}-\mathrm{Z}_{3}\right)[\mathrm{mm} / \mathrm{mm}] \\
\mathrm{M}_{2}=\left(-0.00294 * \mathrm{Z}_{1}+0.00277 * \mathrm{Z}_{2}+0.00017 * \mathrm{Z}_{3}\right)[\mathrm{mm} / \mathrm{mm}]
\end{gathered}
$$

where $Z_{1}, Z_{2}$, and $Z_{3}$ are the gap readings from test thrust bearing proximity probes 1,2 , and 3, respectively. Figure 7 gives an illustration of test thrust bearing misalignment and the proximity probe locations. Details of the derivation of these equations as well as those used for the slave thrust bearing misalignment are provided by Forsberg [16] and Ramirez [17].

Alignment corrections are then conducted in both the vertical and horizontal directions. In the vertical direction, shims are added or removed from the thrust bearing support pedestal while the micrometer adjuster allows misalignment correction in the horizontal direction. In both cases, the required adjustment is obtained by multiplying the previously obtained $M_{1}$ and $M_{2}$ values by the length of the test thrust bearing support pedestal. This process is repeated until the maximum misalignment of the thrust faces to the rotor thrust collars in both horizontal and vertical directions are less than or equal to $0.013 \mathrm{~mm}$, and has been verified by a second test. 


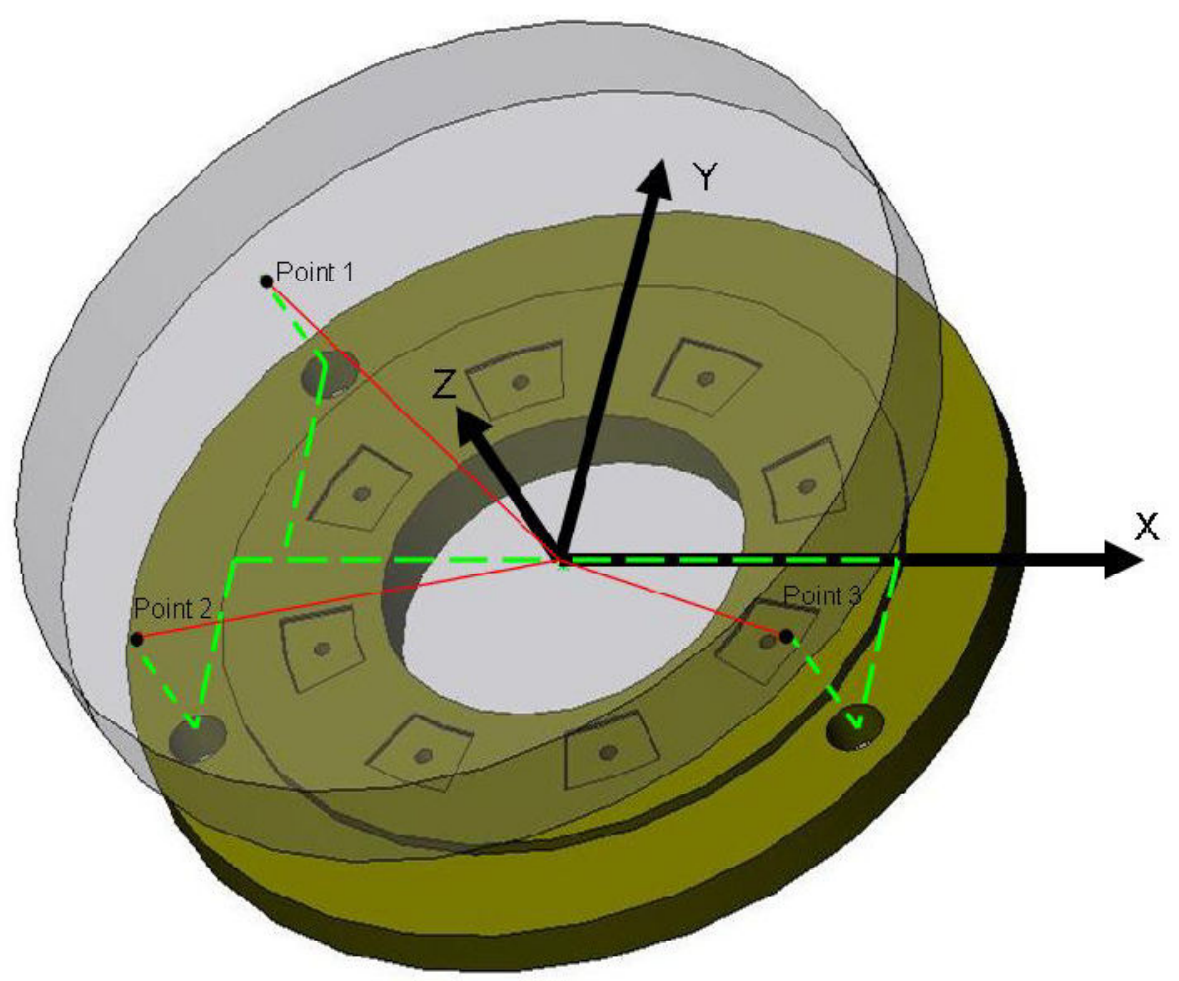

Figure 7: Misalignment illustration and proximity probe locations on the test thrust bearing [16]

\subsection{Test Procedure}

The hydraulic shaker is used to apply the axial load through the test thrust bearing and can be controlled by two possible internal control loops or by an external reference. During a baseline test or alignment assessment, an internal control loop utilizing the load cell mounted in the shaker head is utilized. This "load control" configuration allows testing at specific applied loads without regard to the clearance 
between the test thrust bearing and rotor collar, therefore allowing a wide range of loads including a zero clearance or mated condition required for a baseline.

Alternatively, the shaker can be placed in stroke control mode, which references the length that the cylinder's actuator is extended, instead of the applied load. This configuration also allows an external reference instead of the internal monitoring of the actuator. During regular testing, an axial proximity probe on the test thrust bearing is used as the external reference, which enables the operator to set and maintain a given clearance between the test thrust bearing and the rotor thrust collar. This "displacement control" configuration not only aids in setting precise test conditions, but additionally acts as a safety measure in the case of thrust bearing fluid film collapse under high applied loads.

Under normal test conditions, the journal bearings are initially pressurized to 17.24 bar, while the thrust bearings are pressurized to the desired condition and held constant. A relatively large displacement is then set between the test thrust bearing and the rotor thrust collar using the hydraulic shaker controller in "displacement control." A minimum-load steady-state condition is confirmed by ensuring a minimum (and constant) $P_{\text {ratio }}$ of 0.1 and that the shaker maintains a constant load via real time data displays. Testing would then commence for the zero speed case, incrementally decreasing the displacement to a minimum at $50.8 \mu \mathrm{m}$ while adjusting the thrust bearing supply pressures to keep them constant for the entire test. This process is then repeated at three constant rotational speeds and for all three supply pressures. Outputs of all 
sensors are recorded with the data acquisition system with 20 readings for each case. Uncertainty calculations for measured data are shown in Appendix B. 


\section{TEST RESULTS AND PREDICTIONS}

This research aims to investigate the results of varying orifice diameters on the performance of fixed geometry, water-lubricated hybrid thrust bearings. Bearing parameters of particular interest are recess pressure ratio, operating clearances, inlet and exhaust flow rates, and static axial stiffness. The following sections show results for a bearing with three different orifice diameters tested at a number of test conditions versus predictions. Optimum thrust bearing features include larger minimum film thickness for an applied load, reduced flow rates, and larger axial stiffness with a stable positive stiffness across the expected range of axial clearances. Tests are conducted to show how these variables change as the recess pressure ratio is changed.

Some data presented are for a bearing with an orifice diameter of $1.80 \mathrm{~mm}$, which was presented by Forsberg [16] for non-rotating cases and Ramirez [17] for cases with the rotor spinning. These data were obtained using the same test rig as the present analysis, and a number of test cases of their results were repeated by the author with very good agreement. Therefore, their prior work is reproduced here with confidence and provides the third orifice size for comparisons.

Forsberg and Ramirez provide test data for the test bearing with the $1.80 \mathrm{~mm}$ orifice diameter at supply pressures of $3.45,10.34$, and 17.24 bar. However, the two new orifice diameters $(1.63$ and $1.93 \mathrm{~mm})$ of the test bearing were tested at supply pressures of $5.17,10.34$, and 17.24 bar. This change of the lowest supply pressure from 3.45 to 5.17 was due to difficulties experienced maintaining bearing clearances (fluid 
film thickness) at that lowest pressure. Comparisons are consequently presented for only the $1.63 \mathrm{~mm}$ and $1.93 \mathrm{~mm}$ orifice diameter bearings at the 5.17 bar supply pressure.

All test parameters are functions of fluid properties, operating (rotational) speed, supply pressure, and applied load. Experimental data are compared to show both the influence of orifice diameters on bearing performance parameters and the accuracy of HYDROTHRUST ${ }^{\circledR}$ predictions. Comparisons are made at all three rotational speeds and varying supply pressures. Note that the non-equal differences between the orifice diameter values are due to size limitations of the drill bits used to make the orifices.

HYDROTHRUST ${ }^{\circledR}$ requires physical properties and test conditions as well as relaxation and loss coefficients for analysis. Input parameters include bearing geometry (bearing face inner and outer diameters, axial clearance, surface roughness, land and recess dimensions, number of recesses, and orifice diameters), thrust collar rotational speed, bearing face static misalignment, fluid properties, fluid supply and exit pressures, entrance loss and orifice discharge coefficients, and solution convergence factors. The values used for these additional input parameters used for the predictions presented are given in Table 4. 
Table 4: Input parameters used for HYDROTHRUST ${ }^{\circledR}$ predictions

\begin{tabular}{|c|c|c|c|}
\hline Max Iterations - film lands & 99 & Frequency Analysis Type: & Synchronous \\
\hline Momentum Relaxation Factor & 0.8 & Thermal Analysis Option: & Isothermal fluid film \\
\hline Pressure Relaxation Factor & 0.5 & Analysis Type: & Fixed Clearance \\
\hline Temperature Relaxation Factor & 0.9 & & \\
\hline Collar Relative Roughness & 0.001 & $\begin{array}{l}\text { CONVERGENCE } \\
\text { PARAMETERS }\end{array}$ & error criteria \\
\hline Stator Relative Roughness & 0.001 & Pressure film lands & 0.0001 \\
\hline Moody's Coef Amod & 0.001375 & Pressure recess & 0.01 \\
\hline Moody's Coef Bmod & 500000 & Mass flow - lands & 0.01 \\
\hline Moody's Coef Expo & 0.3333 & Mass flow - recesses & 0.006 \\
\hline No. of Grid Points per Pocket & & Supply Temperature & $43^{\circ} \mathrm{C}$ \\
\hline No. Circ. Grid Points & 9 & Fluid & Water \\
\hline No. Radial Grid Points & 5 & & \\
\hline
\end{tabular}

The orifice discharge coefficient, $C_{d}$, is required as an input in HYDROTHRUST ${ }^{\circledR}$ predictions and is used to model the pressure drop from the supply pressure to the recess pressure. The orifice discharge coefficients are found utilizing the following equation [3] for turbulent flow through an orifice,

$$
C_{d}=\frac{Q_{0}}{A_{0} \sqrt{\frac{2}{\rho}\left(P_{s}-P_{r}\right)}}
$$

Here, $Q_{0}$ is the flow rate through an orifice, $A_{0}$ is the cross-sectional area of the orifice, and $\rho$ is the fluid density. Additionally, $P_{S}$ and $P_{r}$ are the supply and recess pressures, respectively. The use of the above equation assumes equal fluid flow through each of the bearing orifices and equal recess pressures across the bearing face. 
For the predictions presented here, estimates of $C_{d}$ are obtained from the available experimental data. Experimentally determined orifice discharge coefficients are presented in Table 5. Note the decreasing $C_{d}$ values with decreasing orifice diameter, but relatively constant values over the range of tested supply pressures. $C_{d}$ values also decrease very slightly with increasing load (decreasing clearance and flow rate) in experimental results for all bearing configurations and test conditions (less than $5 \%$ over entire clearance range). The average uncertainty for the obtained $C_{d}$ values is $1.95 \%$, with an average maximum uncertainty of $3.65 \%$. The predictions use $C_{d}$ values obtained using this empirical analysis.

Table 5: Average orifice discharge coefficients used for HYDROTHRUST ${ }^{\circledR}$ predictions

\begin{tabular}{|c|ccc|}
\hline \multirow{2}{*}{ Orifice Diameter } & \multicolumn{3}{|c|}{ Supply Pressure } \\
\cline { 2 - 4 } & 5.17 bar & \multicolumn{3}{|c}{ Average Cd bar } & 17.24 bar \\
\hline $1.93 \mathrm{~mm}$ & 0.648 & 0.666 & 0.648 \\
$1.80 \mathrm{~mm}$ & - & 0.599 & 0.586 \\
$1.63 \mathrm{~mm}$ & 0.555 & 0.542 & 0.531 \\
\hline
\end{tabular}

A final input requirement for HYDROTHRUST ${ }^{\circledR}$ is the static misalignment of the thrust bearing face (in radians). These misalignments were found using Equations 2 and 3 for all test conditions. The slopes (in $\mathrm{mm} / \mathrm{mm}$ ) from these equations are converted to radians by taking the inverse tangent. Figure 8 shows thrust face misalignment for all three bearing orifice diameters at a supply pressure of 17.24 bar and $17.5 \mathrm{krpm}$. 
Misalignments are presented as an axial distance (a product of the misalignment angle and the outer diameter of the bearing face, $76.2 \mathrm{~mm}$ ). All tests for this case (and nearly all others) show misalignment within the desired limits of $\pm 0.013 \mathrm{~mm}$, as indicated by the marker lines. Additional misalignment figures are found in Appendix D.

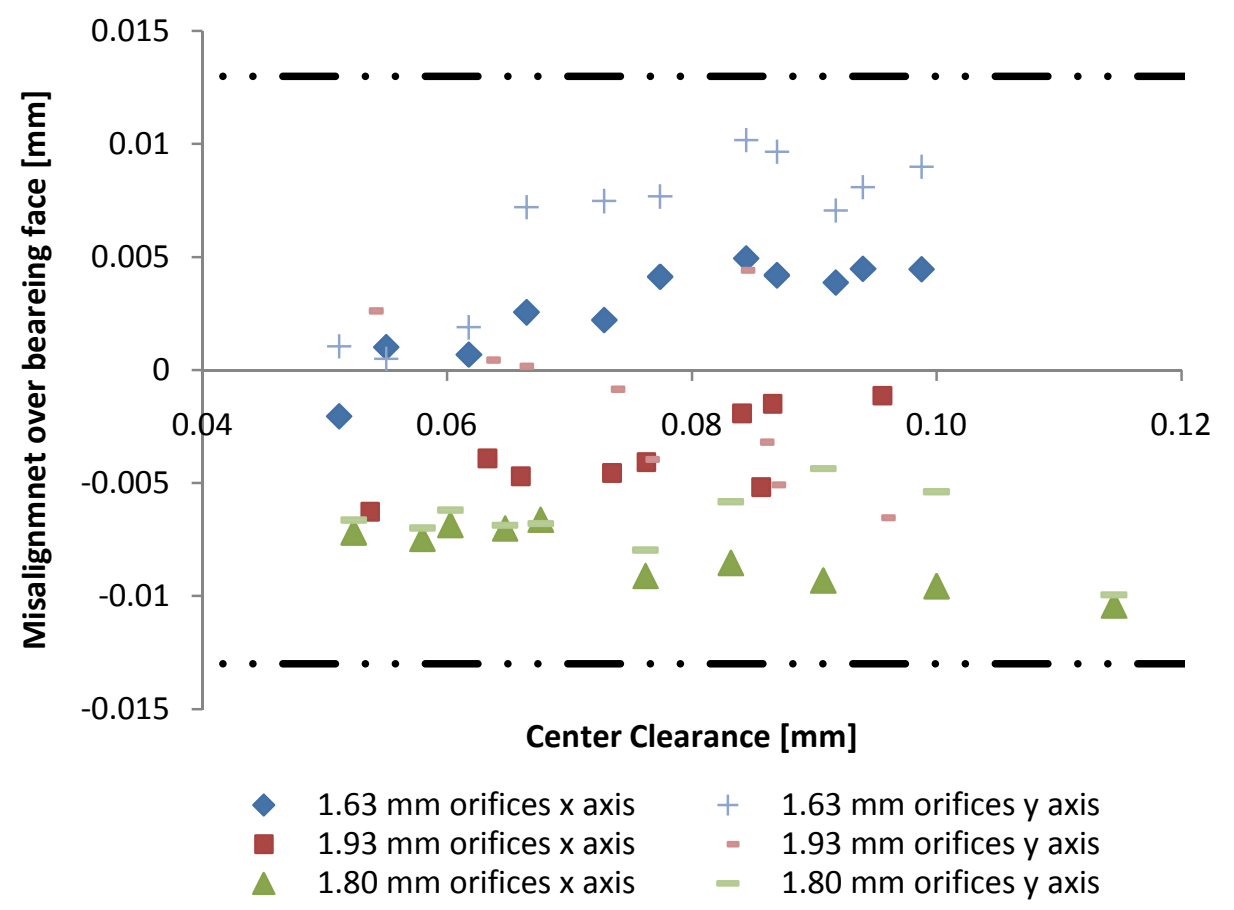

Figure 8: Misalignment over the bearing face about the $x$ and $y$ axes versus center clearance at 17.24 bar supply and $17.5 \mathrm{krpm}$. Lines note desired misalignment limits $( \pm 0.013 \mathbf{~ m m})$

Relevant comparisons between the various test results and predictions are presented here. Comparisons are made over a range of operating conditions, drawing on the influence of the orifice diameters and the recess pressure ratios on the bearing 
parameters. Measurement uncertainties are included on all plots of experimental data in the form of error bars. Percent errors between the experimental data and predictions for all of the results presented are calculated the following equation.

$$
\% \text { Error }=\frac{\mid \text { Measured Value }- \text { Predicted Value } \mid}{\text { Measured Value }} * 100
$$

\subsection{Inlet Flow Rate}

Bearing inlet flow rate plots are shown in Figure 9 for the 10.34 bar supply pressure case and in Figure 10 for the 17.24 supply pressure case at 7.5 and $12.5 \mathrm{krpm}$, respectively. The figures display very similar trends when comparing the three orifice diameters, with all three tending toward convergence at the lowest clearances (highest loads). The smaller axial clearance limits the flow rate though the bearing. Inlet flow rate requirements are nearly constant for all three orifice configurations and supply pressures.

Comparisons are also depicted for fluid inlet flow rate predictions in the same figures. Very good agreement is seen in Figure 9 between measurements and predictions for both the $1.80 \mathrm{~mm}$ and $1.93 \mathrm{~mm}$ orifice diameter bearings, while the smaller, $1.63 \mathrm{~mm}$ orifice diameter bearing predictions show a larger error. Note the best agreement is achieved at the lower clearances (high applied loads) for all three orifice diameter configurations and test conditions. Similar results are displayed in Figure 9, with 
slightly better agreement for the $1.93 \mathrm{~mm}$ orifice diameter case. The maximum average error between measurements and predictions was $17.0 \%$ for the $1.63 \mathrm{~mm}$ orifice diameter case, but average percent errors lower than 3\% are seen for the larger orifice bearings. The $1.80 \mathrm{~mm}$ orifice diameter data matches nearly exactly with predictions for both cases, especially at the lowest clearances. The results presented for inlet flow rate show a good representation of the remaining data, and flow rate predictions tend to correlate very well with the measured data.

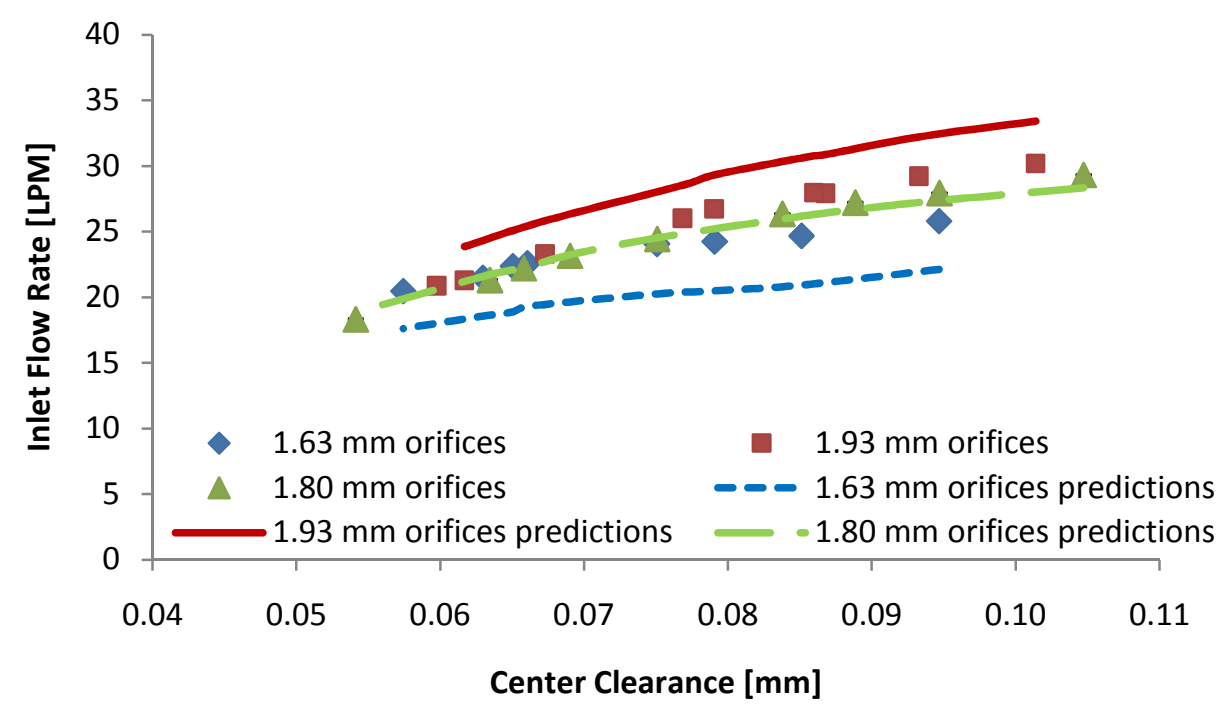

Figure 9: Measured and predicted [3] inlet flow rate versus center clearance at 10.34 bar supply and $12.5 \mathrm{krpm}$ 


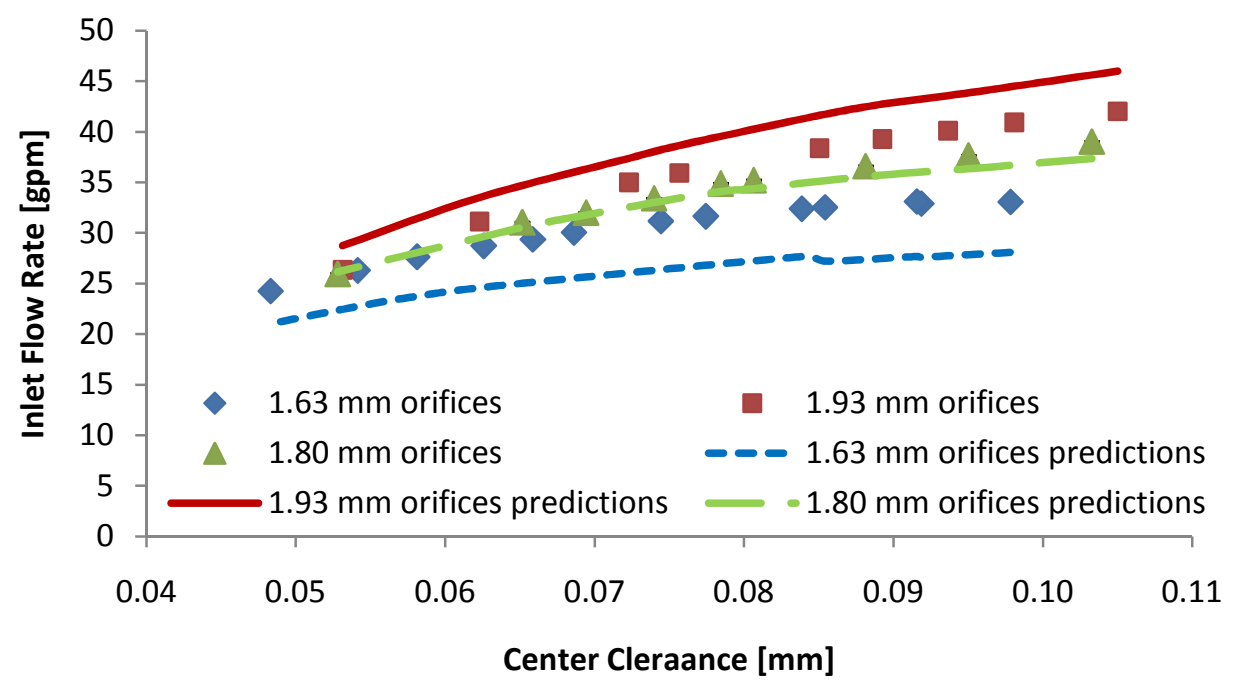

Figure 10: Measured and predicted [3] inlet flow rate versus clearance at $\mathbf{1 7 . 2 4}$ bar supply and $7.5 \mathrm{krpm}$

Figure 11 displays the measured flow rates versus predictions for the lowest (5.17 bar) supply pressure and at the non-rotating condition. Note the particularly good agreement at the lowest clearances for both orifice diameters and near exact match for the $1.93 \mathrm{~mm}$ diameter case. These low supply pressure plots consistently reflect excellent correlation with predictions for all rotational speeds, and are significantly improved over the higher supply pressure data. 


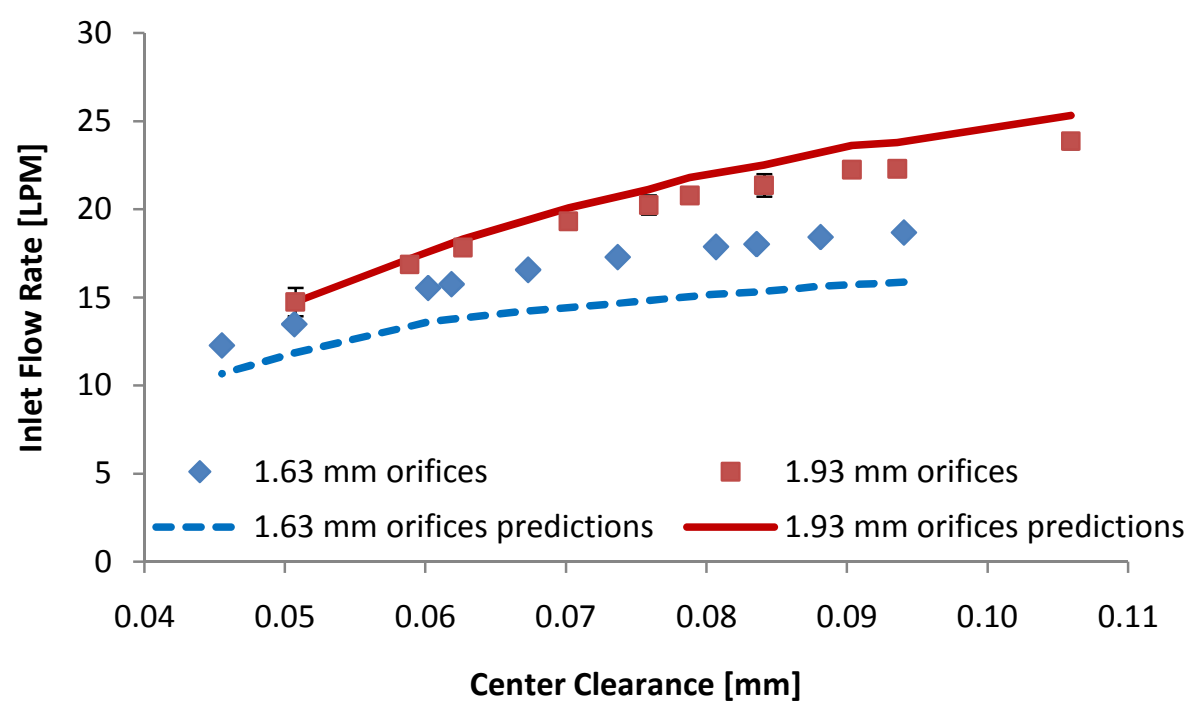

Figure 11: Measured and predicted [3] inlet flow rate versus center clearance at 5.17 bar supply and 0 rpm

\subsection{Recess Pressure Ratio}

The following plots display how the various diameters affect the recess pressure ratios for the three supply pressure conditions, found by taking the average of the pressure measurements in the two recesses (pockets) on the bearings for each case. The two measured recess pressures for each bearing were generally in good agreement, which verifies adequate bearing face alignment and uniform flow across the bearing face. Plots presented correspond to the same test conditions as the figures shown with inlet flow rate measurements (Figures 9-11). Figure 12 shows the relationship of the recess pressure ratios between the three bearings for the middle (10.34 bar) supply pressure at $12.5 \mathrm{krpm}$. This trend is consistent for all speeds at the 10.34 supply pressure 
case and for the slowest speeds of the low (5.17 bar) and high (17.24 bar) supply pressures. Note that in Figure 9 the closest agreement between measurements and predictions for inlet flow rates is shown for the $1.80 \mathrm{~mm}$ orifice diameter while the 1.63 $\mathrm{mm}$ orifice displays the best agreement for recess pressure ratios (Figure 12).

The 17.24 and 5.17 bar supply pressures display similar results to the 10.34 bar case at 7.5 and $0 \mathrm{krpm}$, as depicted in Figures 13 and 14 . Neither plot provides agreements with predictions that match those shown in the inlet flow rate figures at the same test condition given previously (Figures 10 and 11). In fact, while the $1.63 \mathrm{~mm}$ orifice diameter provides better agreement than the other two orifice configurations in Figure 13. In contrast, Figure 10 shows better agreement for the larger two orifice configurations with the closest matches occurring at the smallest clearances. The 1.63 $\mathrm{mm}$ orifice diameter case again shows the better agreement in Figure 14, but the corresponding inlet flow rate figure shows best agreement with the $1.93 \mathrm{~mm}$ orifice diameter.

In general, predictions show reasonable agreement with the recess pressure measurements, especially for the $1.63 \mathrm{~mm}$ and $1.80 \mathrm{~mm}$ orifice diameter cases. Note that the smallest $(1.63 \mathrm{~mm})$ orifice configuration provides best agreement with predictions for the clearance versus recess pressure ratio plots. Recall that for the inlet flow rate figures both the $1.93 \mathrm{~mm}$ and $1.80 \mathrm{~mm}$ orifice diameters showed better agreement with predictions. Additionally, inlet flow rate plots correlated especially well at the lowest clearances, with the $1.80 \mathrm{~mm}$ orifice diameter data providing near exact matches with predictions. The recess pressure ratio data does tend to show notably 
better agreement at either low or high clearances, and they do not correspondingly match predictions in the same manner as the inlet flow rate data. There is no obvious correlation between the ability of HYDROTHRUST ${ }^{\circledR}$ to predict inlet flow rates and recess pressures, although adequate results are produced for both.

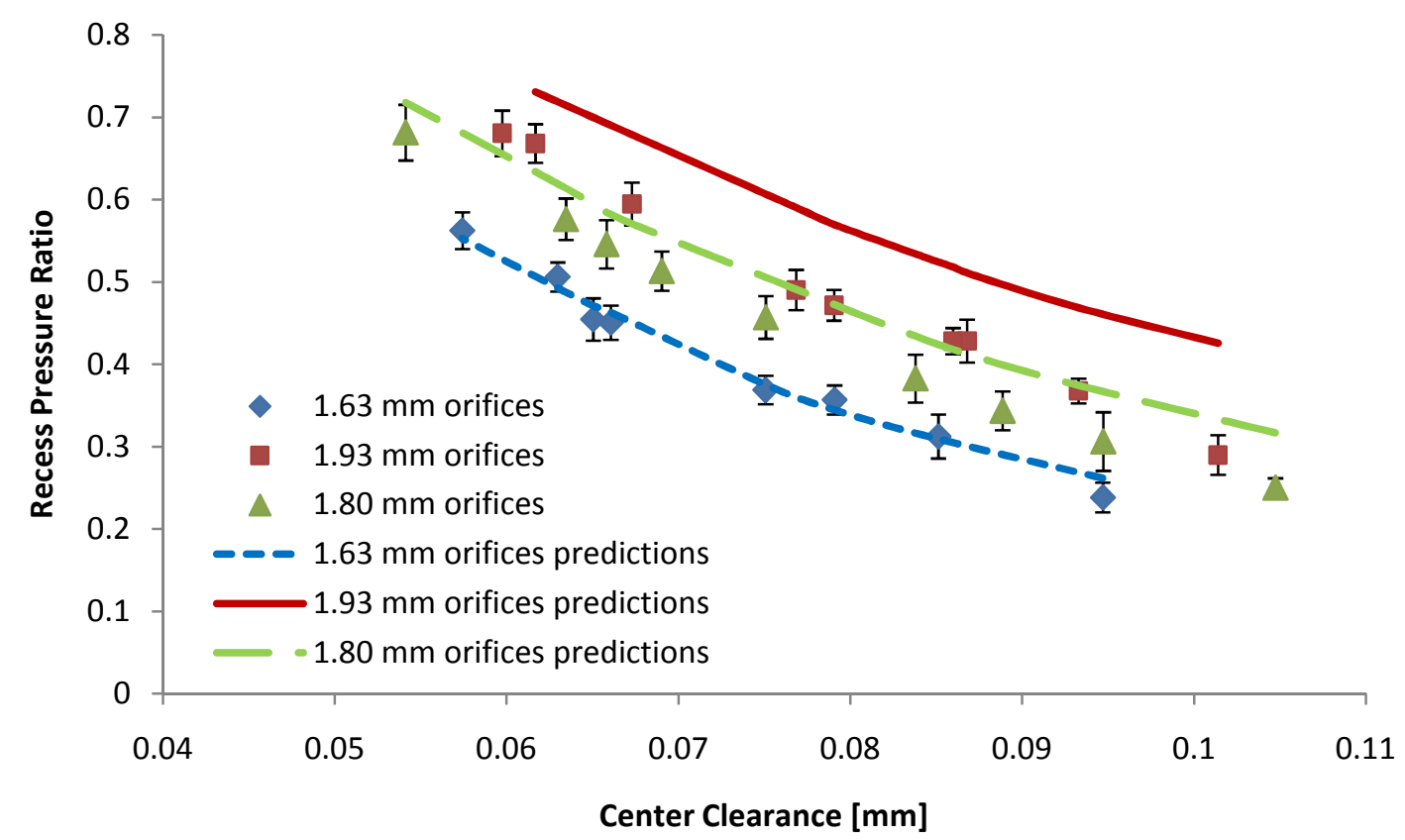

Figure 12: Measured and predicted [3] recess pressure ratio versus clearance at 10.34 bar supply and $12.5 \mathrm{krpm}$ 


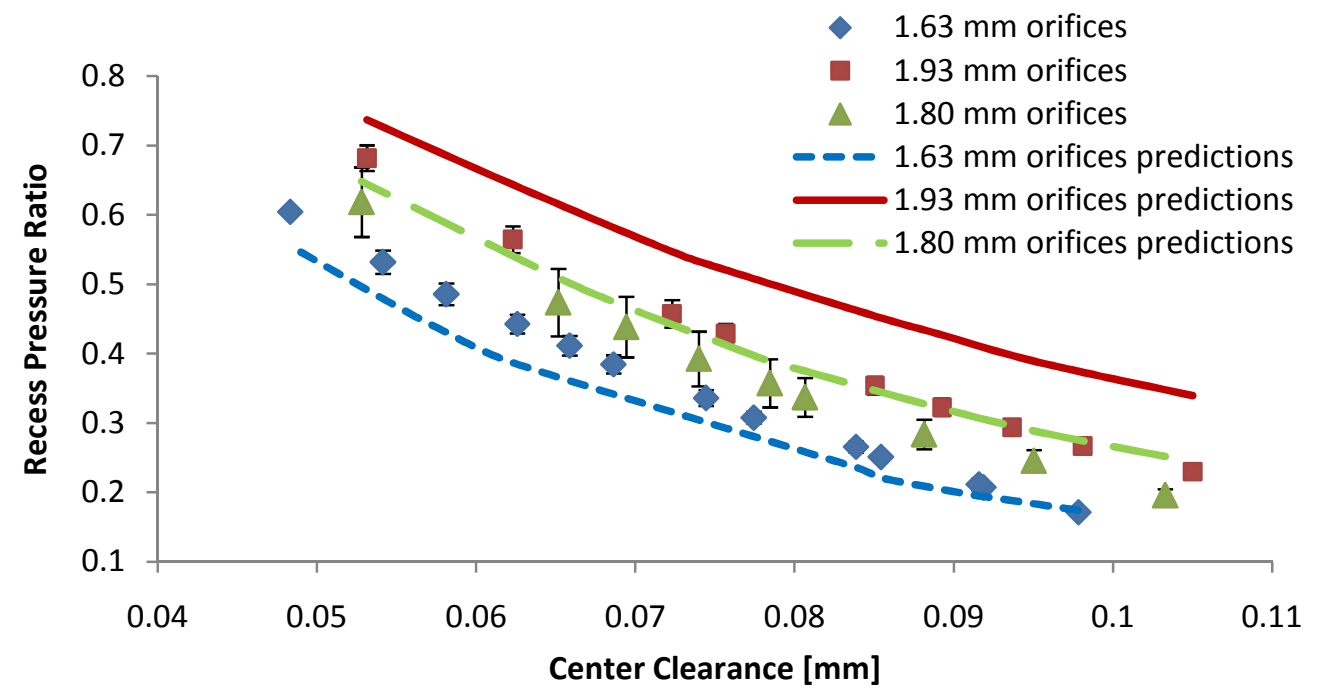

Figure 13: Measured and predicted [3] recess pressure ratio versus clearance at 17.24 bar supply and $7.5 \mathrm{krpm}$

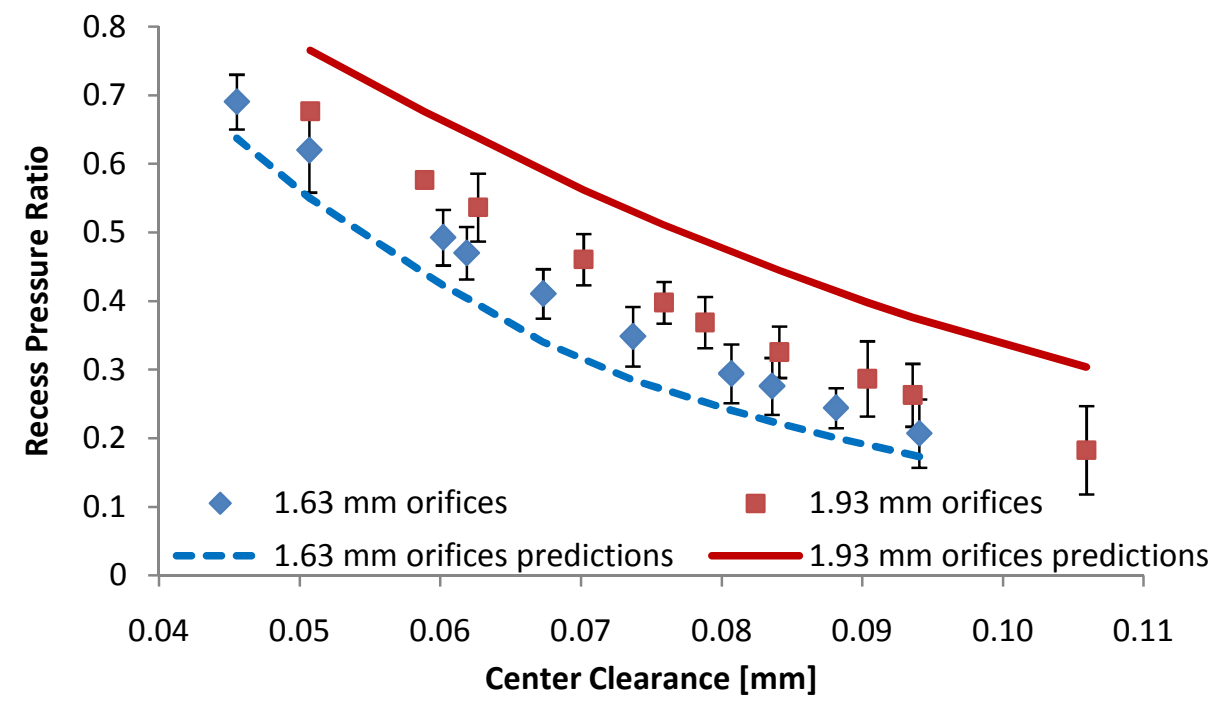

Figure 14: Measured and predicted [3] recess pressure ratio versus clearance at 5.17 bar supply and 0 rpm 
Data for the largest $(1.93 \mathrm{~mm})$ orifice diameter at the highest speeds for both the 5.17 and 17.24 bar supply pressures do not follow the same trend as the previous test conditions. Figure 15 shows that at $17.5 \mathrm{krpm}$ the recess pressure ratio in the largest $(1.93 \mathrm{~mm})$ orifice configuration is very similar to what is seen in smallest $(1.63 \mathrm{~mm})$ orifice diameter. This is also true for the 17.24 bar case as displayed in Figure 16. This plot also shows that the medium $(1.80 \mathrm{~mm})$ diameter orifice recess pressure ratio remains similarly larger than the $1.63 \mathrm{~mm}$ configuration as before. Overall, the experimental results for the largest $(1.93 \mathrm{~mm})$ orifice diameter tested display a strong dependence on both supply pressure and speed not seen in either of the other two orifice diameters nor any of the HYDROTHRUST ${ }^{\circledR}$ predictions. Also, these results do not correspond to inlet flow rate results, which were similar for all test conditions, and likewise showed similarly good agreement with predictions. This is an unexpected and interesting result that does not yet have an explanation. The other remaining bearing performance parameters including inner radius exhaust flow rate, operating clearances, and estimated axial stiffnesses are investigated for possible causes or clarification. 


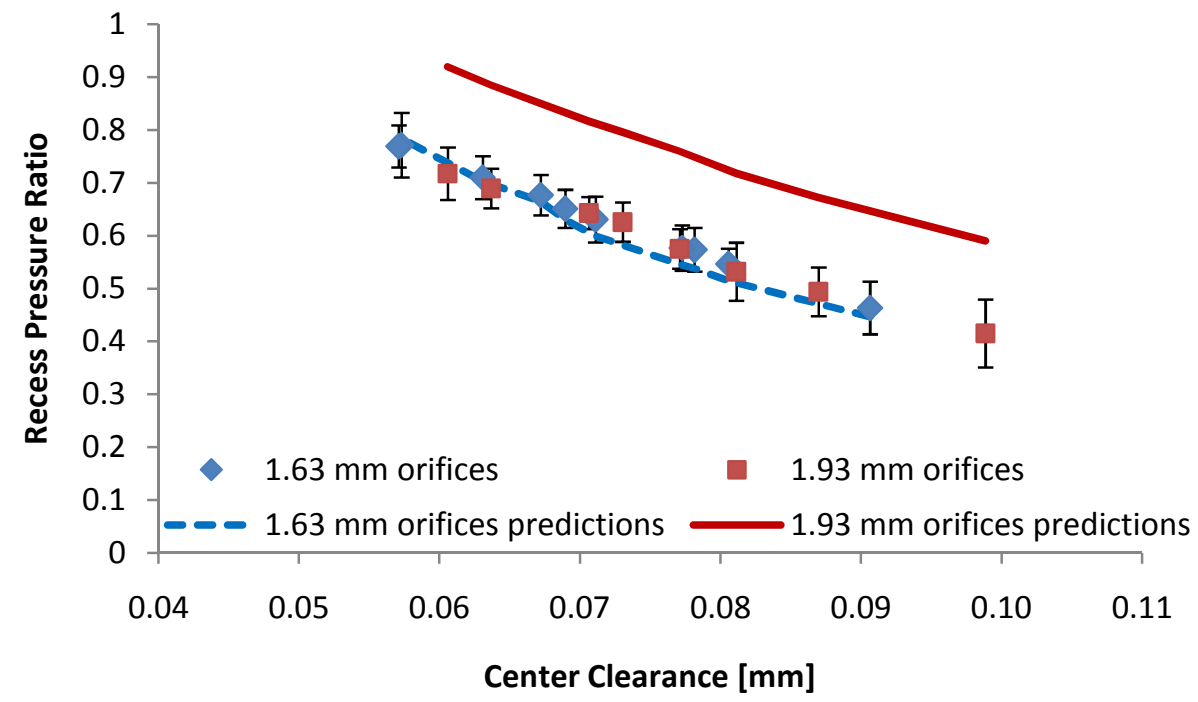

Figure 15: Measured and predicted [3] recess pressure ratio versus clearance at 5.17 bar supply and $17.5 \mathrm{krpm}$

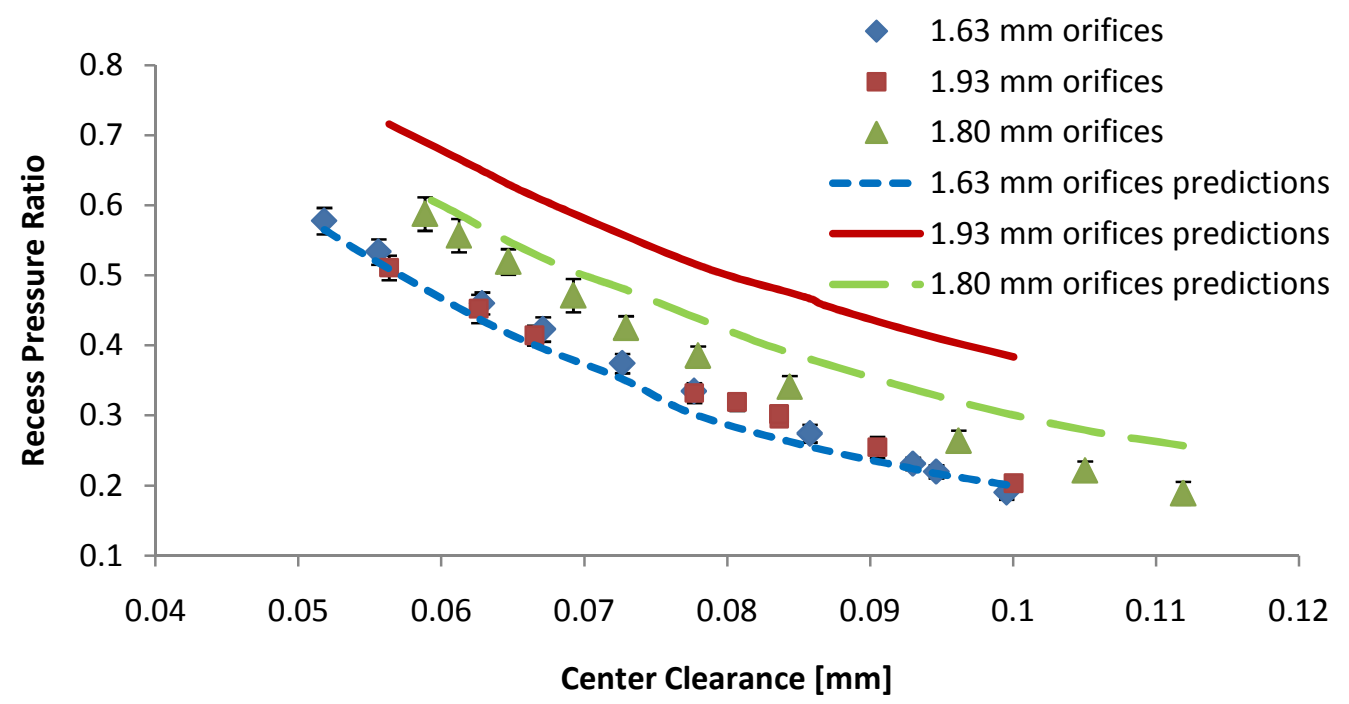

Figure 16: Measured and predicted [3] recess pressure ratio versus clearance at 17.24 bar supply and $12.5 \mathrm{krpm}$ 


\subsection{Inner Radius Exhaust Flow Rate}

Inner radius discharge flow rates are depicted in the following figures. Figures 17 and 18 show reasonable agreement between predictions and measurements for all three orifice diameters at $12.5 \mathrm{krpm}$ and supply pressures of 17.24 and $10.34 \mathrm{bar}$, respectively. While uncertainties are generally larger those shown for the bearing inlet flow rate measurements, due to the smaller flow rates measured, the predications exhibit even better agreement with measurements. Similar to the inlet-flow-rate experimental results, these data show increasing inner radius exhaust flow rates with increases in orifice diameter for all test cases. There is also no further indication as to what may cause the surprising recess pressure ratio results for the large $(1.93 \mathrm{~mm})$ orifice diameter case.

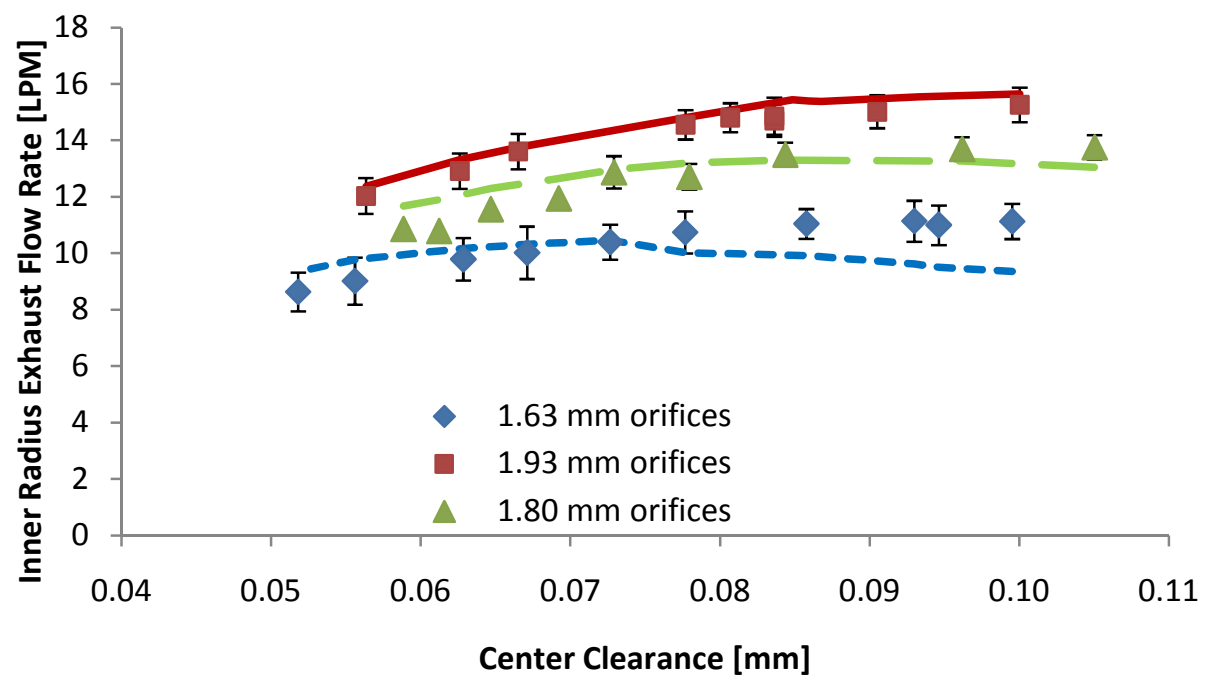

Figure 17: Measured and predicted [3] inner radius exhaust flow rate versus center clearance at 17.24 bar supply and $12.5 \mathrm{krpm}$ 


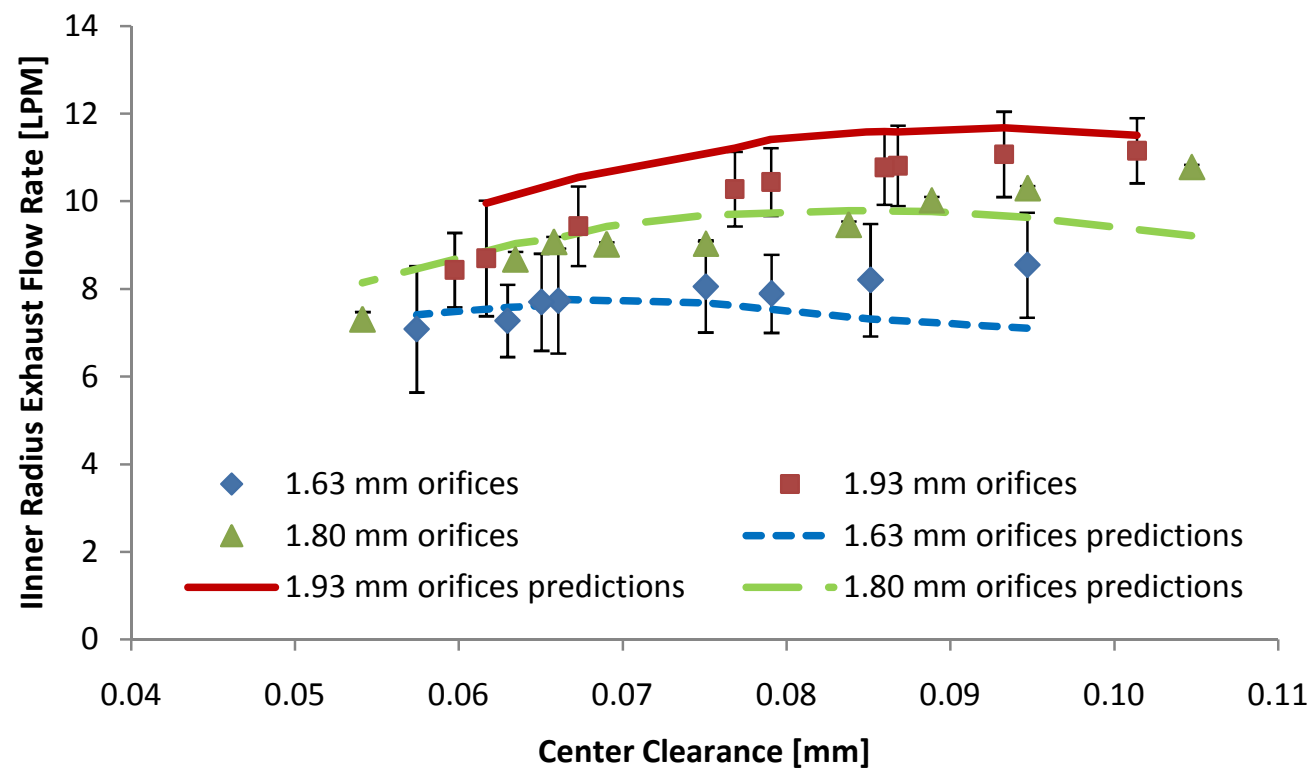

\section{Figure 18: Measured and predicted [3] inner radius exhaust flow rate versus center clearance at 10.34 bar supply and $12.5 \mathrm{krpm}$}

The inner radius discharge flow rate for the lower supply pressure of 5.17 bar is shown in Figures 19 and 20 at the lowest and highest tested speeds of 0 and $17.5 \mathrm{krpm}$, respectively. While larger relative uncertainties are seen (once again due to the even smaller flow rates measured) the same trend is seen as in the higher supply pressures. Note the significantly lower flow rates for the high speed test compared to the nonrotating case in both the data and predictions due to rotational effects more water to flow to the bearing's outer radius and limiting exhaust flow through the inner radius.

These results are particularly useful to predict the destructive phenomenon of bearing fluid starvation in bearings used at high speeds and low loads, as previously shown by Ramirez [17]. These results reinforce the ability of the HYDROTHRUST® 
predictive tool to calculate starvation as these plots trend toward starvation at the described test conditions. While the 5.17 bar supply pressure is higher, Ramirez showed the 3.45 bar pressure to exhibit this phenomenon and the trend shown is obviously similar. Also, note that the exhaust flow rates through the inner radius of the bearing are less than half of the total flow rate through the bearing shown in the inlet flow rate plots (Appendix E) for all supply pressures and speeds, as expected by San Andrés et al. [18].

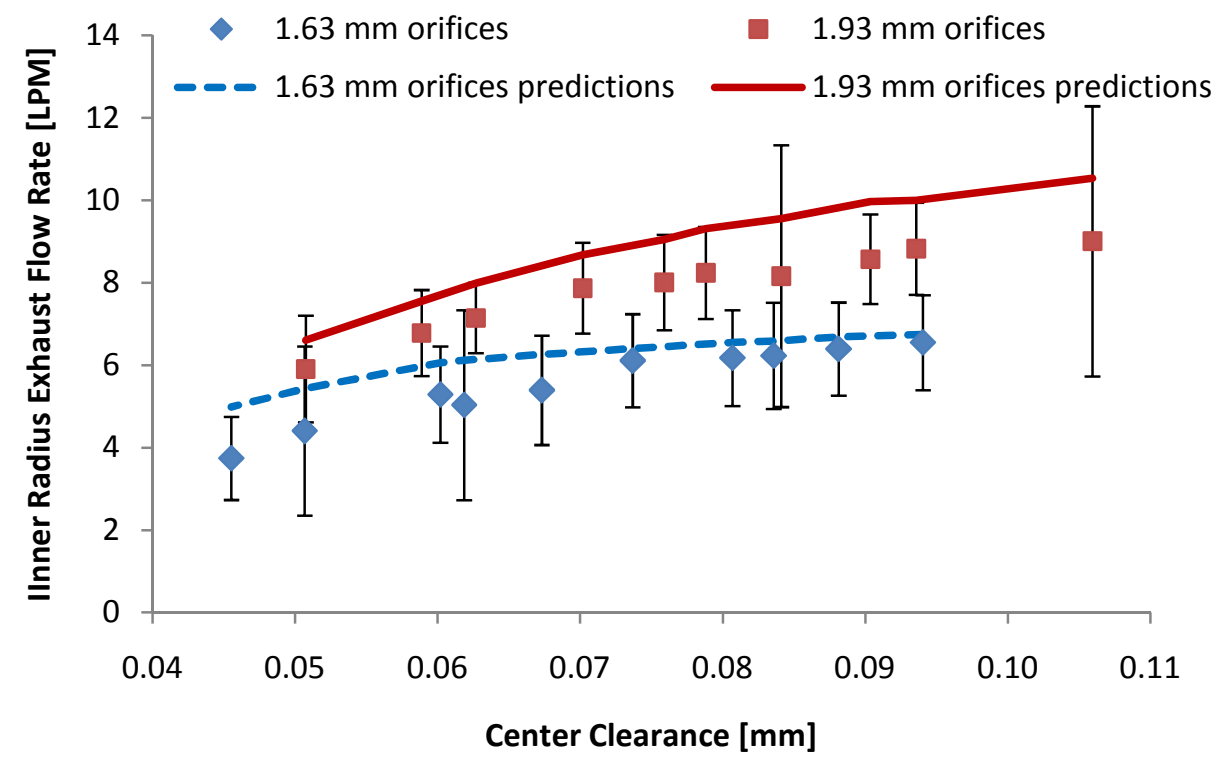

Figure 19: Measured and predicted [3] inner radius exhaust flow rate versus center clearance at 5.17 bar supply and 0 rpm 


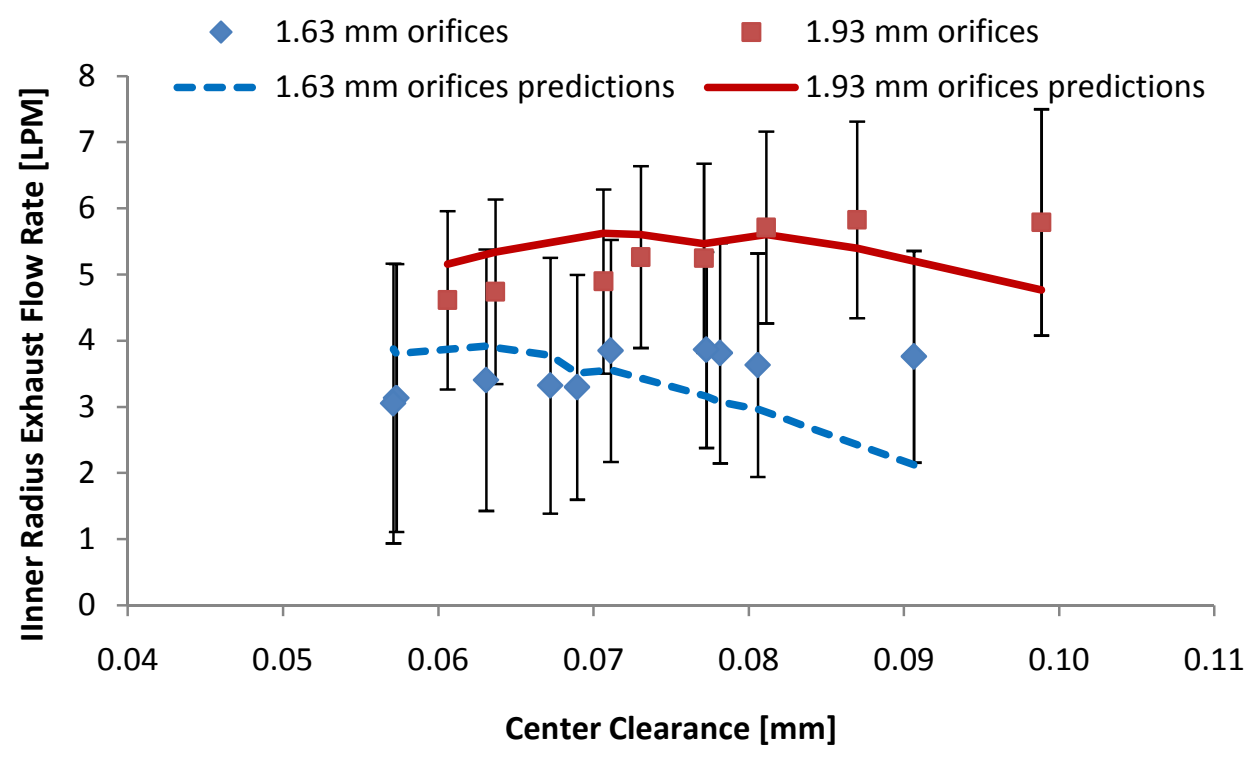

Figure 20: Measured and predicted [3] inner radius exhaust flow rate versus center clearance at 5.17 bar supply and $17.5 \mathrm{krpm}$

\subsection{Operating Center Clearance}

The measured axial clearance of a thrust bearing provides an indication of its fluid film thickness. An example of a center clearance versus load plot for individual thrust bearing proximity probes over an entire range of loads for a given supply pressure and speed test condition is displayed in Figure 21. The clearance-load behavior shown is similar for all three thrust bearings and all tests. Here, the output from the three proximity probes are plotted against the applied load for $1.63 \mathrm{~mm}$ orifice diameter bearing at a supply pressure of 17.24 bar and $7.5 \mathrm{krpm}$ test condition. The misalignment discussed previously is mainly responsible for the discrepancies shown between the three proximity probes plotted. Also, note the prediction plotted is the bearing center 
clearance while the three proximity probes are located around the bearing flange. These variations between the three probes depicted are typical for all alignment measurements obtained. Note that the worst agreement between the probe outputs and prediction appears at low load conditions. The agreement between the three proximity probe measurements and predicted clearances also tends to improve as clearances get tighter. Additionally, the plot shows a similar trend to those presented by San Andrés [2], Wang and Yamaguchi [13], Forsberg [16], and Ramirez [17].

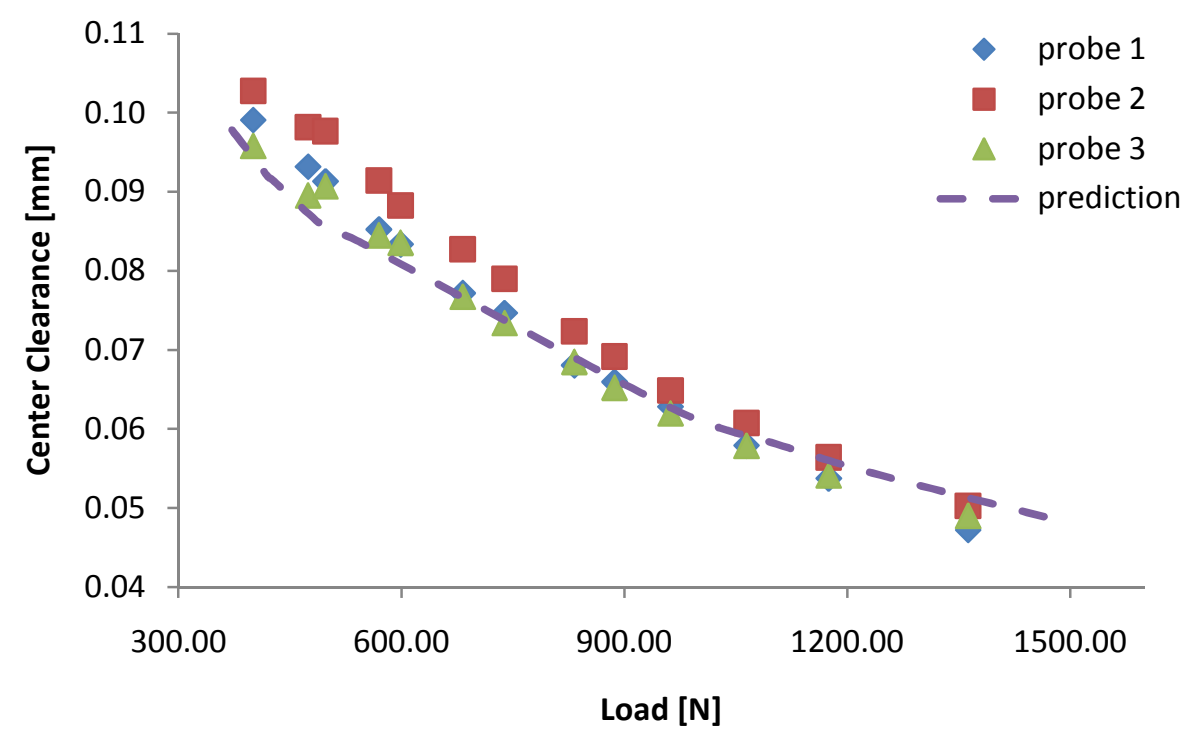

Figure 21: Measured and predicted [3] center clearance versus load for $1.63 \mathbf{~ m m}$ orifice bearing at 17.24 bar supply and $7.5 \mathrm{krpm}$

The desired thrust bearing performance is a larger clearance for the same applied load. Figures 22 and 23 depict center clearance (fluid film thickness) versus load for the tested orifice diameters and predictions at 0 and $7.5 \mathrm{krpm}$ and supply pressures of 5.17 
and 10.34 bar, respectively. Both plots show similar results for the $1.63 \mathrm{~mm}$ and 1.93 $\mathrm{mm}$ orifice diameter bearings, with the larger orifice configuration displaying an increased operating clearance and therefore better performance. Also, predictions in the two plots show adequate agreement with measurements, especially for the 1.63 and 1.93 $\mathrm{mm}$ orifice diameter bearings. Figure 22 is representative of the 5.17 bar supply pressure data for all remaining speeds and predictions. Average measurement versus prediction error for clearance versus load data at this supply pressure are $11.7 \%$ and $14.2 \%$ for the small and large orifices, respectively.

Figure 23 shows a significantly lower operating clearance of the smallest diameter $(1.63 \mathrm{~mm})$ orifice bearing when compared to the two bearings with larger orifices diameters, which are surprising similar. The only small difference in center clearance is seen between the $1.80 \mathrm{~mm}$ and $1.93 \mathrm{~mm}$ orifice diameters at low loads. This difference diminishes at higher loads, as the two curves tend to converge. Figure 23 also shows that the $1.63 \mathrm{~mm}$ orifice diameter bearing consistently exhibits the lowest operating clearance at a given load when compared to the other two bearings over all speeds and supply pressures.

Also note there is virtually zero operating clearance increase gained by using the largest $(1.93 \mathrm{~mm})$ orifices compared to the medium diameter $(1.80 \mathrm{~mm})$ in the highest, 17.24 bar, supply pressure case, as shown in Figure 24. Experimental results suggest negligible differences in center clearances for the $1.80 \mathrm{~mm}$ and $1.93 \mathrm{~mm}$ orifice diameters over all supply pressures and speeds. However, both of these bearings display significant gains when compared to the smaller $(1.63 \mathrm{~mm})$ orifice diameter 
configuration. Again, the $1.80 \mathrm{~mm}$ and $1.93 \mathrm{~mm}$ orifice diameters provide best performance in terms of higher operating clearances. Clearance versus load results do not appear to aid in understanding the recess pressure measurements for the large orifice diameter bearing previously discussed.

Predictions for operating center clearance for both the small $(1.63 \mathrm{~mm})$ and large (1.93 mm) orifice diameters correlate well with experimental measurements. Comparisons with the middle diameter orifice bearing $(1.80 \mathrm{~mm})$ show reasonable agreement but generally slightly under predict clearances. All test cases show similar agreement, with average percent differences between measured and predicted center clearances falling between $6.1 \%$ and $22.8 \%$. This trend continues for the remaining data, at all supply pressures and speeds documented in Appendix $\mathrm{H}$.

The clearance versus load data confirms that the larger orifice diameters, which generally have higher recess pressure ratios, also provide larger minimum clearances (fluid film thickness) for an applied load. In terms of operating clearance, larger orifices display the most desirable results. Additionally note that the larger clearances gained using the larger orifice diameters is offset by a higher flow rate requirement (discussed in Section 5.1) especially between the $1.93 \mathrm{~mm}$ and $1.63 \mathrm{~mm}$ orifice diameters. Obviously, higher flow rates would be expected through the larger orifice area provided by the larger orifice diameters (and larger $C_{d}$ values). 


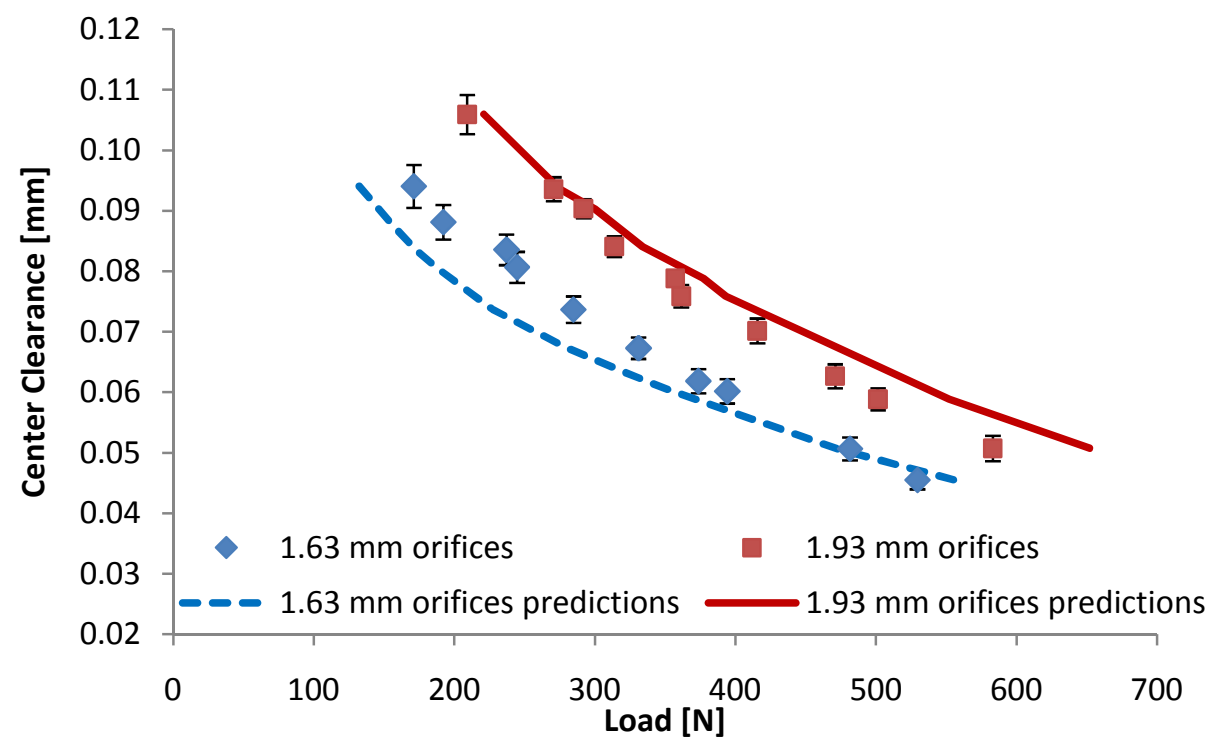

Figure 22: Measured and predicted [3] center clearance versus load at 5.17 bar supply and 0 rpm

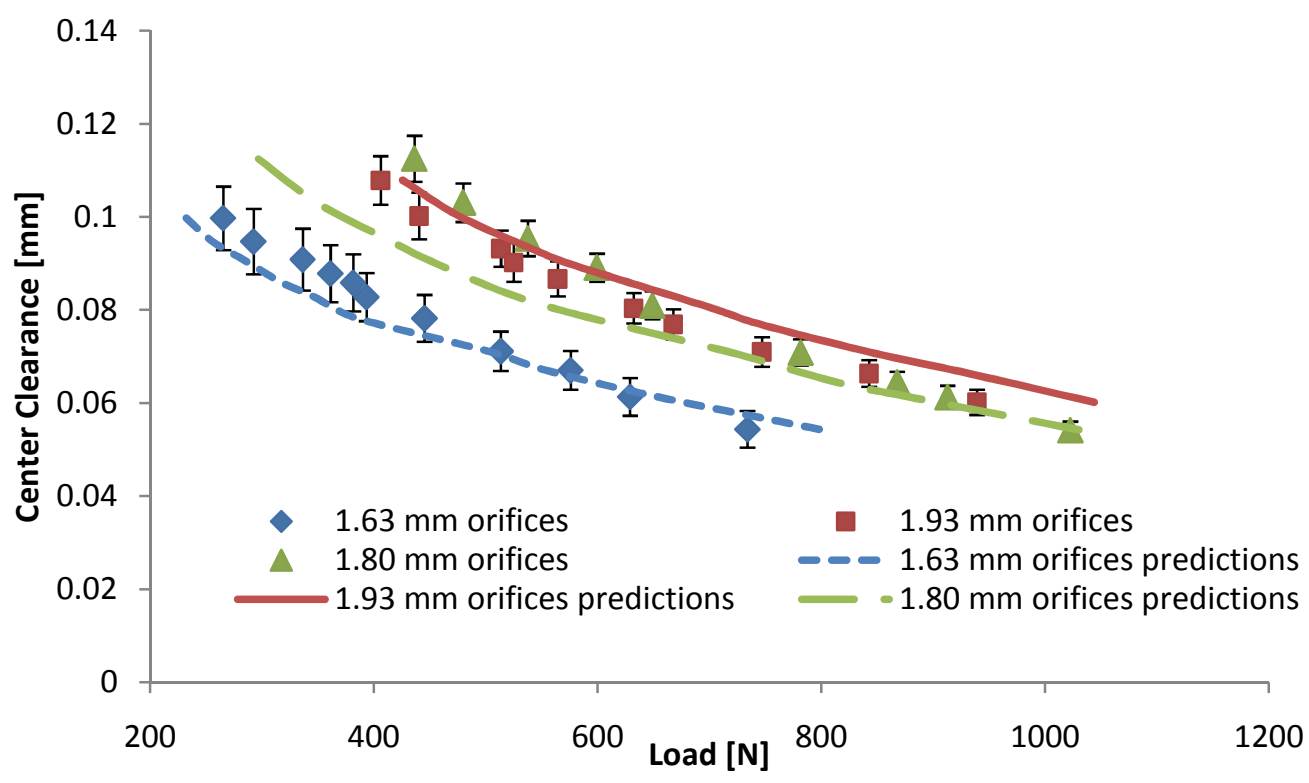

Figure 23: Measured and predicted [3] center clearance versus load at 10.34 bar supply and $7.5 \mathrm{krpm}$ 


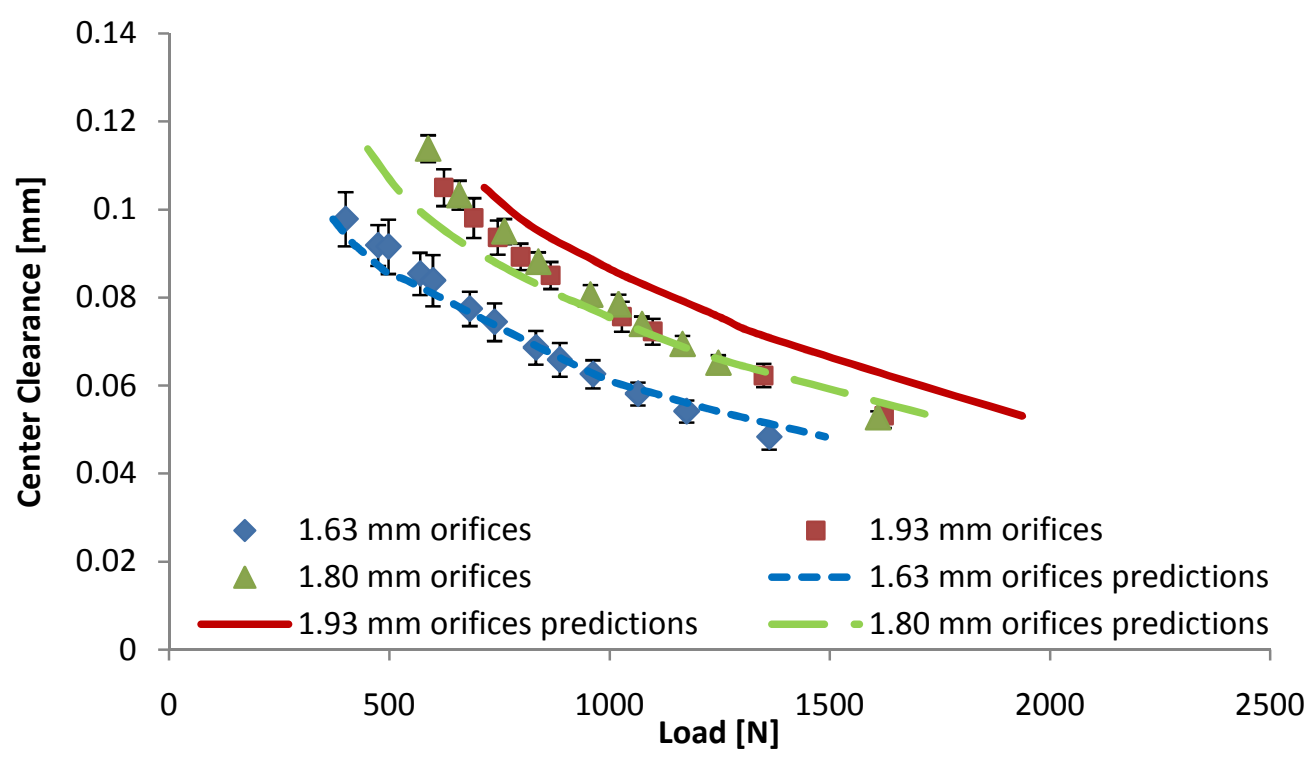

Figure 24: Measured and predicted [3] center clearance versus load at 17.24 bar supply and $7.5 \mathrm{krpm}$

Finally, Ramirez [17] found that the center clearance of this geometry bearing is not strongly influenced by shaft rotational speed (hydrodynamic effects) using the 1.80 $\mathrm{mm}$ orifice diameter bearing. The result is confirmed using the $1.63 \mathrm{~mm}$ and $1.93 \mathrm{~mm}$ orifice diameter bearings, with the $1.63 \mathrm{~mm}$ orifice diameter at 10.34 bar supply pressure data shown in Figure 25. The two larger orifices continue to have similar clearances for given loads and are not included in Figure 25 to limit its complexity. Similar results also occur for other supply pressures, albeit at increasing loads and clearances for increasing supply pressures. Supplemental figures for both of these results are found in Appendix H. 


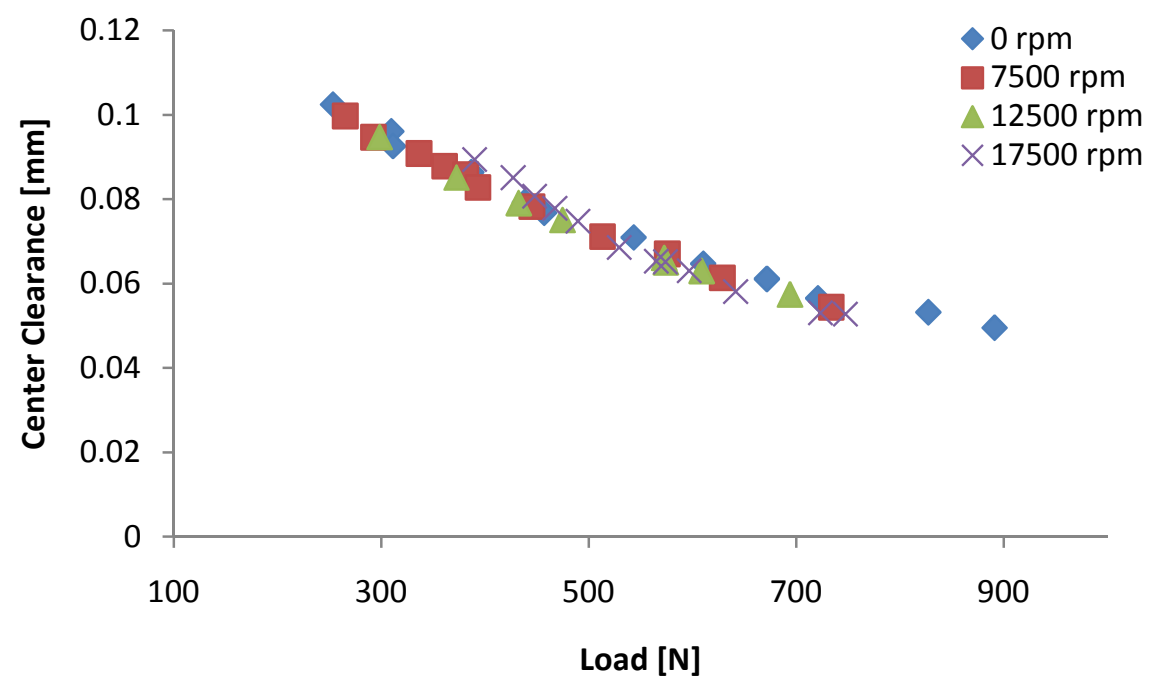

Figure 25: Measured and predicted [3] center clearance versus load at 10.34 bar supply and $1.63 \mathrm{~mm}$ orifice diameters for all speeds

\subsection{Estimation of Axial Stiffness}

Thrust bearing stiffnesses are vital performance characteristics, and the method used here to calculate the statically loaded axial stiffness is outlined in further detail by Forsberg [16] Stiffness predictions from HYDROTHRUST® are output in the matrix format 


$$
\left[\begin{array}{c}
F_{z} \\
M_{\Phi_{x}} \\
M_{\Phi_{y}}
\end{array}\right]=\left[\begin{array}{ccc}
K_{z z} & K_{z \Phi_{x}} & K_{z \Phi_{y}} \\
K_{\Phi_{x z}} & K_{\Phi_{x} \Phi_{x}} & K_{\Phi_{x} \Phi_{y}} \\
K_{\Phi_{y z}} & K_{\Phi_{y} \Phi_{x}} & K_{\Phi_{y} \Phi_{y}}
\end{array}\right]\left[\begin{array}{c}
z \\
\Phi_{x} \\
\Phi_{y}
\end{array}\right]
$$

Here, $F_{z}$ is the load on the bearing face, $M_{a}$ is the moment acting on the axis "a," $K_{m n}$ is the stiffness coefficient for the " $\mathrm{m}$ " direction from the " $\mathrm{n}$ " variable, $z$ is the thrust bearing clearance, and $\Phi_{b}$ is the misalignment angle about axis "b." Equation 6 leads to the following equation for axial force.

$$
F_{z z}=K_{z z} * z+K_{z \Phi_{x}} * \Phi_{x}+K_{z \Phi_{y}} * \Phi_{y}
$$

The data obtained here use static axial loading of the current thrust bearing rig and precludes direct comparisons between these predictions due to the inability to isolate a single stiffness term. However, an estimation of axial stiffness is obtained from the measurements by differentiating the clearance versus load curves.

This stiffness estimate is achieved by first curve fitting the clearance-versus-load data for each bearing and test condition. For both the $1.63 \mathrm{~mm}$ and $1.93 \mathrm{~mm}$ orifice data, a second order polynomial was used. For the $1.80 \mathrm{~mm}$ data, Forsberg [16] and Ramirez [17] use third and forth order fits respectively. In all cases, these are the lowest order polynomials that could follow the clearance versus load plot with reasonable error. The thrust bearing stiffness estimate is then found by differentiating the curve-fit equation. 
This estimation method presents a significant uncertainty due to the differentiation function. This uncertainty is found using the following equation,

$$
E_{d F / d Z}=\sqrt{E_{A}^{2}+E_{B}^{2}+E_{C}^{2}+E_{D}^{2}}
$$

The overall uncertainty is given as $E_{d F / d Z}$ and $E_{N}$ is the uncertainty associated with the term $N$. The uncertainty of each term is found using TableCurve 2D software. This program provides a second method of curve fitting the data to check the previous one found using Excel, and produces uncertainties associated with each of the terms given. The overall uncertainties obtained for these results vary widely depending on the test condition, and generally range from less than $10 \%$ of the maximum value for the low speed, high pressure test conditions, to greater than $25 \%$ for high speed, low pressure conditions. As in other measurements, a decrease in speed (especially to zero) or increase in supply pressure causes a decrease in the uncertainties of the stiffness plots.

Thrust bearing stiffness is expected to increase with decreasing fluid film thickness. Plots of estimated stiffness follow. Estimated stiffness for the lowest supply pressure case of 5.17 bar is given in Figure 26 for the non-rotating case. Here, there is a small difference between the $1.63 \mathrm{~mm}$ and $1.93 \mathrm{~mm}$ orifice bearings.

Figure 27 provides a comparison of estimated stiffness for the three orifice diameters at 10.34 bar supply pressure and $7.5 \mathrm{krpm}$. For this case, the three bearings show similar stiffnesses at high clearances (low loads). As expected, the stiffness 
estimate increases for all three orifice diameters as the clearance decreases. In these reduced clearance conditions, the stiffness estimate increases with increasing bearing orifice diameter (and flow rates). The highest stiffness is the most desirable result as it provides increased rotor axial stability. Note that the maximum estimated stiffness appears at the minimum measured clearances for all three orifice diameters. Figure 28 shows an inverted version of the clearance-load data described previously and confirms the estimated stiffnesses correspond to the measured slopes. Here, the $1.93 \mathrm{~mm}$ orifice shows a steeper (larger) slope than the $1.80 \mathrm{~mm}$ orifice, which corresponds to the higher stiffness values shown.

Figure 29 shows the stiffness estimation results for the 17.24 bar supply pressure case. Here the estimated axial stiffness all three orifices have similar values, with slightly higher stiffness shown for increasing orifice diameters. The data does show a significant increase in stiffness for all three orifices with increasing supply pressure, as expected. Also, none of the three orifice diameters show significant changes in estimated stiffness with changes in speed for any supply pressure. The trends shown in these figures continue for the remaining data found in Appendix I.

Note that the lowest operating clearance (shown in Figures $22-24$ previously) for all test cases does not necessarily have the highest stiffness (preferred for better rotor axial stability). This indicates that orifice diameters providing the highest centering (reaction) forces on the rotor do not necessarily provide the highest stiffness. It will depend on the application to select a best configuration for these parameters. 


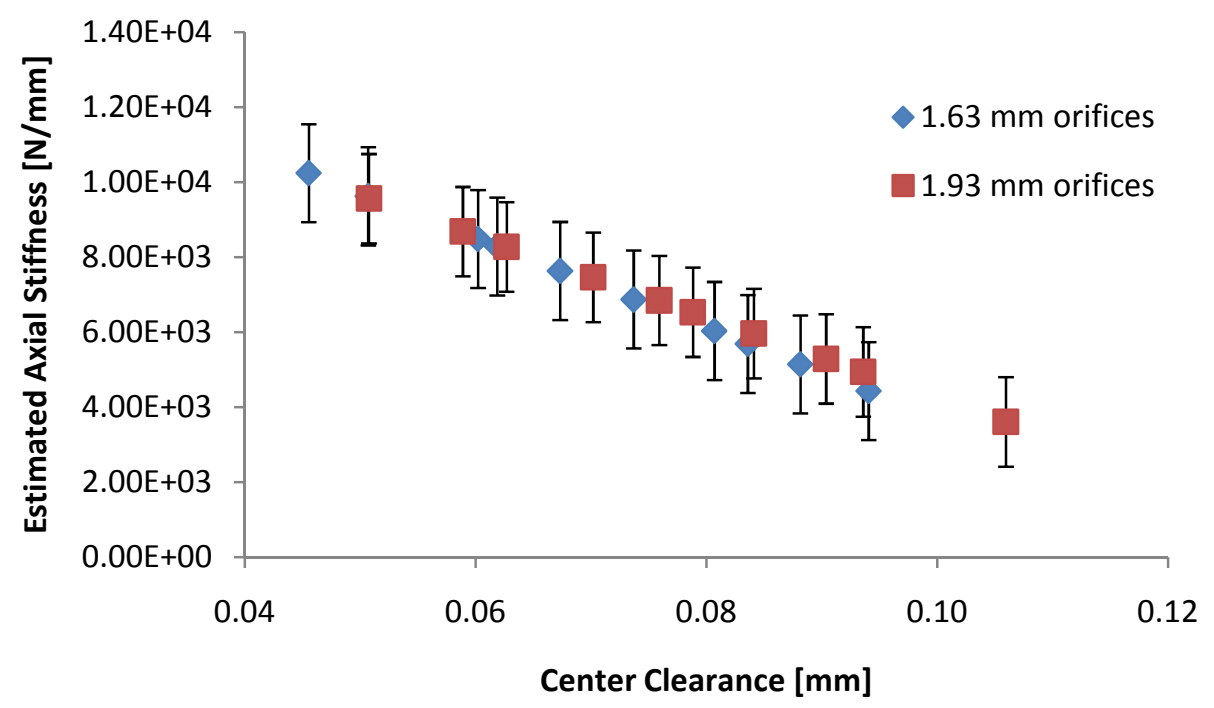

Figure 26: Estimated axial stiffness versus clearance at 5.17 bar supply and 0 rpm

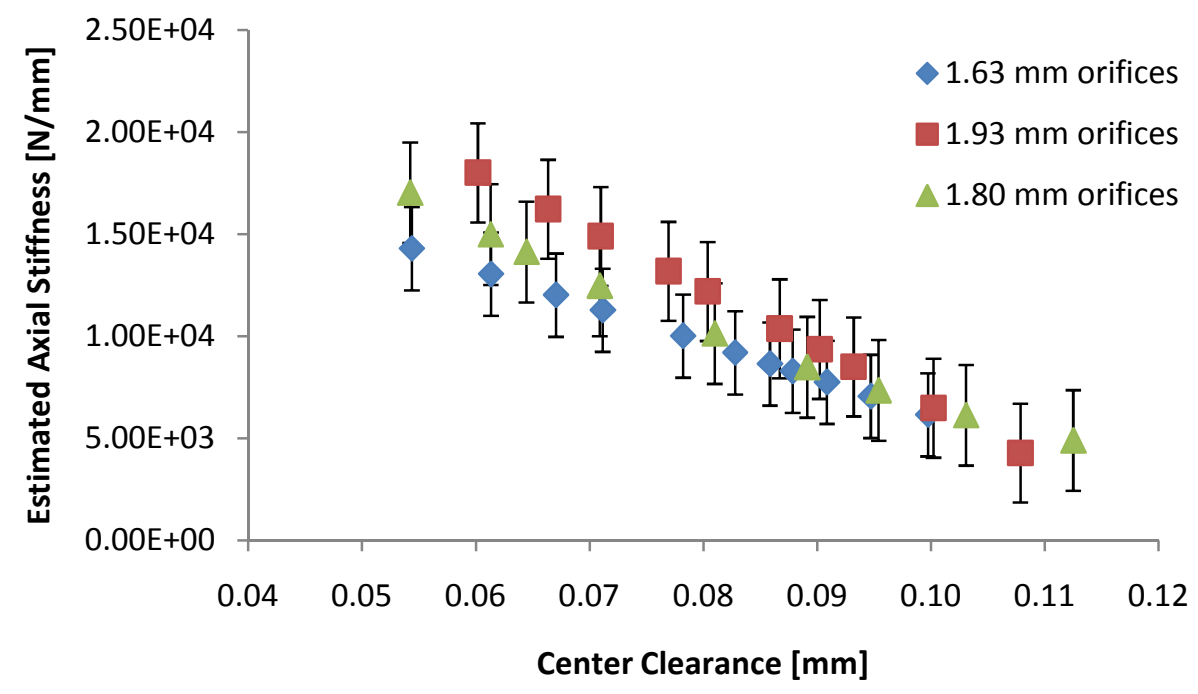

Figure 27: Estimated axial stiffness versus clearance at $\mathbf{1 0 . 3 4}$ bar supply and 7.5 krpm 


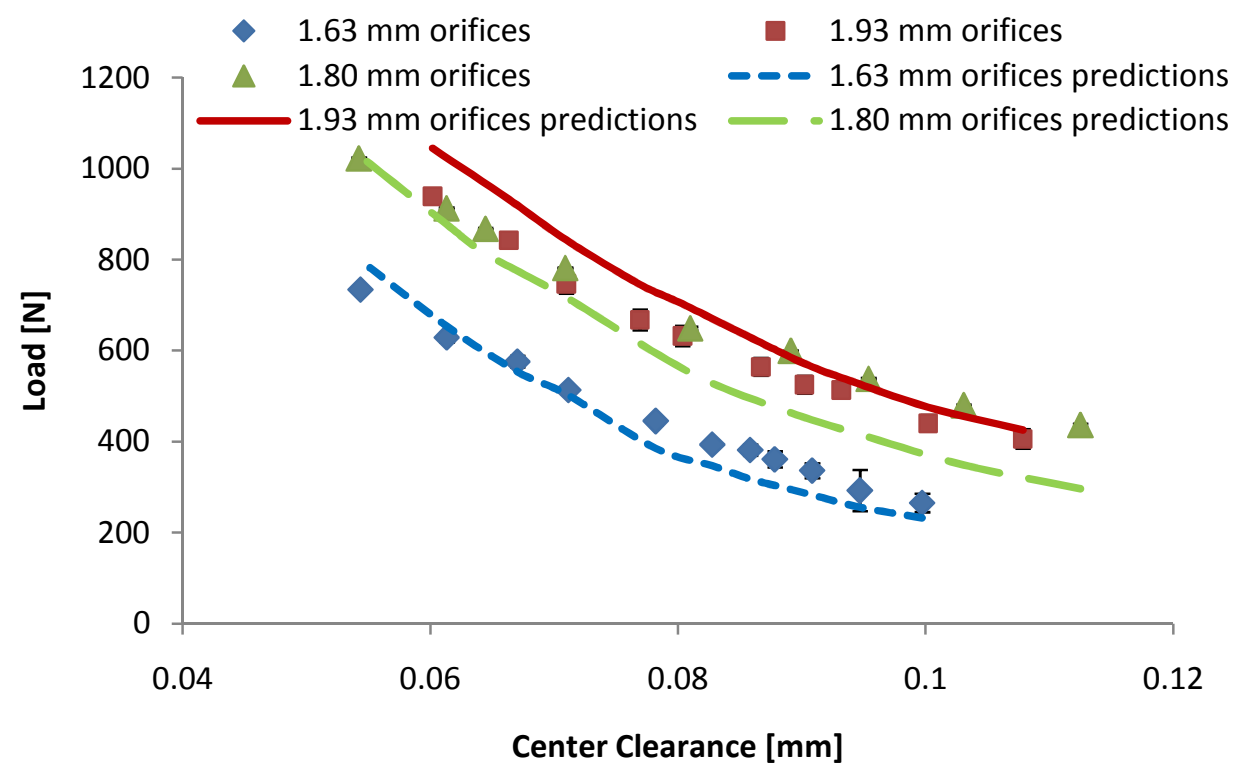

Figure 28: Measured and predicted [3] load versus center clearance at 10.34 bar supply and $7.5 \mathrm{krpm}$

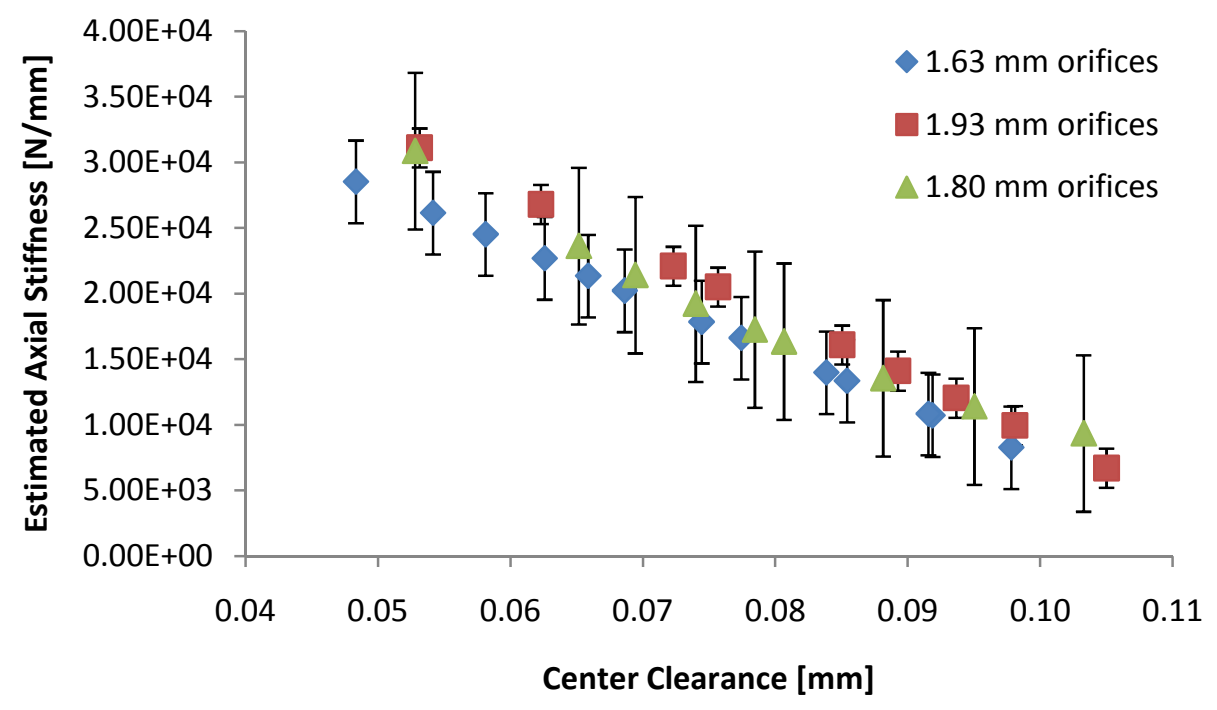

Figure 29: Estimated axial stiffness versus clearance at $\mathbf{1 7 . 2 4}$ bar supply and 7.5 krpm 


\section{SUMMARY AND CONCLUSIONS}

A water-lubricated, hybrid thrust bearing was tested with three different orifice diameters using a face-to-face style test rig with supply pressures of 5.17, 10.34, and 17.24 bar, shaft rotational speeds of $0,7.5,12.5$, and $17.5 \mathrm{krpm}$, and static loads from 125 to $1650 \mathrm{~N}$. Experimental results were compared to predictions obtained using HYDROTHRUST ${ }^{\circledR}$ for recess pressure ratios, operating clearances, and inlet and exhaust flow rates. An estimation of axial stiffness was also presented.

Flow rate predictions for both the bearing inlet and inner radius exhaust tended to correlate very well with the data for all test conditions and configurations. Increasing orifice diameters showed an increase in flow rates for a given clearance, which also verifies that different orifice diameters were achieved. Average total differences between measurements and predictions were less than $10 \%$ for both flow rate measurements. The small $(1.63 \mathrm{~mm})$ orifice diameter bearing showed the lowest recess pressure ratios of the three bearings, with the middle $(1.80 \mathrm{~mm})$ orifice diameter bearing consistently being higher. Unexpected results were seen for the large $(1.93 \mathrm{~mm})$ orifice diameter bearing at both the low and high supply pressures where the bearing displayed similar recess pressures to the small orifice diameter bearing. Conversely, the large orifice diameter bearing had the highest recess pressure ratios at the 10.34 bar supply pressure. The cause of these results is unknown.

A limited increase in operating clearance for a given load was shown between the $1.80 \mathrm{~mm}$ and $1.93 \mathrm{~mm}$ orifice diameters, but both diameters exhibited an advantage over 
the smallest, $1.63 \mathrm{~mm}$ orifice diameter configuration. Bearing inlet supply and inner radius exhaust flow rates increased with increasing orifice diameter for all test cases. Inner radius exhaust flow rates decreased with decreasing orifice diameter and supply pressure and increasing speed. As a matter of performance, limited operating clearance and estimated stiffness gains were seen over the test conditions through the use of the larger orifice diameter bearing, but it still required additional flow rates (and therefore additional loss in application), especially at higher supply pressures and low loads.

Predictions correlated well with recess pressure measurements for the medium, 10.34 bar, supply pressure condition for all three bearings configurations. Experimental results were lower than predictions for the largest $(1.93 \mathrm{~mm})$ orifice diameter bearing at both the low and high supply pressures (5.17 and 17.24 bar). Predictions for the other two smaller orifice diameter bearings continued to show adequate agreement with recess pressure measurements. Load predictions also showed adequate agreement with experimental data with a total percent difference near 13\%. Exit flow rates displayed exceptionally good agreement with predictions for all three orifice diameters and all test conditions. Overall, HYDROTHRUST $®$ continues to prove to be a powerful predictive tool.

It is difficult to suggest an optimum orifice diameter for hybrid thrust bearings. Larger orifices provide larger operating clearances and higher stiffnesses, but also require higher flow rates. A compromise between these parameters is obviously desired, and a desired axial clearance is often located in the middle of a bearing's load range to allow for some fluctuation. Additional data are needed to select an optimum orifice 
diameter, and such a selection would undoubtedly depend on the desired operating characteristics of the bearing and its application.

Possible future work includes an investigation of stiffness and damping in hybrid thrust bearing performance. A further study of the effects of varying orifice diameters on both of these parameters would be a very useful tool and extension of this research. With few modifications, the same test rig used in obtaining data presented here could be utilized for dynamic (loading) testing of hybrid thrust bearings and to allow this data to be obtained, including direct stiffness and damping comparisons with predictions. 


\section{REFERENCES}

[1] Minick, A., and Peery, S., 1998, "Design and Development of an Advanced Liquid Hydrogen Turbopump," AIAA Paper 1998-3681.

[2] San Andrés, L., 2000, "Bulk-Flow Analysis of Hybrid Thrust Bearings for Process Fluid Applications,” ASME J. Tribol., 122, pp. 170-180.

[3] San Andrés, L., 2002, "Effects of Misalignment on Turbulent Flow Hybrid Thrust Bearings," ASME J. of Tribol., 124, pp. 212-219.

[4] Mosher, P. and Childs, D.W., 1998, "Theory Versus Experiment for the Effects of Pressure Ratio on the Performance of an Orifice-Compensated Hybrid Bearing," ASME J. of Vibr. and Acoust., 120 (4), pp. 930-936.

[5] Pinkus, O. and Lund, J.W., 1981, "Centrifugal Effects in Thrust Bearings and Seals Under Laminar Conditions,” ASME J. of Lubr. Technol., 103, pp. 126-136.

[6] Hashimoto, H., 1990, "The Effects of Fluid Inertia Forces on the Static Characteristics of Sector-Shaped High Speed Thrust Bearings in Turbulent Flow Regime," ASME J. of Tribol., 111, pp. 406-411.

[7] Safar, Z.S., 1983, "Centrifugal Effects in Misaligned Hydrostatic Thrust Bearings," ASME J. of Lubr. Technol., 105, pp. 621-624.

[8] New, N.H., 1974, "Experimental Comparison of Flooded, Directed, and Inlet Orifice Type of Lubrication for a Tilting Pad Thrust Bearing," ASME J. of Lubr. Technol., 96, pp. 22-27.

[9] Gregory, R.S., 1974, "Operating Characteristics of a Fluid-Film Thrust Bearing Subjected to High Shaft Speeds,” ASME J. of Lubr. Technol., 96 (1), pp. 7-14.

[10] Neal, P.B., 1982, "Heat Transfer in Pad Thrust Bearings," Proceedings of the Institution of Mechanical Engineers, London, UK, pp. 217-228.

[11] Horner, D., Simmons, J.E.L. and Advani, S.D., 1988, "Measurements of Maximum Temperature in Tilting-Pad Thrust Bearings," STLE Tribol. Trans., 31 (1), pp. 4453. 
[12] Harada, M., Miyaji, R. and Anada, Y., 1987, “Turbulent Lubrication for a Hydrostatic Thrust Bearing with a Circular Recess: Vibration, Control Engineering, Engineering for Industry," Bulletin of the JSME, 30 (269), pp. 18191825.

[13] Wang, X. and Yamaguchi, A., 2002, "Characteristics of Hydrostatic Bearing/Seal Parts for Water Hydraulic Pumps and Motors. Part 1: Experiment and Theory," Tribol. Int., 35 (7), pp. 425-433.

[14] Gardner, W.W., 1975, "Performance Tests on Six-Inch Tilting Pad Thrust Bearings," ASME J. of Lubr. Technol., 97 (3), pp. 460-438.

[15] Glavatskih, S.B., 2002, "Laboratory Research Facility for Testing Hydrodynamic Thrust Bearings,” Proc. Inst. Mech. Eng., 216, (Part J), pp. 105-116.

[16] Forsberg, M., 2008, “Comparison Between Predictions and Experimental Measurements for an Eight Pocket Annular Hydrostatic Thrust Bearing," M.Sc. project report, May, Texas A\&M University, College Station, TX.

[17] Ramirez, F., 2008, "Comparison Between Predictions and Measurements of Performance Characteristics for an Eight Pocket Hybrid (Combination Hydrostatic/Hydrodynamic) Thrust Bearing," M.Sc. project report, August, Texas A\&M University, College Station, TX.

[18] San Andrés, L., Phillips, S. and Childs, D., 2008, "Static Load Performance of a Hybrid Thrust Bearing: Measurements and Validation of Predictive Tool," 6th Modeling and Simulation Subcommittee / 4th Liquid Propulsion Subcommittee / 3rd Spacecraft Propulsion Subcommittee Joint Meeting, December 8-12, Orlando, Florida, JANNAF-120 Paper (Paper of restricted distribution - Joint Army, Navy, NASA, Air Force Interagency Propulsion Committee).

[19] Coleman, H.W. and Steele, G.W., 1988, Experimentation and Uncertainty Analysis for Engineers, John Wiley \& Sons, Inc., New York. 


\section{APPENDIX A}

\section{RADIAL AND AEROSTATIC BEARING DETAIL}
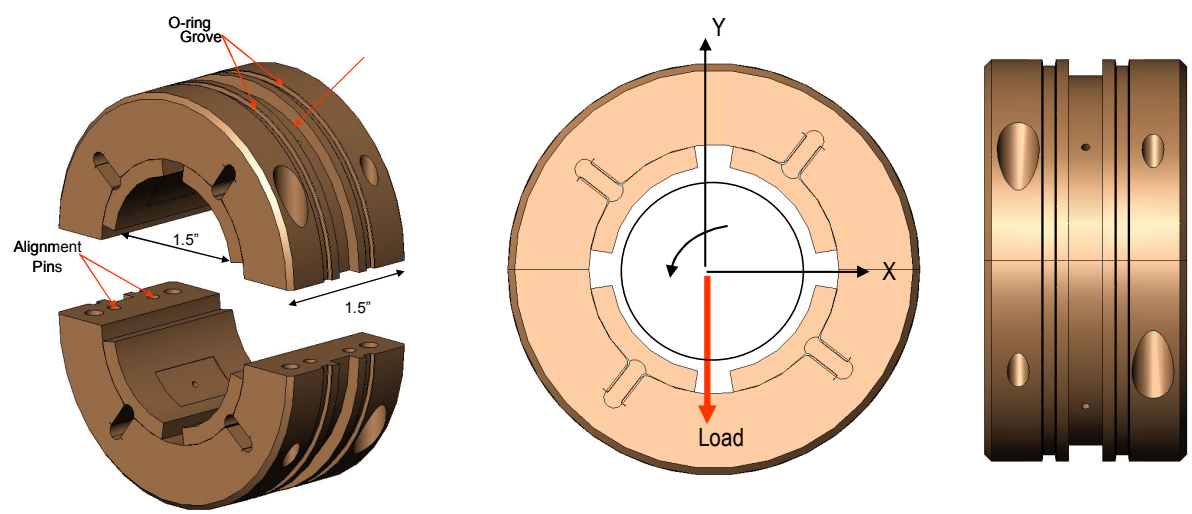

Figure A-1: Depiction of radial hybrid bearings [17]

Table A-1: Dimensions and physical parameters of hybrid radial bearings (flexure pivot type and made of bearing bronze) [17]

\begin{tabular}{lll}
\hline Nominal & Radial clearance & $76.2 \mu \mathrm{m}(3 \mathrm{mil})$ \\
\hline Bearing & Inner Diameter & $38.1 \mathrm{~mm}(1.5 \mathrm{inch})$ \\
& Outer Diameter & $76.2 \mathrm{~mm}(3 \mathrm{inch})$ \\
& Length & $38.1 \mathrm{~mm}(1.5 \mathrm{inch})$ \\
\hline Pads & Number of pads & 4 \\
& Arc length & $72 \circ$ \\
& Pivot offset (dim) & $60 \%$ arc length \\
& Preload (dim) & 0.20 \\
& Flexure rotational stiffness & $199.97 \mathrm{~N}-\mathrm{m} / \mathrm{rad}$ \\
& & $(1,770 \mathrm{lb}$-in/rad $)$ \\
\hline Pocket & Axial length & $12.7 \mathrm{~mm}(0.50 \mathrm{inch})$ \\
one per pad & Arc length & $24 \circ$ \\
& Depth & $.508 \mathrm{~mm}(20 \mathrm{mil})$ \\
& Mean Diameter & $54.864 \mathrm{~mm}(2.16 \mathrm{inch})$ \\
& Pocket/wetted area ratio & 0.11 \\
& Inlet coefficient from pocket to land & 0.20 \\
\hline Orifice & Diameter & $1.702 \mathrm{~mm}(0.067 \mathrm{inch})$ \\
one per pocket & Radial injection & $50 \% \mathrm{of} \mathrm{pocket} \mathrm{length}$ \\
& Entrance Loss Coefficient & 0.80 \\
\hline Web & Radial width & $3.56 \mathrm{~mm}(0.140 \mathrm{inch})$ \\
& Axial width & $3.81 \mathrm{~mm}(0.150 \mathrm{inch})$ \\
& Length (radius-to-radius $)$ & $6.38 \mathrm{~mm}(0.251 \mathrm{inch})$ \\
& Radius & $20.32 \mathrm{~mm}(0.80 \mathrm{inch})$ \\
\hline
\end{tabular}



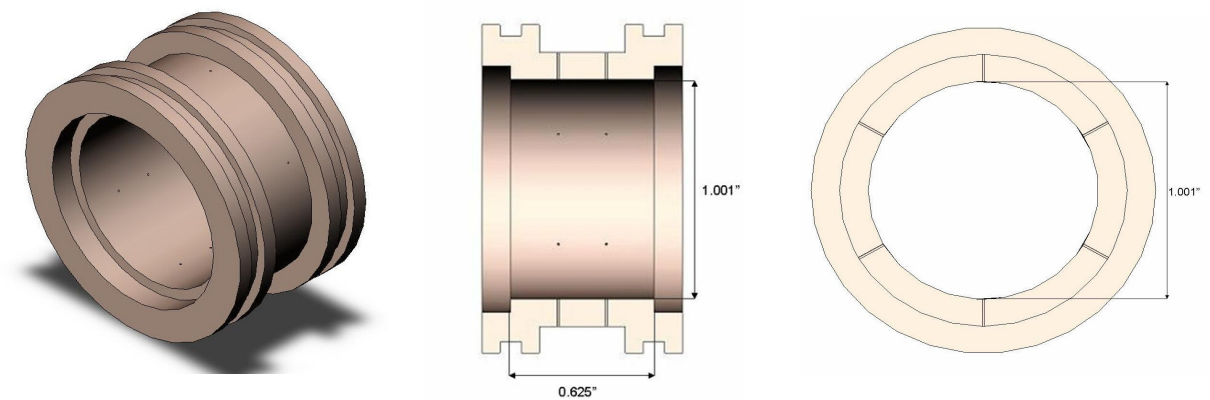

Figure A-2: View of aerostatic bearing (3d, side and front cross sections) [17]

Table A-2: Dimensions of aerostatic bearings, force coefficients and lateral natural frequencies of TB section and axial load shaft [17]

AEROSTATIC BEARINGS

Supply Pressure: 6.89 bar (100 psig)

Radial Clearance

Diameter

Axial Length

Number of holes

Hole Diameter

Hole Pattern

Static load

Static displacement

Mass Flow

Pressure Ratio

$\left(\mathrm{P}_{\max }-\mathrm{P}_{\text {atm }}\right) /\left(\mathrm{P}_{\text {supply }}-\mathrm{P}_{\text {atm }}\right.$

\section{Vertical motions}

Stiffness $\left(\mathrm{K}_{\mathrm{xx}}\right)$

Damping $\left(\mathrm{C}_{\mathrm{xx}}\right)$

$9911.7^{\mathrm{N}} / \mathrm{mm}\left(56.6^{\mathrm{lb} / \mathrm{mil}}\right)$

$10139.3^{\mathrm{N} / \mathrm{mm}}\left(57.9^{\mathrm{lb} / \mathrm{mil}}\right)$

$518.35^{\mathrm{N} / \mathrm{s}} / \mathrm{m}\left(2.96^{\mathrm{lb} / \mathrm{s}} /\right.$ in $)$

Natural frequency \&

Damping ratio

\section{Horizontal motions}

Stiffness $\left(\mathrm{K}_{\mathrm{yy}}\right)$

Damping $\left(\mathrm{C}_{\mathrm{yy}}\right)$

$10156.84^{\mathrm{N}} / \mathrm{mm}\left(58.0^{\mathrm{lb}} / \mathrm{mil}\right)$

$374.75^{\mathrm{N} / \mathrm{m}}\left(2.14^{\mathrm{lb} * \mathrm{~s}} /\right.$ in $)$

$10191.87^{\mathrm{N}} / \mathrm{mm}\left(58.2^{\mathrm{lb}} / \mathrm{mil}\right)$
$336.23 \mathrm{~N} / \mathrm{m}\left(1.92^{\mathrm{lb} * \mathrm{~s}} / \mathrm{in}\right)$

Natural frequency \&

$199 \mathrm{~Hz}$

Damping ratio
$\mathrm{C}_{\mathrm{d}}=0.86$

$2.642 \mathrm{~mm}$ (0.104 inch) from midplane

\section{Right Bearing}

$10.14 \mathrm{~N}$ (2.28 lb) (up)

$.99 \mu \mathrm{m}$ (0.039 mil) (up)

$$
\begin{gathered}
1.27 \times 10^{-4} \mathrm{~kg} / \mathrm{s} \\
\left(2.81 \times 10^{-4} \mathrm{lb} / \mathrm{s}\right) \\
0.50
\end{gathered}
$$

$196 \mathrm{~Hz}$

$12.7 \mu \mathrm{m}(0.5 \mathrm{mil})$

$15.875 \mathrm{~mm}(0.625 \mathrm{inch})$

$.254 \mathrm{~mm}$ (0.010 inch)

$351.99^{\mathrm{N} * \mathrm{~s}} / \mathrm{m}\left(2.01^{\mathrm{lb} / \mathrm{s}} /\right.$ in $)$

$3.1 \%$

$1,000 \mathrm{~Hz}$ $16 \%$ 


\section{APPENDIX B}

\section{UNCERTAINTY ANALYSIS OF EXPERIMENTAL MEASUREMENTS}

Forsberg [16] and Ramirez [17] previously conducted an uncertainty analysis using the following method to estimate errors in experimental measurements and the validity of the data. Their method was simply repeated for the additional data obtained for this research. Errors can come from two sources (bias and precision). In this analysis, bias error is considered negligible and precision error is assumed to be the major error source. The precision error can come from several sources and must be propagated appropriately. To combine these errors the following equation is used [19].

$$
E_{N}=\left[\Sigma\left(\frac{d F\left(X_{1}, X_{2}, \ldots, X_{N}\right)}{d X_{N}} * E_{X N}\right)^{2}\right]^{1 / 2}
$$

The overall error can be estimated with this equation as long as the function and individual variable errors are known. The measurement uncertainty $(\sigma)$ can also be included into Equation (B.1) as one half of a summed squared term. Most of these individual errors are known from the error of the instrumentation; however, to determine the error from the calibration of the instrumentation Equation (B.2) must be introduced, 


$$
S E E=\left[\frac{\Sigma\left[Y_{i}-\left(a X_{i}-b\right)\right]^{2}}{M-2}\right]^{1 / 2}
$$

to determine the standard error of estimation (SEE) [19]. The SEE can then be used similarly to determine standard deviation of the error associated with a given curve fit parameter. The error derived from the SEE that is associated with a given variable is $2 *$ SEE. This error band to either side of the calculated value will include approximately $95 \%$ of the possible points. The errors of the experimental measurements are defined with these two equations.

The flow rate is next found using the following equation.

$$
\text { FlowRate }=A_{\text {Flow Meter }} * V-B_{\text {FlowMeter }}
$$

Where

$$
\begin{aligned}
& A_{\text {FlowMeter }}=\text { Linear calibration constant of the flow meter } \\
& B_{\text {FlowMeter }}=\text { Flow meter calibration offset } \\
& V=\text { Flow meter output voltage }
\end{aligned}
$$

This equation can then be used with Equation (B.1) to find the expression for overall error. 


$$
E_{\text {Flowrate }}=\sqrt{\left(V^{*} E_{\text {AFlowMeter }}\right)^{2}+\left(A_{\text {FlowMeter }} * E_{V}\right)^{2}+\left(2 * \sigma_{\text {Flow }}\right)^{2}}
$$

Where

$E_{\text {FlowMeter }}=$ Flow meter error

$E_{\text {AFlowMeter }}=$ Error of $A_{\text {FlowMeter }}$ term

$E_{V}=$ Error of flow meter voltage measurment

$\sigma_{\text {Flow }}=$ Standard deviation of flow meter reading

This process can be repeated to find the error associated with the load measurement from

$$
\text { Load }=A_{\text {LoadCell }} * V-B_{\text {LoadCell }}
$$

Where

$A_{\text {LoadCell }}=$ Linear calibration constant of the load cell

$B_{\text {LoadCell }}=$ Load cell calibration offset

$V=$ Load cell output voltage

Applying Equation (B.1) to Equation (B.5) the error expression is

$$
E_{\text {Load }}=\sqrt{\left(A_{\text {Load }} * E_{V}\right)^{2}+\left(2 * \sigma_{\text {Load }}\right)^{2}}
$$

Where

$$
\begin{aligned}
& E_{\text {Load }}=\text { Load cell error } \\
& E_{V}=\text { Error of load cell voltage measurment } \\
& \sigma_{\text {Load }}=\text { Standard deviation of flow meter reading }
\end{aligned}
$$

Finally the error associated with the differentiation estimation of the stiffness can be determined using 


$$
E_{d F / d Z}=\sqrt{E_{A}^{2}+E_{B}^{2}+E_{C}^{2}+E_{D}^{2}}
$$

Where

$$
\begin{aligned}
& \text { Load }=A^{*} Z_{C}^{4}+B^{*} Z_{C}^{3}+C^{*} Z_{C}^{2}+D^{*} Z_{C}+E \\
& E_{N}=\text { Error associated with term } \mathrm{N} \\
& Z_{C}=\text { Thrust bearing clearance }
\end{aligned}
$$

This equation requires that the error from each term is known; hence, the TableCurve2D software was utilized. This software calculates the error from each of the terms in the polynomial curve fit load expression. These errors were then substituted into Equation (B.7). 


\section{APPENDIX C}

\section{LABVIEW FRONT PANEL AND INSTRUMENTATION DETAIL}

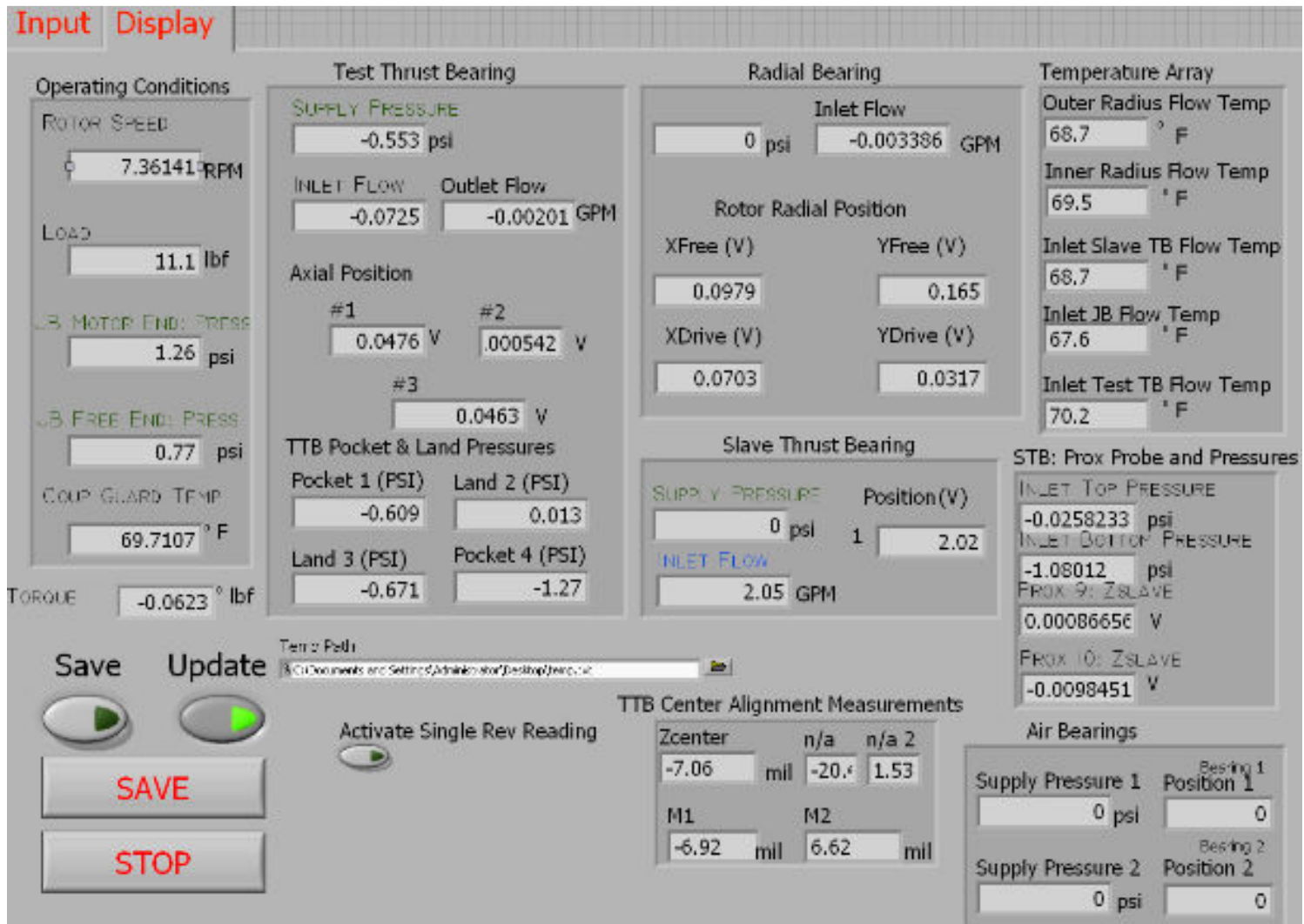

Figure C-1: LabVIEW VI front panel [17] 
Table C-1: Instrumentation specifications [16]

\begin{tabular}{|c|c|c|c|c|c|c|c|c|}
\hline \multicolumn{2}{|c|}{ Item description } & $\begin{array}{c}\text { Manufacturer's } \\
\text { part number }\end{array}$ & & $\begin{array}{l}\text { Desired } \\
\text { range }\end{array}$ & $\begin{array}{l}\text { Sensor } \\
\text { range }\end{array}$ & $\begin{array}{c}\text { Power } \\
\text { requirements }\end{array}$ & Output & Resolution \\
\hline \multicolumn{9}{|l|}{ Vendor - SKF } \\
\hline \multirow[t]{2}{*}{ Drivers } & $\begin{array}{l}\text { CMSS } 655 \mathrm{~mm} \\
\text { rrabe }\end{array}$ & r.MSS $35-002-00-12-10$ & $\begin{array}{l}\text { Tast thrust berring } \\
\text { pobe system } \\
\text { d've' }\end{array}$ & 1-2U nil & $10-90 \mathrm{mil}$ & $-24 \mathrm{~V}$ at $15 \mathrm{~mA}$ & U to $-15 \%$ & LuU $\mathrm{m} \backslash / \mathrm{ml}$ \\
\hline & $\begin{array}{l}\text { CMSS' b5 5mm } \\
\text { Prstee }\end{array}$ & CMSS j6-UUL-UU- $\angle 3-1 U$ & $\begin{array}{l}\text { Raslal prcbe } \\
\text { srsler'l divel }\end{array}$ & 6 rriil & $10-90 \mathrm{mil}$ & $-24 \mathrm{~V}$ 'al 15 rıA & $010 \cdot 13 \%$ & $2[1 \mathrm{ri} / / \mathrm{ril}$ \\
\hline Prusinrily Prubes & CMSS 65 sensor & CMSS 365 & $\begin{array}{l}\text { Se'Isur: Tur l'It } \\
\text { dive's }\end{array}$ & & & & & \\
\hline Exters on Cables & $\begin{array}{l}\text { ' meter } \\
\text { exten=iาn r:ah e }\end{array}$ & & $\begin{array}{l}\text { Ex:ensior cables } \\
\text { fcr proximity probe } \\
\text { system }\end{array}$ & & & & & \\
\hline \multicolumn{9}{|l|}{ Vendor.FTI } \\
\hline & FT 10 & FT 10VENW LE32 & \begin{tabular}{|l} 
Ra-jial bear ng \\
irlet flow mzter
\end{tabular} & 815 Эวำ & $0.315 \mathrm{GPM}$ & & & \\
\hline & $\begin{array}{l}\text { FT8-8 } \\
\text { FT-12 }\end{array}$ & 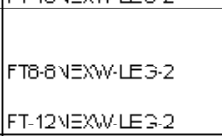 & $\begin{array}{l}\text { Tast bəaring inner } \\
\text { radius discharge } \\
\text { nuw rnete } \\
\text { Tast baring inlet } \\
\text { flow nete' }\end{array}$ & $\begin{array}{l}0-4.75 \mathrm{GPM} \\
0.27-13.4 \mathrm{E} \mathrm{GPM}\end{array}$ & $\begin{array}{l}0.16-7.5 \text { GPM } \\
0.25-20 \text { GPM }\end{array}$ & & & \\
\hline Dixital Inyizator & FTI Li'teatr_ìt. & $\mathrm{BR} 30 \mathrm{O} \cdot 2 \cdot \mathrm{C}-4$ & $\begin{array}{l}\text { L nearizes ard } \\
\text { ostputs flowmcter } \\
\text { reading } \\
\text { r.All Flowre:ers } \\
\text { requirt urie }\end{array}$ & & & $24 \vee \div=000 \mathrm{mi} / \mathrm{N}$ & 4-2丁 гाlA. & $\begin{array}{l}\text { 프: \% or } \\
\text { Itexdiny }\end{array}$ \\
\hline \multicolumn{9}{|l|}{ Vendor -0mega } \\
\hline \multirow[t]{4}{*}{$\begin{array}{l}\text { Tressu'e } \\
{ }_{\text {ransduce }} \\
\end{array}$} & $\begin{array}{l}\text { Omeça FX209 } \\
\text { Tressure } \\
\text { TransJucer }\end{array}$ & $P \times 209-30035 \mathrm{~V}$ & $\begin{array}{l}\text { I ast thrust bearing } \\
\text { lends/pocket } \\
\text { p'essure } \\
\text { trancuzers }\end{array}$ & $0-25[p s i$ & 0-300 psi & $21 \mathrm{~V}$ at $15 \mathrm{nh}$ & & $0.75 \mathrm{p} s i$ \\
\hline & $\begin{array}{l}\text { Omeça FX209 } \\
\text { Pressure } \\
\text { Tranoyucer }\end{array}$ & Py209 3C035V & $\begin{array}{l}\text { Tast thrust bezriาg } \\
\text { irlet pressure } \\
\text { traned Jcor }\end{array}$ & $025[\mathrm{psi}$ & 0300 poi & $24 v$ at $15 m$ & & $0.75 \mathrm{pci}$ \\
\hline & $\begin{array}{l}\text { Ompra FX7ng } \\
\text { Pressure } \\
\text { Trans Jucer } \\
\text { Sigral display } \\
\text { and output }\end{array}$ & 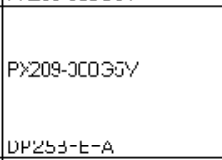 & $\begin{array}{l}\text { Inurnal } 1 \text { arinc: } \\
\text { irlet pressure } \\
\text { transducer } \\
\text { Dicp ayo for } \\
\text { p'esscre } \\
\text { transducers }\end{array}$ & $0-25 C \mathrm{psi}$ & 0-J00 psi & $\begin{array}{l}24 \mathrm{~V} \text { at } 15 \mathrm{~mA} \\
\text { I } 20 \mathrm{Vac}\end{array}$ & $\pm 5 \mathrm{~V}$ & $\begin{array}{l}0.75 \mathrm{psi} \\
0.02 \% \text { of } \\
\text { reading }\end{array}$ \\
\hline & $\begin{array}{l}\text { Sigr al displey } \\
\text { and output } \\
\text { (Thermocouples) }\end{array}$ & LP253-TC-A & $\begin{array}{l}\text { Dicp ays for } \\
\text { thermocouples }\end{array}$ & & & 120Vac & $\pm 5 \mathrm{~V}$ & $0.5^{c} \mathrm{r}$ \\
\hline he'mocsuple wire & 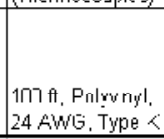 & $P 2-K-24-100$ & $\begin{array}{l}\text { Whi'e for } \\
\text { therrnocouples on } \\
\text { oster ond irner } \\
\text { test 'hri s- hFa'ing } \\
\text { radius }\end{array}$ & & & & & \\
\hline \multicolumn{9}{|c|}{ Vendol - ENCORE } \\
\hline Amplifier & $\begin{array}{l}\text { Trayimity sensor } \\
\text { amplifier }\end{array}$ & Ercore Model 619M-002 & & & & $-24 \vee t_{0} 2 N$ & & \\
\hline $\begin{array}{l}\text { Rack w/'P Jwt } \\
\text { Supply }\end{array}$ & $\begin{array}{l}\text { Rac< anc power } \\
\text { supply i. } \\
\text { amplificer }\end{array}$ & Ercore Model 4015-124 & & & & 120 vac & $24 V$ to $24 V$ & \\
\hline
\end{tabular}




\section{APPENDIX D}

MISALIGNMENT FIGURES

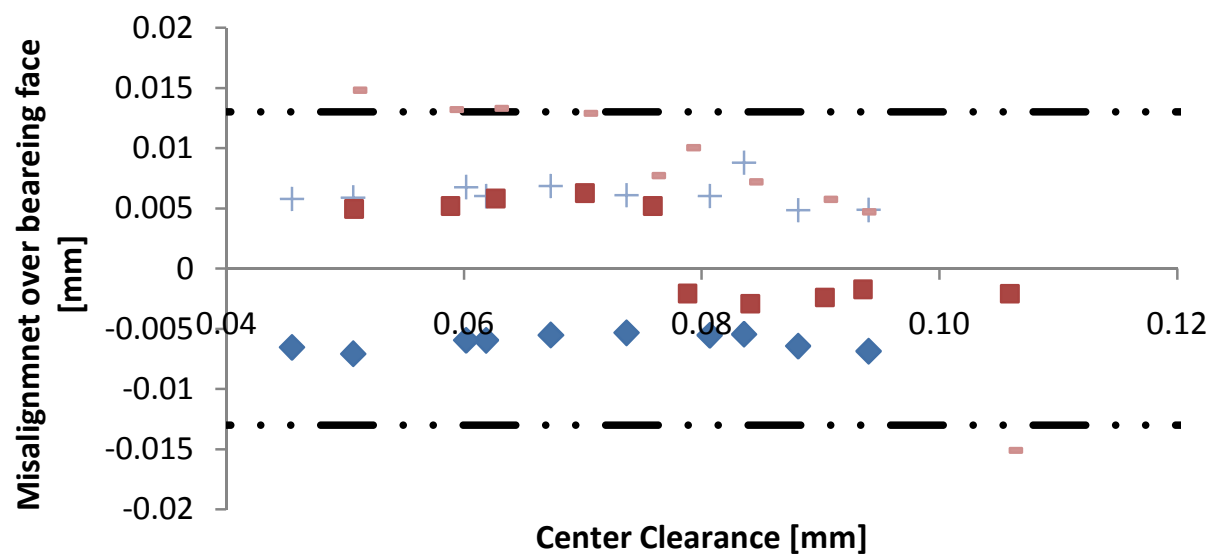

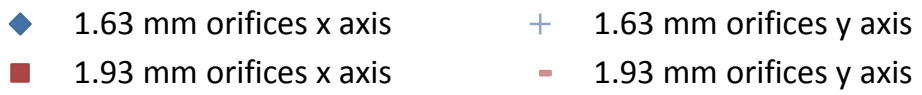

Figure D-1: Misalignment over the bearing face about the $x$ and $y$ axes versus center clearance at 5.17 bar supply and 0 rpm

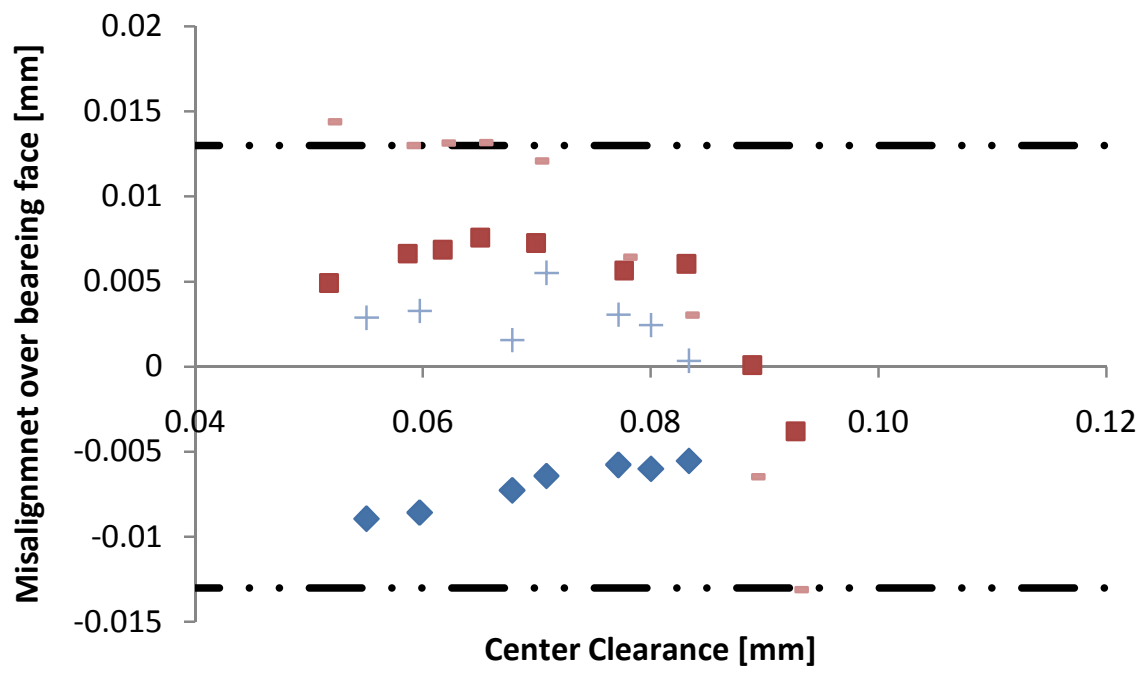

- $1.63 \mathrm{~mm}$ orifices $x$ axis

$+\quad 1.63 \mathrm{~mm}$ orifices y axis

- $1.93 \mathrm{~mm}$ orifices $x$ axis

- $1.93 \mathrm{~mm}$ orifices y axis

Figure D-2: Misalignment over the bearing face about the $x$ and $y$ axes versus center clearance at 5.17 bar supply and $7.5 \mathrm{krpm}$ 


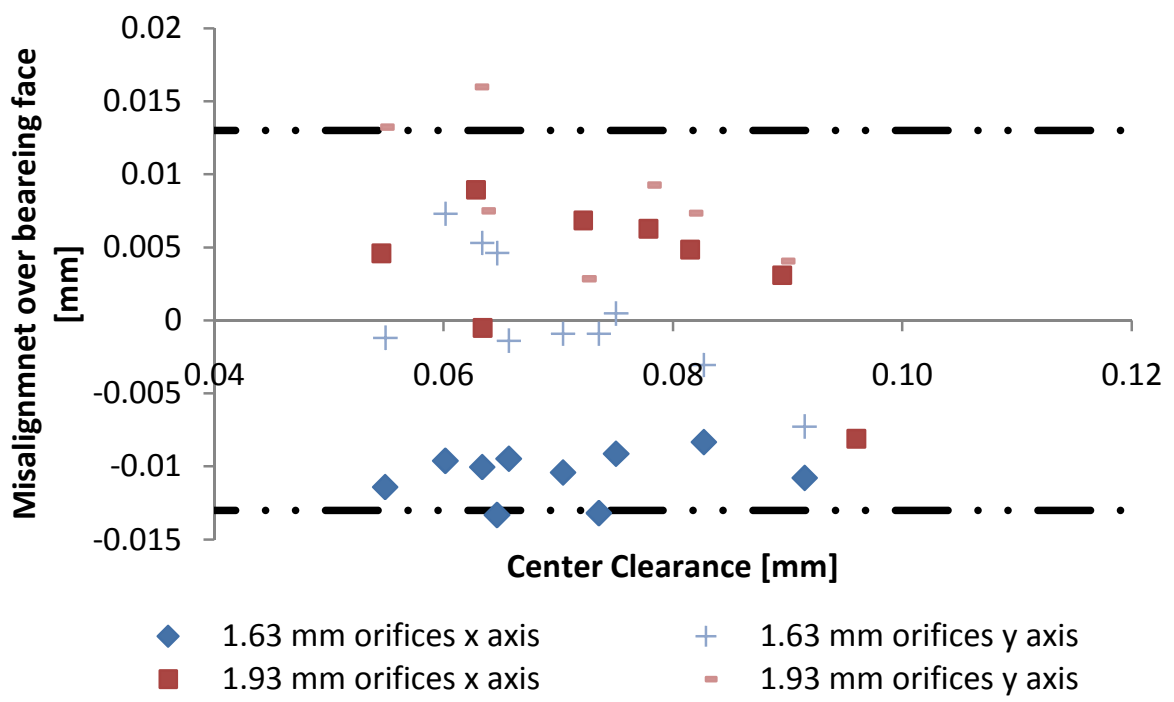

Figure D-3: Misalignment over the bearing face about the $x$ and $y$ axes versus center clearance at 5.17 bar supply and $12.5 \mathrm{krpm}$

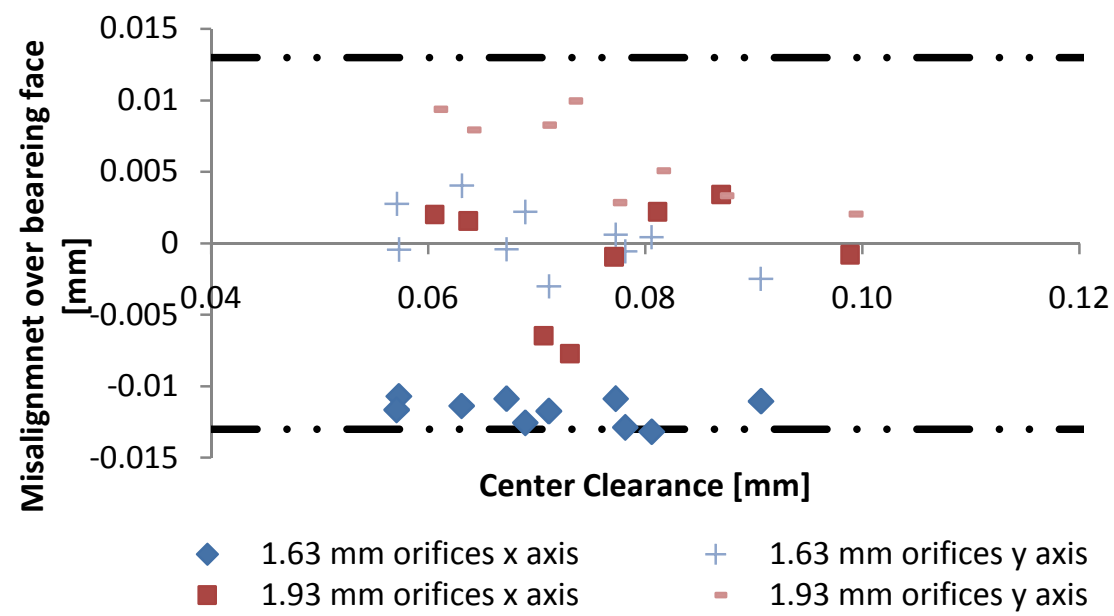

Figure D-4: Misalignment over the bearing face about the $x$ and $y$ axes versus center clearance at 5.17 bar supply and $17.5 \mathrm{krpm}$ 


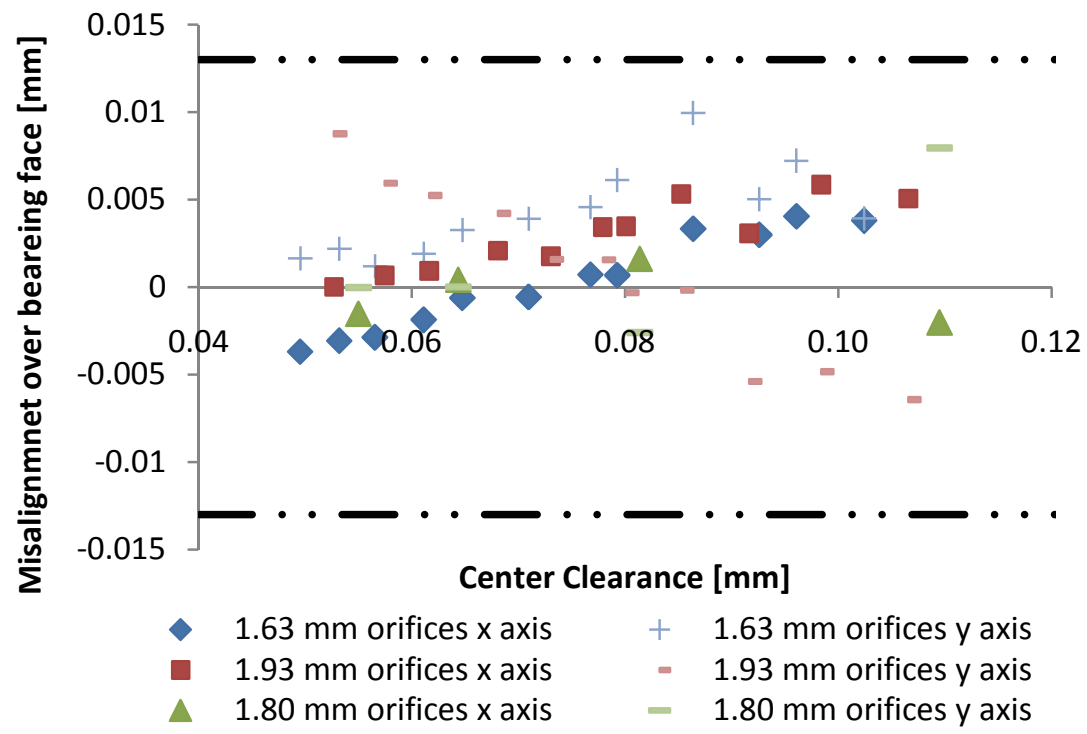

Figure D-5: Misalignment over the bearing face about the $x$ and $y$ axes versus center clearance at $\mathbf{1 0 . 3 4}$ bar supply and $0 \mathrm{rpm}$

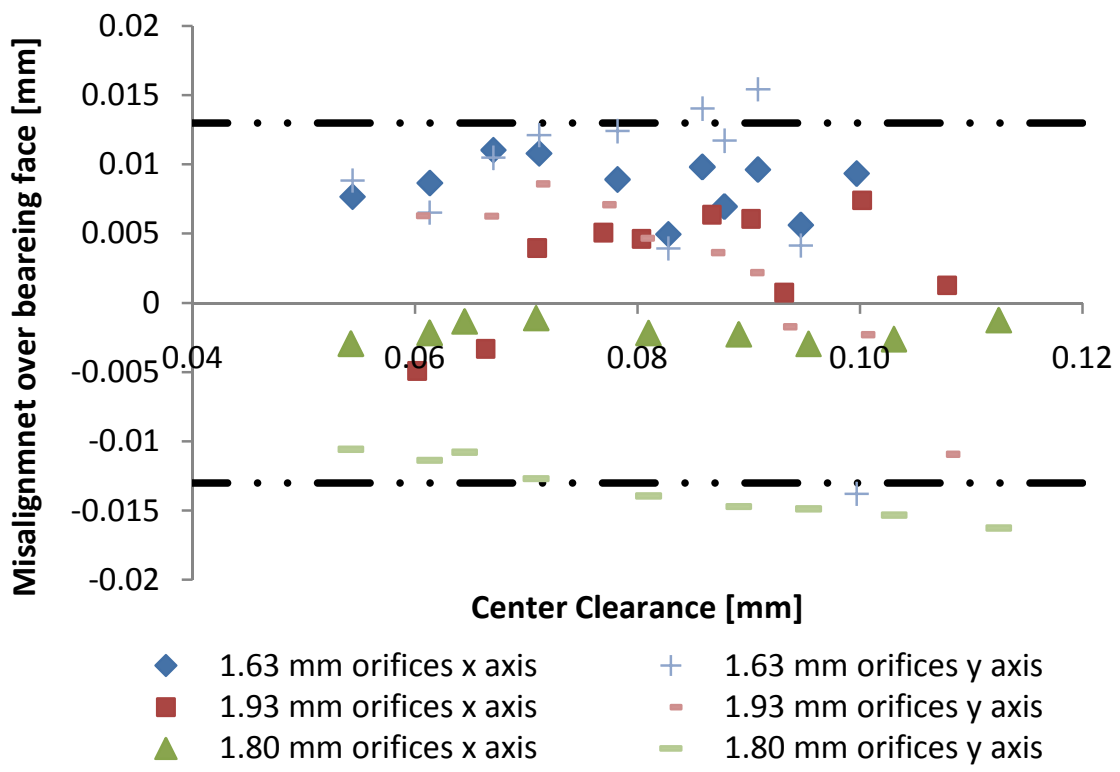

Figure D-6: Misalignment over the bearing face about the $x$ and $y$ axes versus center clearance at 10.34 bar supply and $7.5 \mathrm{krpm}$ 


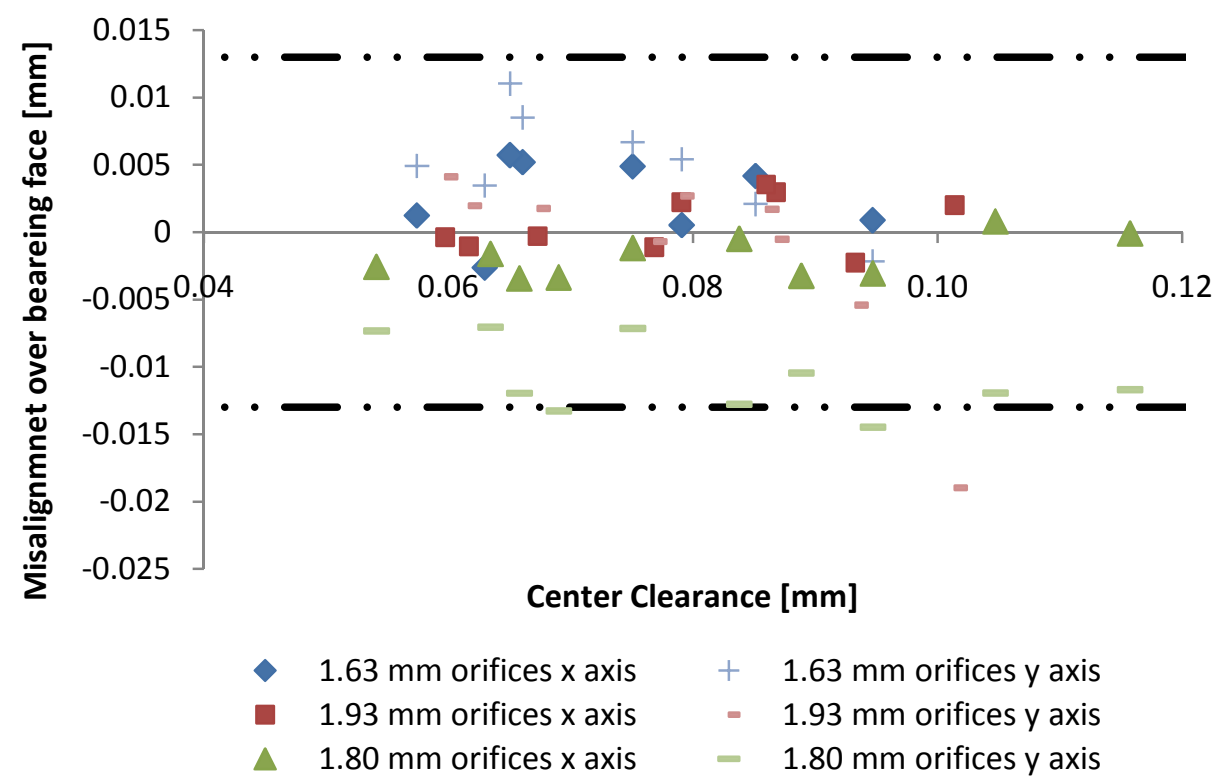

Figure D-7: Misalignment over the bearing face about the $x$ and $y$ axes versus center clearance at 10.34 bar supply and $12.5 \mathrm{krpm}$

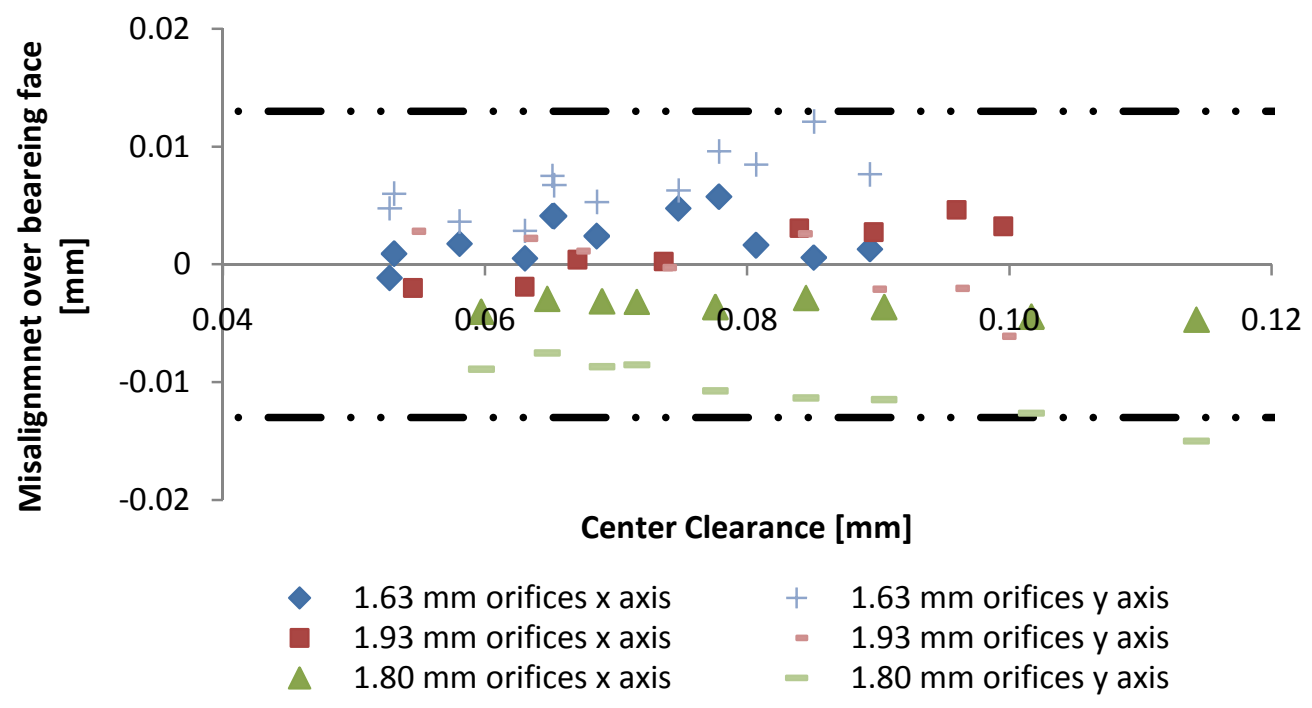

Figure D-8: Misalignment over the bearing face about the $x$ and $y$ axes versus center clearance at 10.34 bar supply and $17.5 \mathrm{krpm}$ 


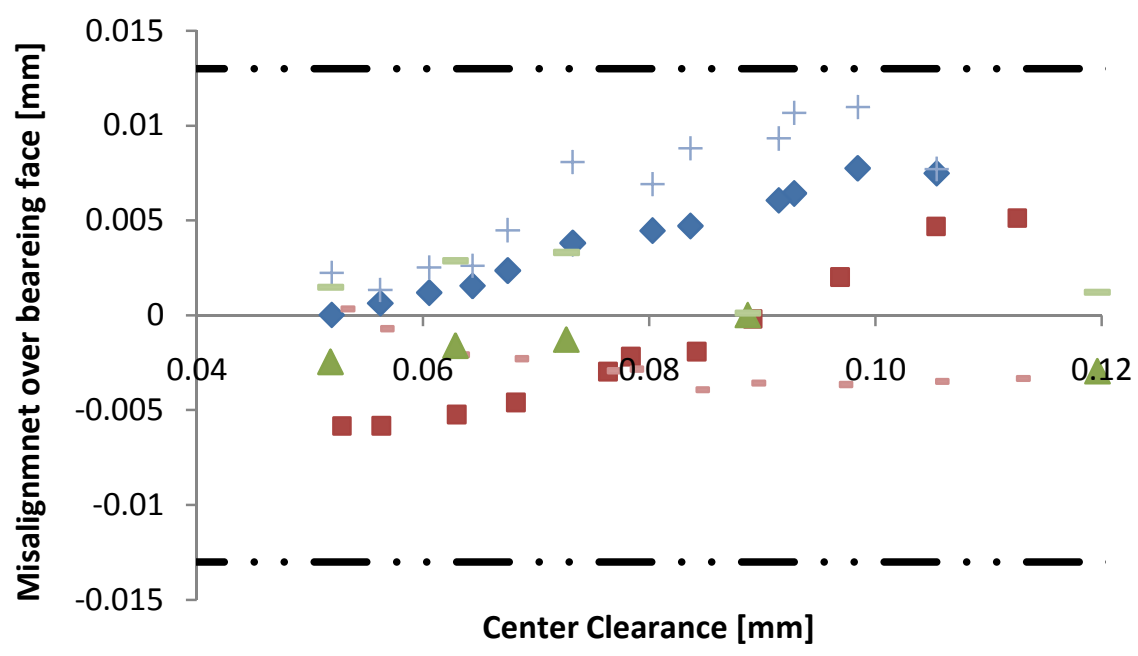

$\checkmark 1.63 \mathrm{~mm}$ orifices $x$ axis $\quad+1.63 \mathrm{~mm}$ orifices $y$ axis

- $1.93 \mathrm{~mm}$ orifices $x$ axis $\quad=1.93 \mathrm{~mm}$ orifices $y$ axis

$\Delta \quad 1.80 \mathrm{~mm}$ orifices $x$ axis $\quad-1.80 \mathrm{~mm}$ orifices $y$ axis

Figure D-9: Misalignment over the bearing face about the $x$ and $y$ axes versus center clearance at $\mathbf{1 7 . 2 4}$ bar supply and $0 \mathrm{rpm}$

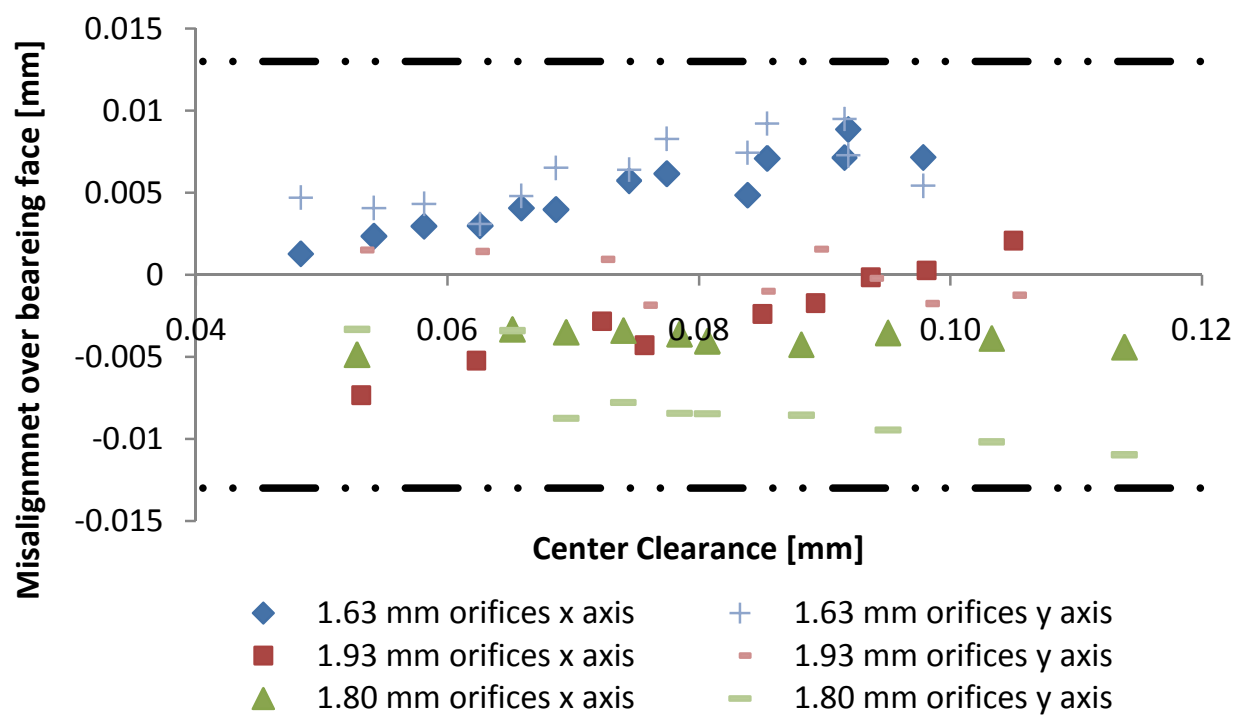

Figure D-10: Misalignment over the bearing face about the $x$ and $y$ axes versus center clearance at 17.24 bar supply and $7.5 \mathrm{krpm}$ 


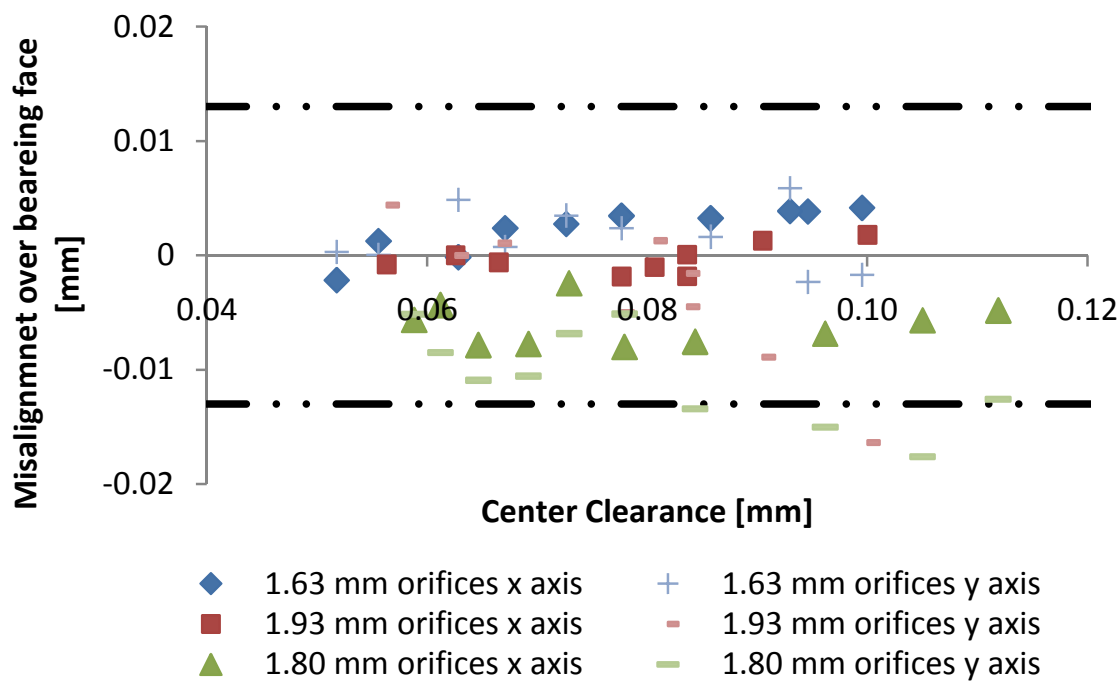

Figure D-11: Misalignment over the bearing face about the $x$ and $y$ axes versus center clearance at 17.24 bar supply and $12.5 \mathrm{krpm}$

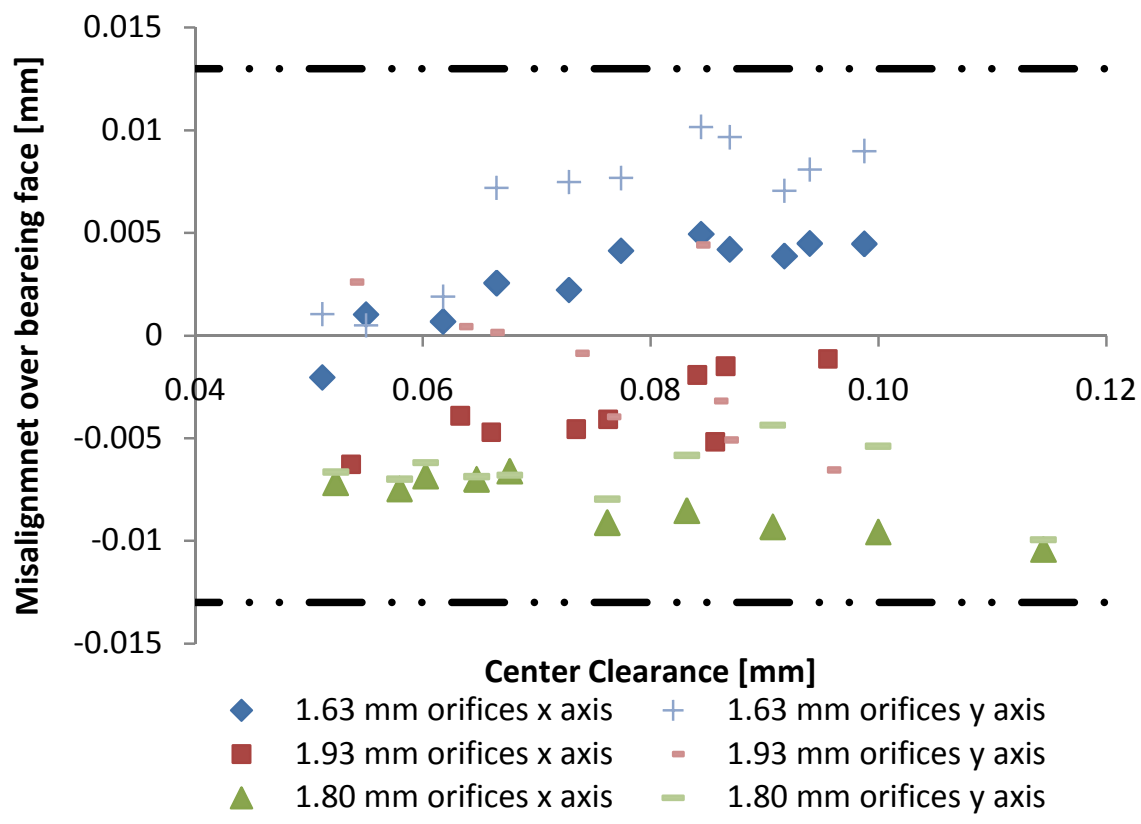

Figure D-12: Misalignment over the bearing face about the $x$ and $y$ axes versus center clearance at 17.24 bar supply and $17.5 \mathrm{krpm}$ - repeated for reference 


\section{APPENDIX E}

\section{INLET FLOW RATE FIGURES}

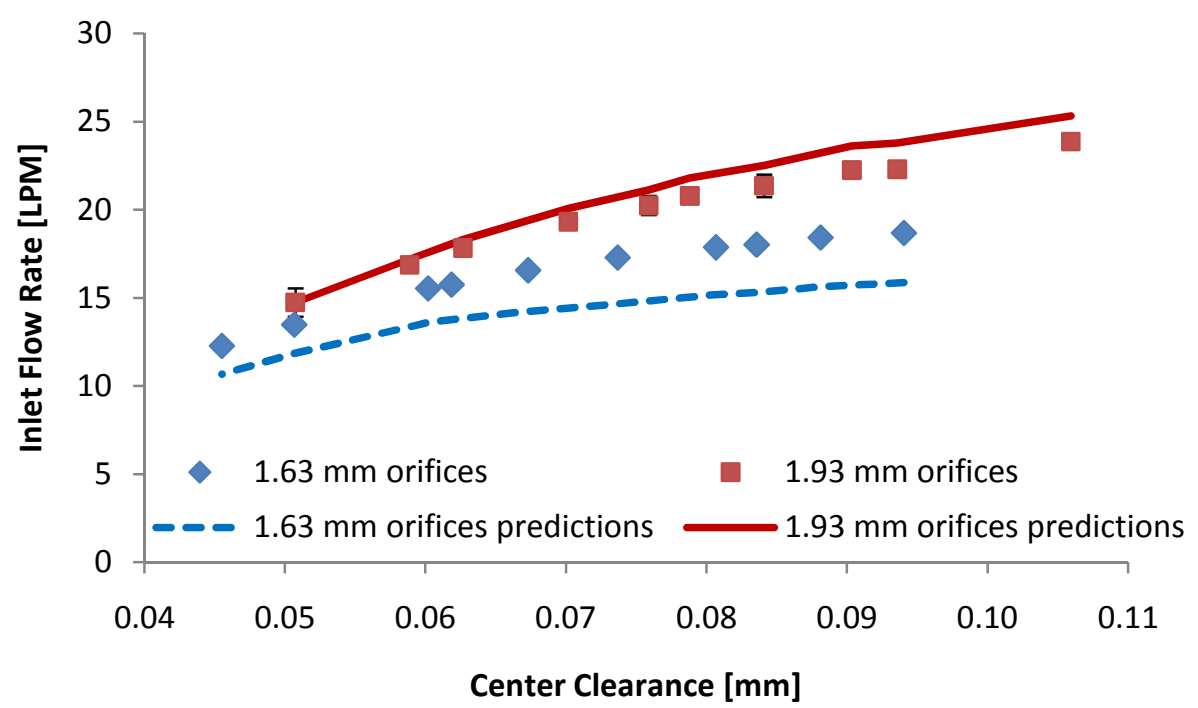

Figure E-1: Measured and predicted [3] inlet flow rate versus clearance at 5.17 bar supply and $0 \mathrm{rpm}$ - repeated for reference

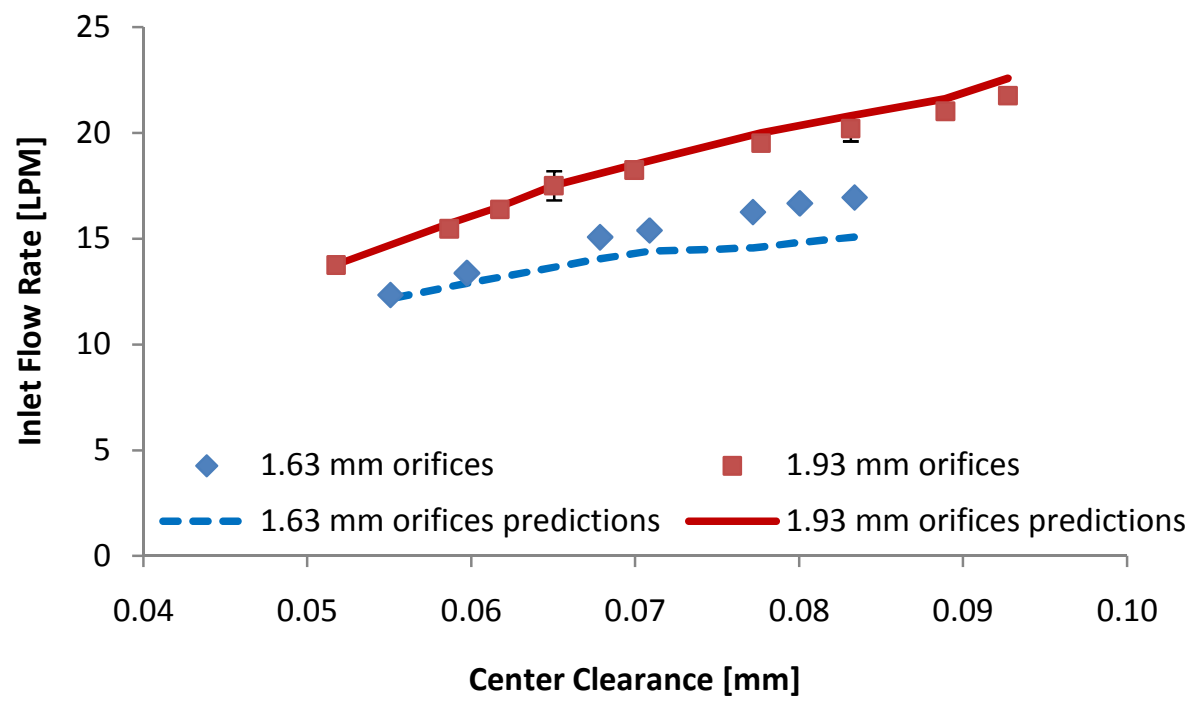

Figure E-2: Measured and predicted [3] inlet flow rate versus clearance at 5.17 bar supply and $7.5 \mathrm{rpm}$ 


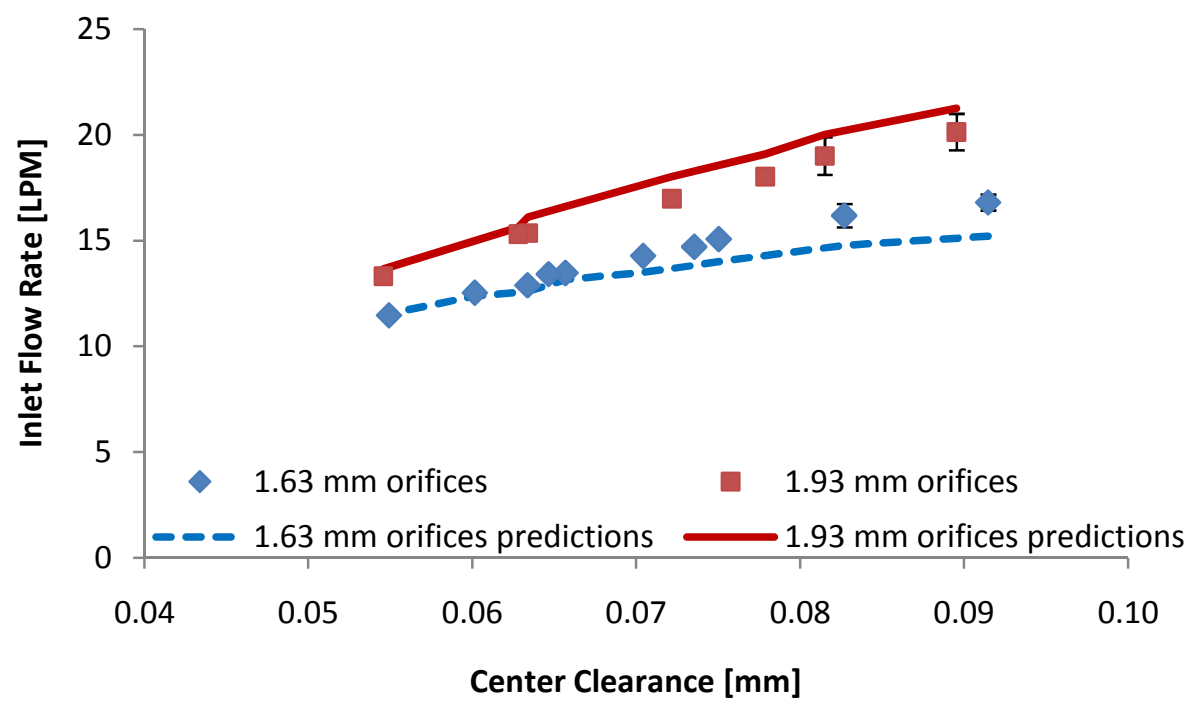

Figure E-3: Measured and predicted [3] inlet flow rate versus clearance at 5.17 bar supply and $12.5 \mathrm{rpm}$

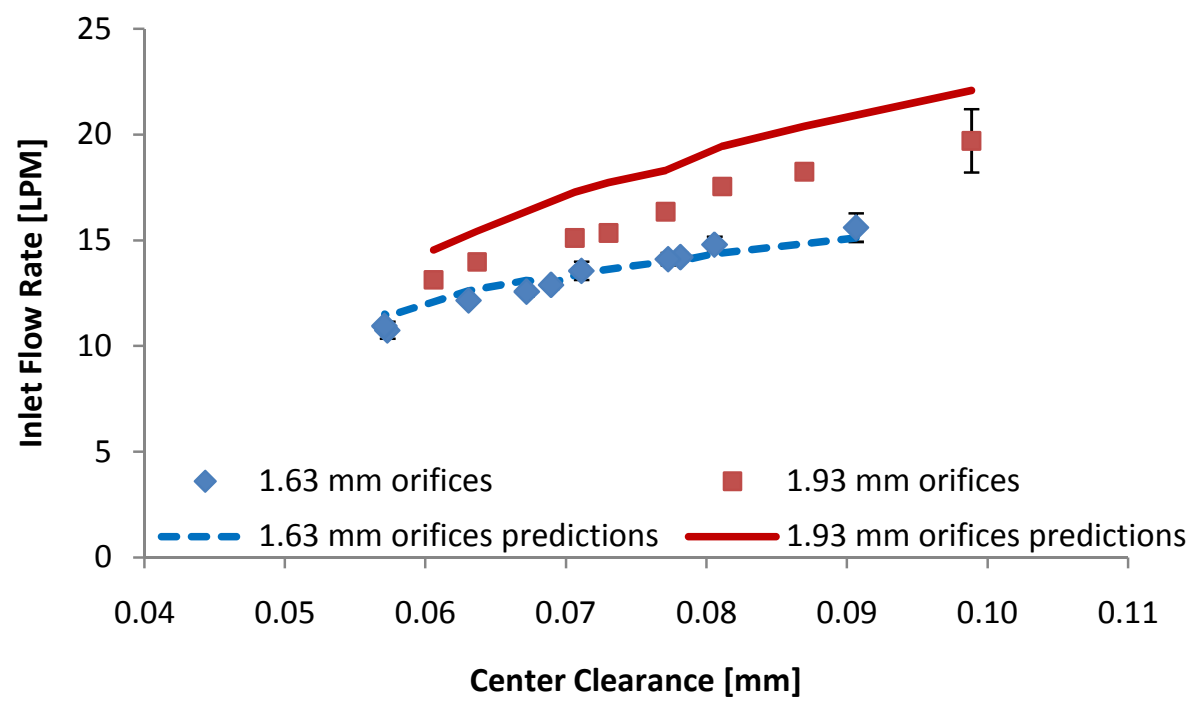

Figure E-4: Measured and predicted [3] inlet flow rate versus clearance at 5.17 bar supply and $17.5 \mathrm{rpm}$ 


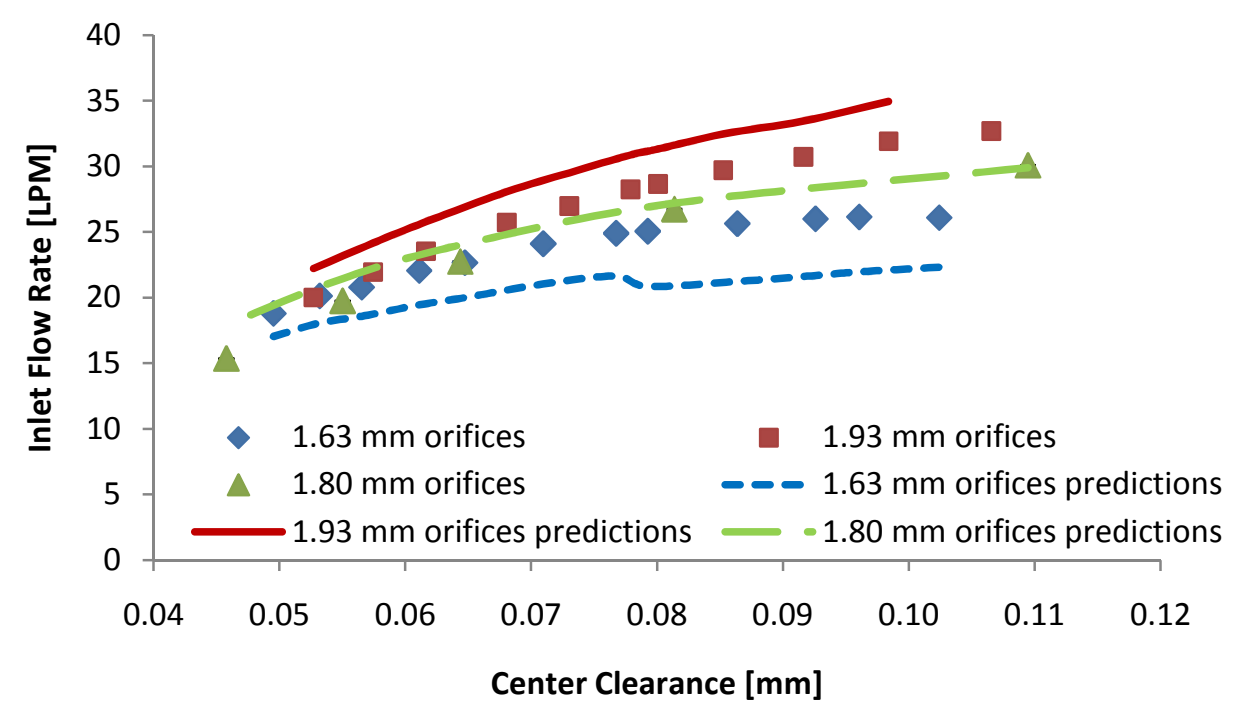

Figure E-5: Measured and predicted [3] inlet flow rate versus clearance at $\mathbf{1 0 . 3 4}$ bar supply and 0 rpm

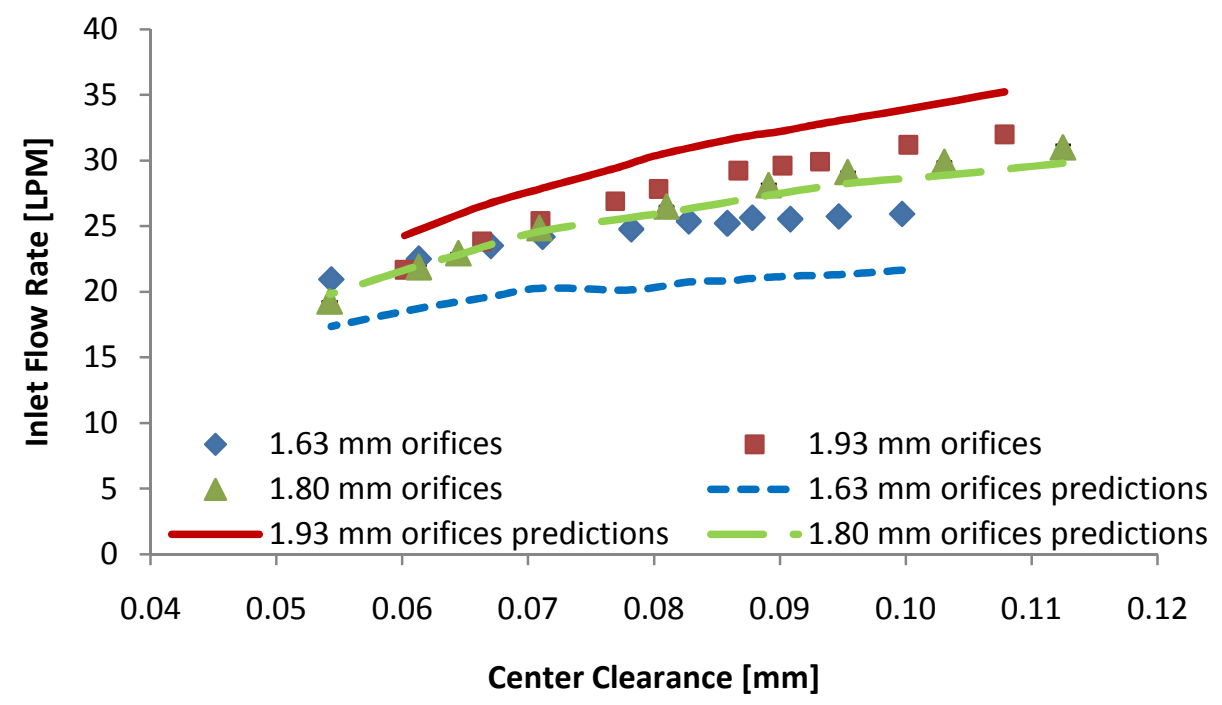

Figure E-6: Measured and predicted [3] inlet flow rate versus clearance at 10.34 bar supply and $7.5 \mathrm{krpm}$ 


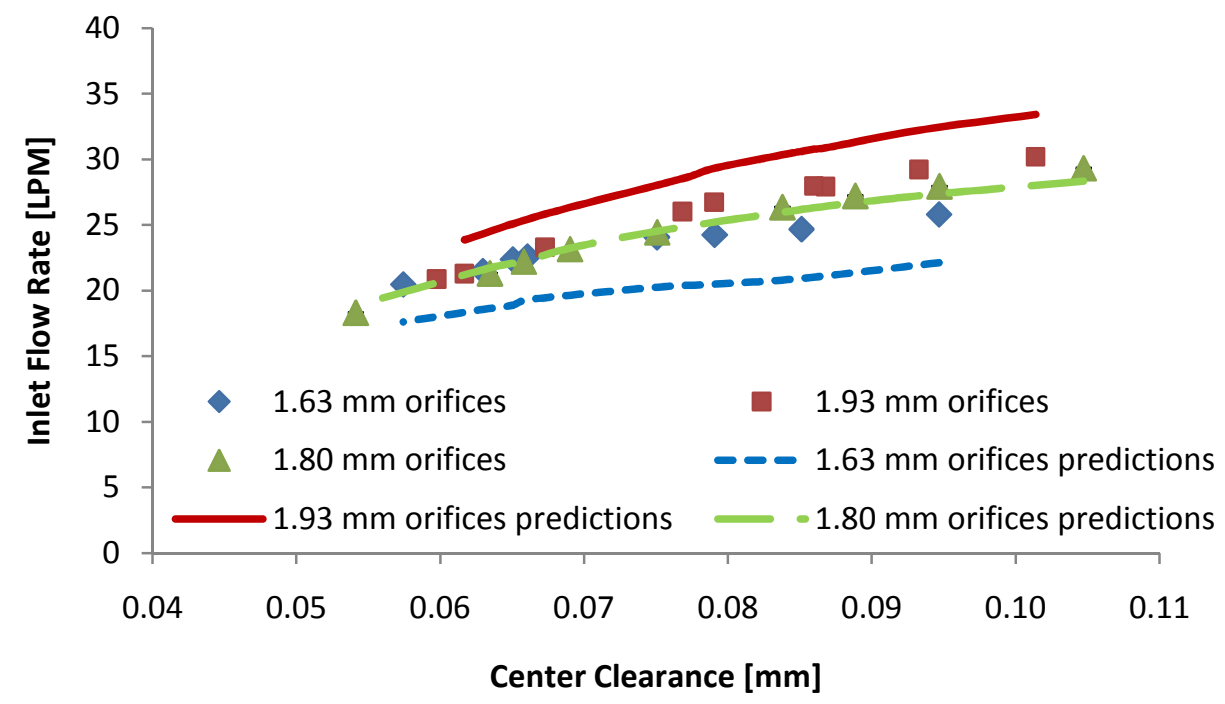

Figure E-7: Measured and predicted [3] inlet flow rate versus clearance at 10.34 bar supply and $12.5 \mathrm{krpm}$ - repeated for reference

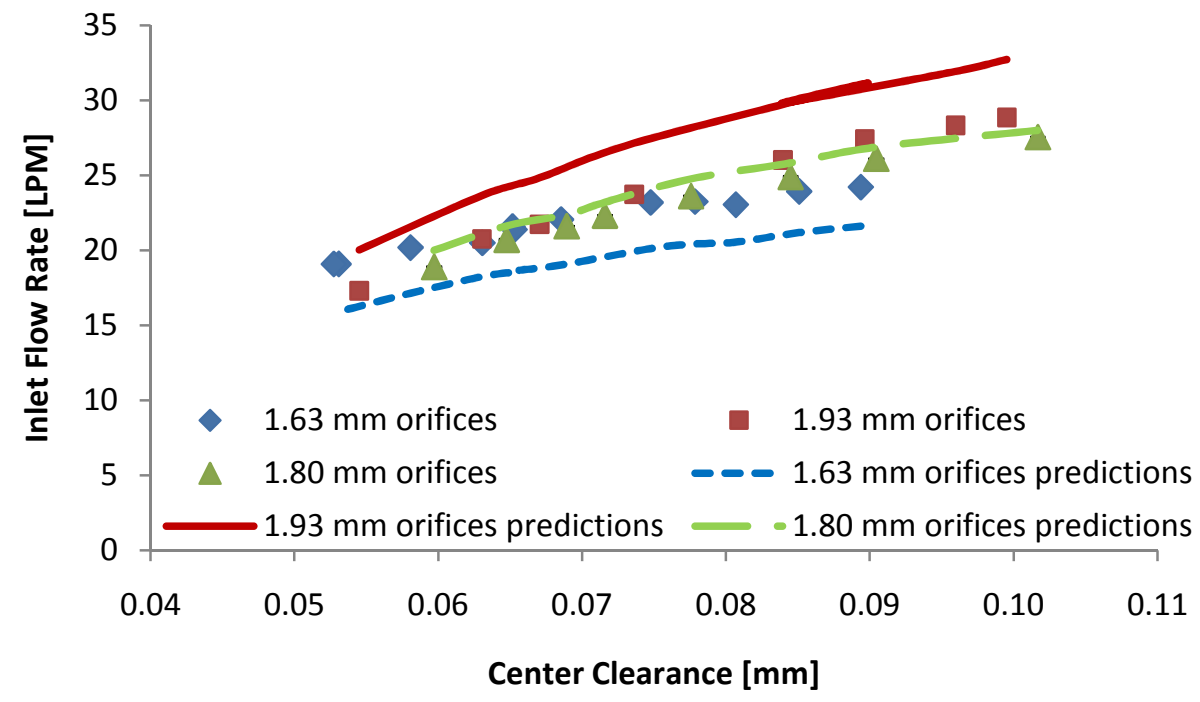

Figure E-8: Measured and predicted [3] inlet flow rate versus clearance at 10.34 bar supply and $17.5 \mathrm{krpm}$ 


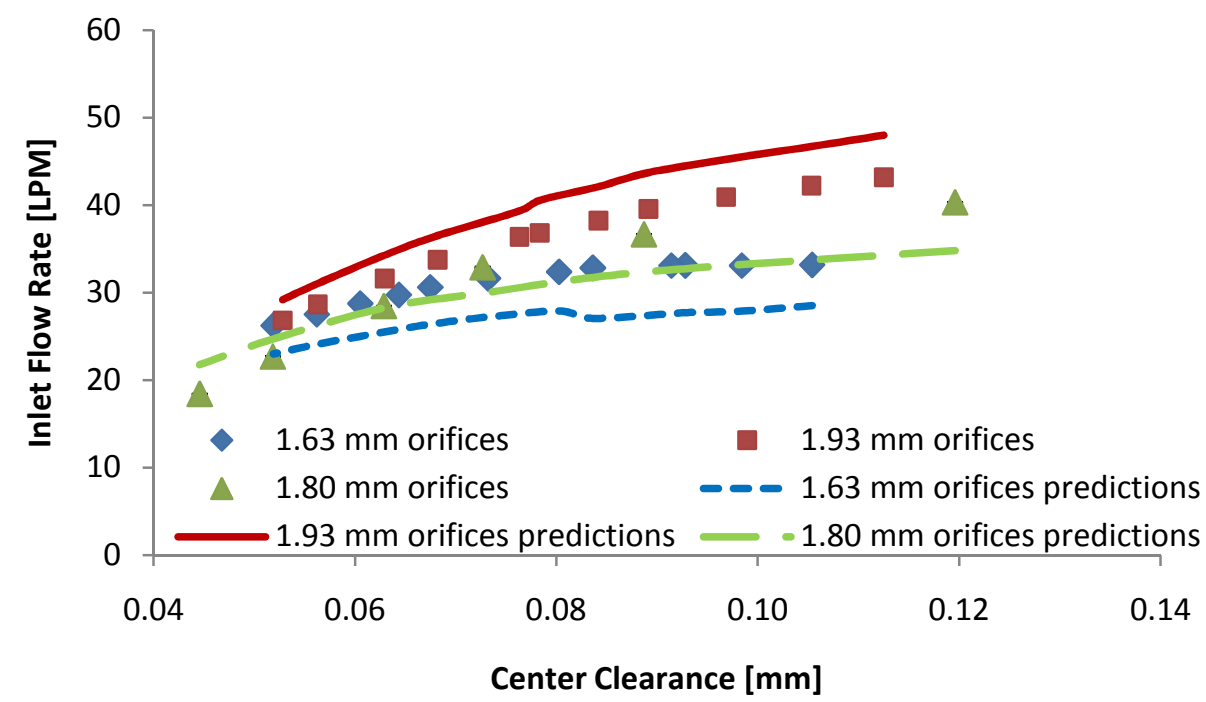

Figure E-9: Measured and predicted [3] inlet flow rate versus clearance at $\mathbf{1 7 . 2 4}$ bar supply and 0 rpm

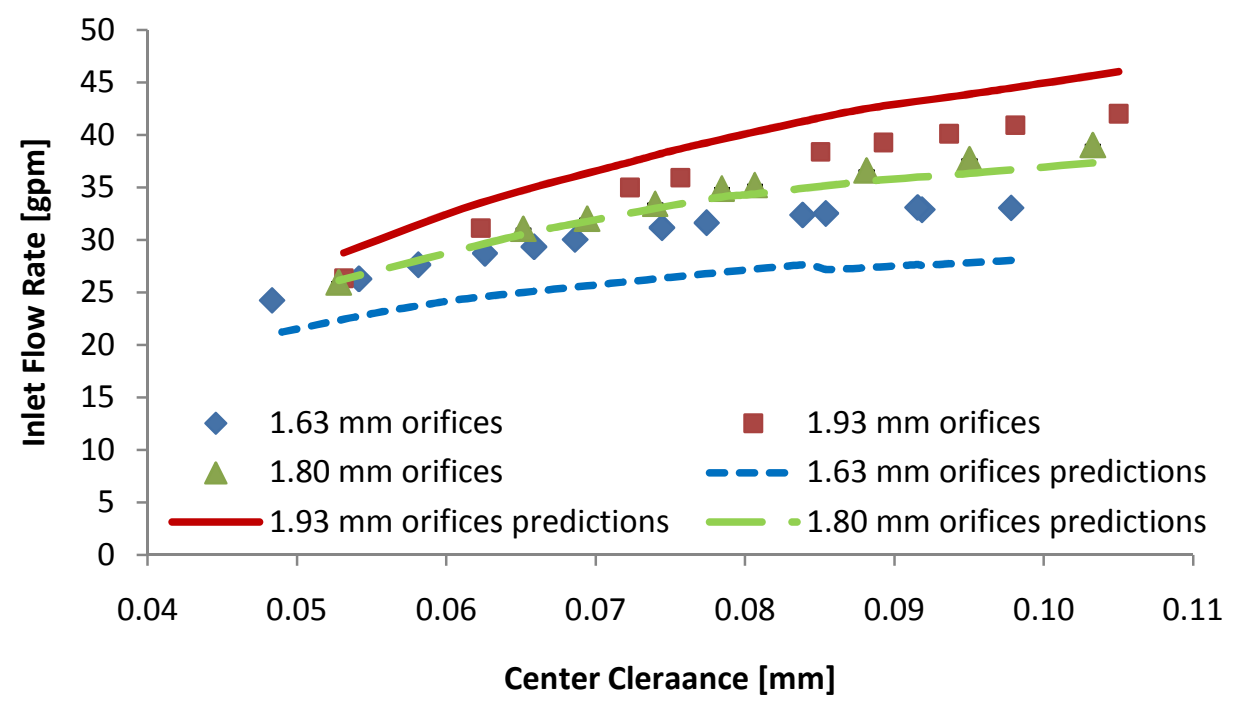

Figure E-10: Measured and predicted [3] inlet flow rate versus clearance at $\mathbf{1 7 . 2 4}$ bar supply and $7.5 \mathrm{krpm}$ - repeated for reference 


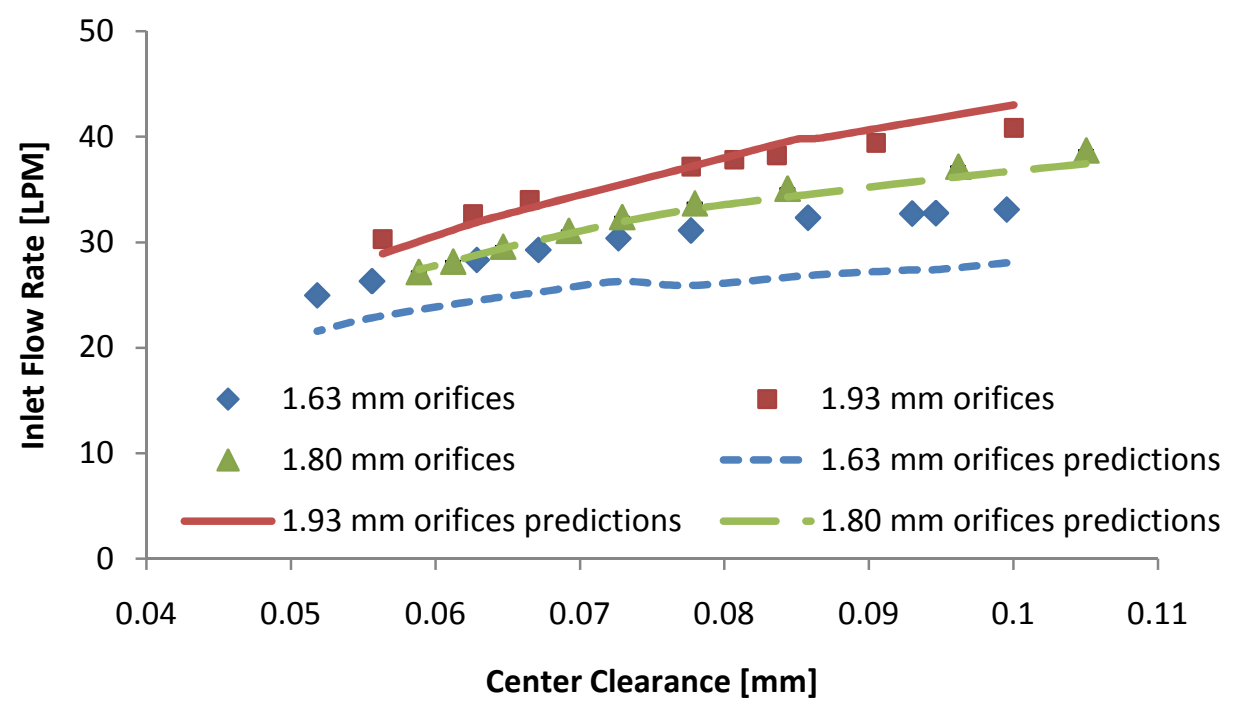

Figure E-11: Measured and predicted [3] inlet flow rate versus clearance at $\mathbf{1 7 . 2 4}$ bar supply and $12.5 \mathrm{krpm}$

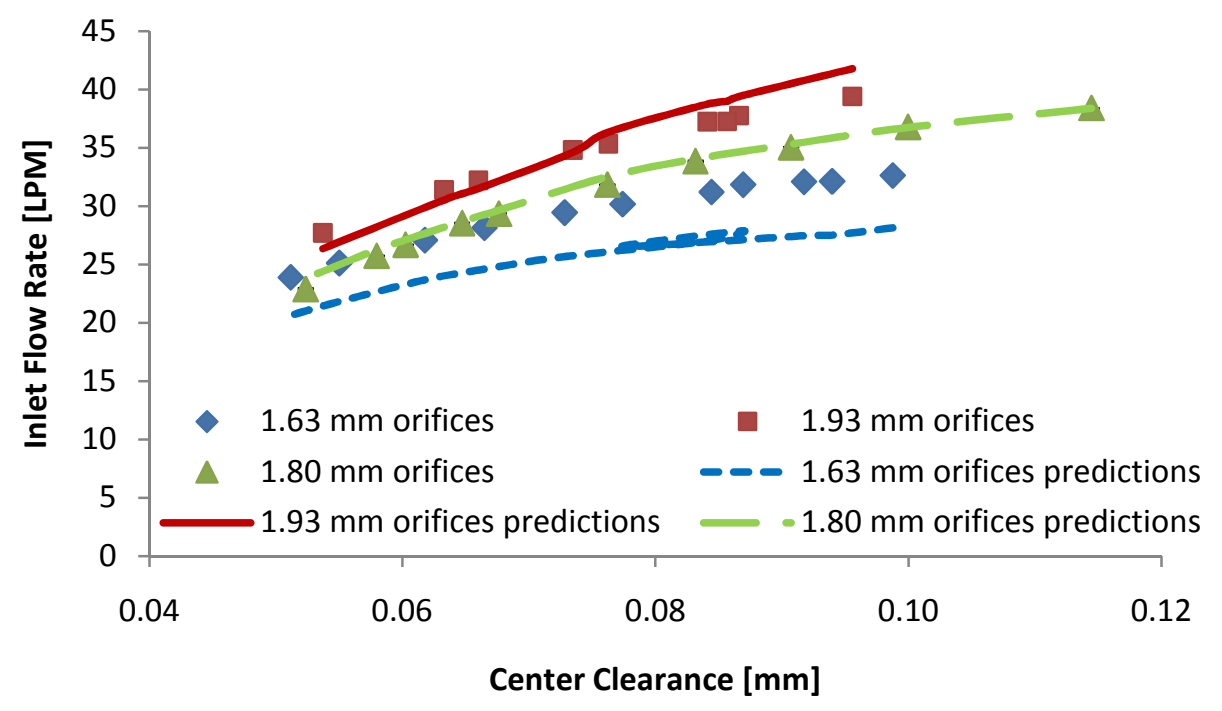

Figure E-12: Measured and predicted [3] inlet flow rate versus clearance at 17.24 bar supply and $17.5 \mathrm{krpm}$ 


\section{APPENDIX F}

\section{RECESS PRESSURE RATIO FIGURES}

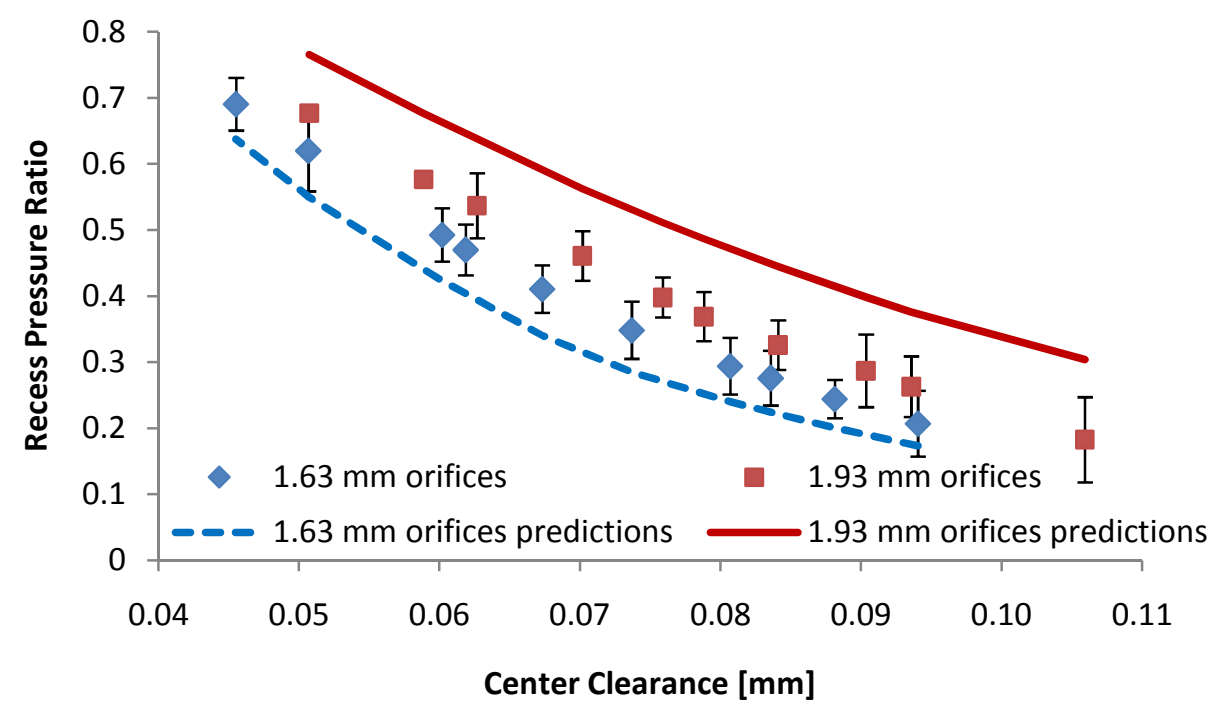

Figure F-1: Measured and predicted [3] recess pressure ratio versus clearance at 5.17 bar supply and $0 \mathrm{rpm}$ - repeated for reference

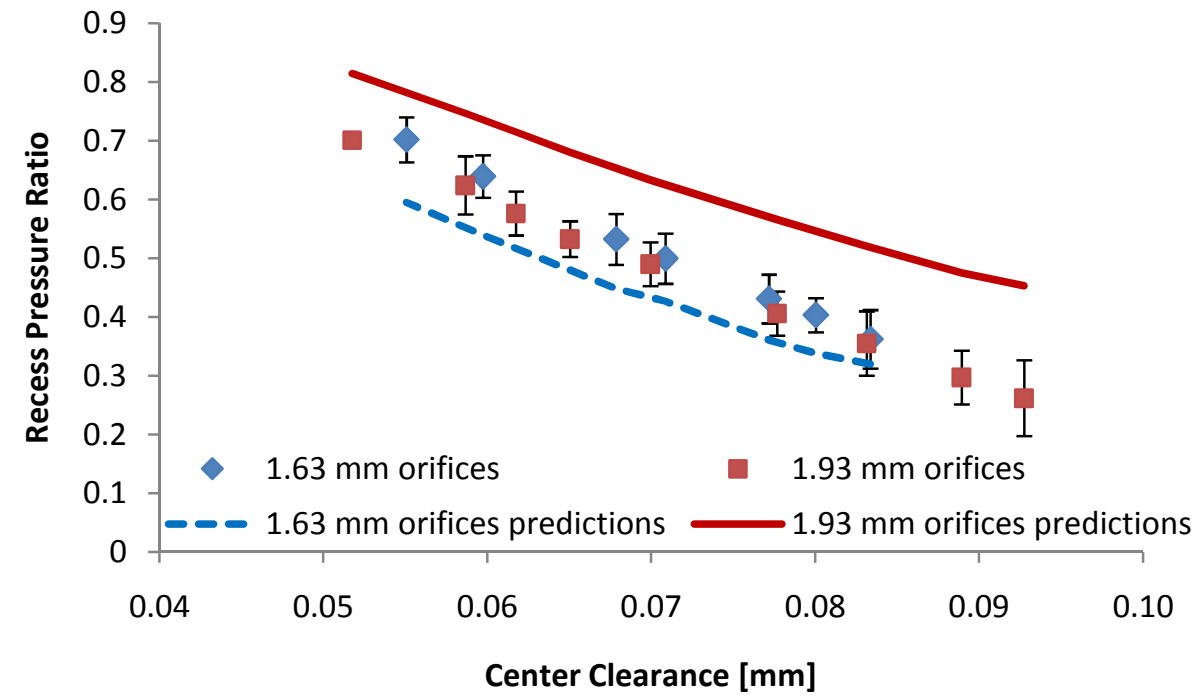

Figure F-2: Measured and predicted [3] recess pressure ratio versus clearance at 5.17 bar supply and $7.5 \mathrm{krpm}$ 


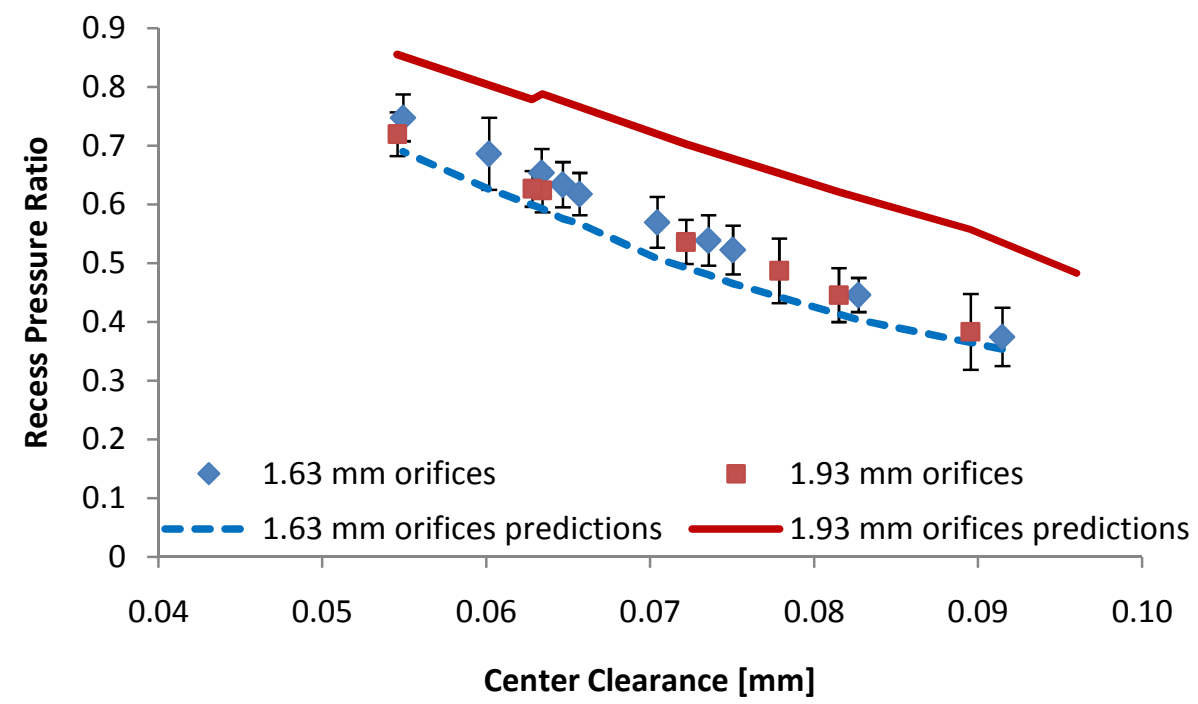

Figure F-3: Measured and predicted [3] recess pressure ratio versus clearance at 5.17 bar supply and $12.5 \mathrm{krpm}$

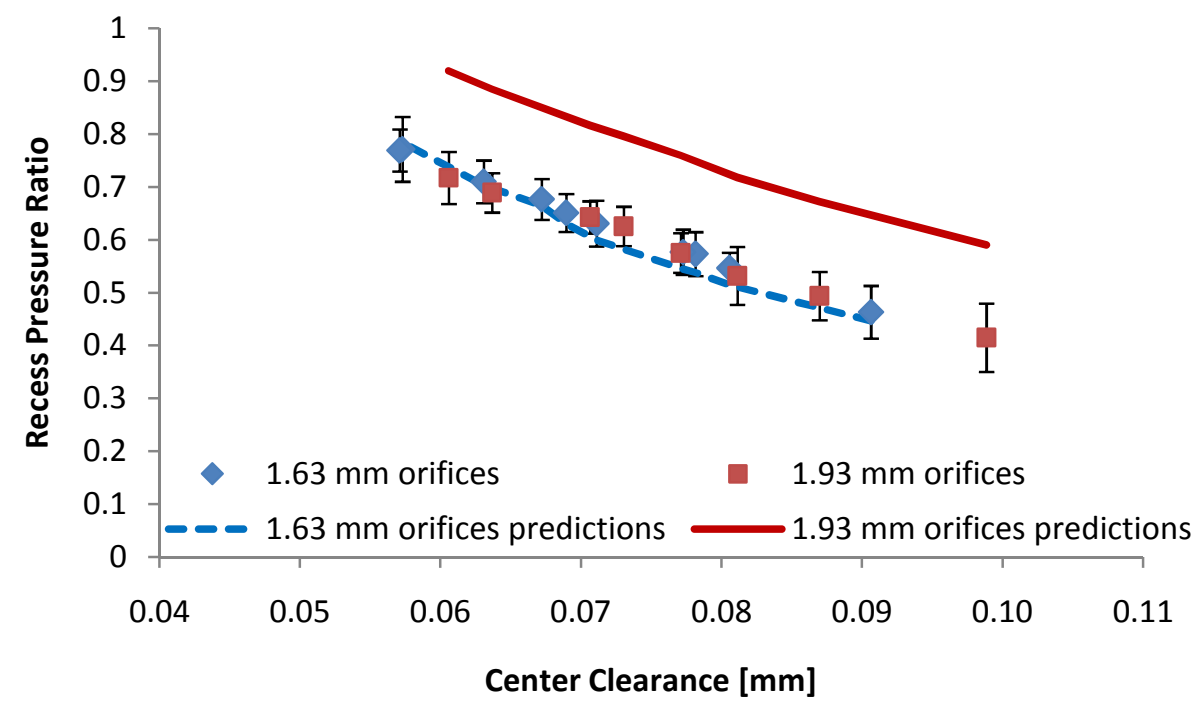

Figure F-4: Measured and predicted [3] recess pressure ratio versus clearance at 5.17 bar supply and $17.5 \mathrm{krpm}$-repeated for reference 


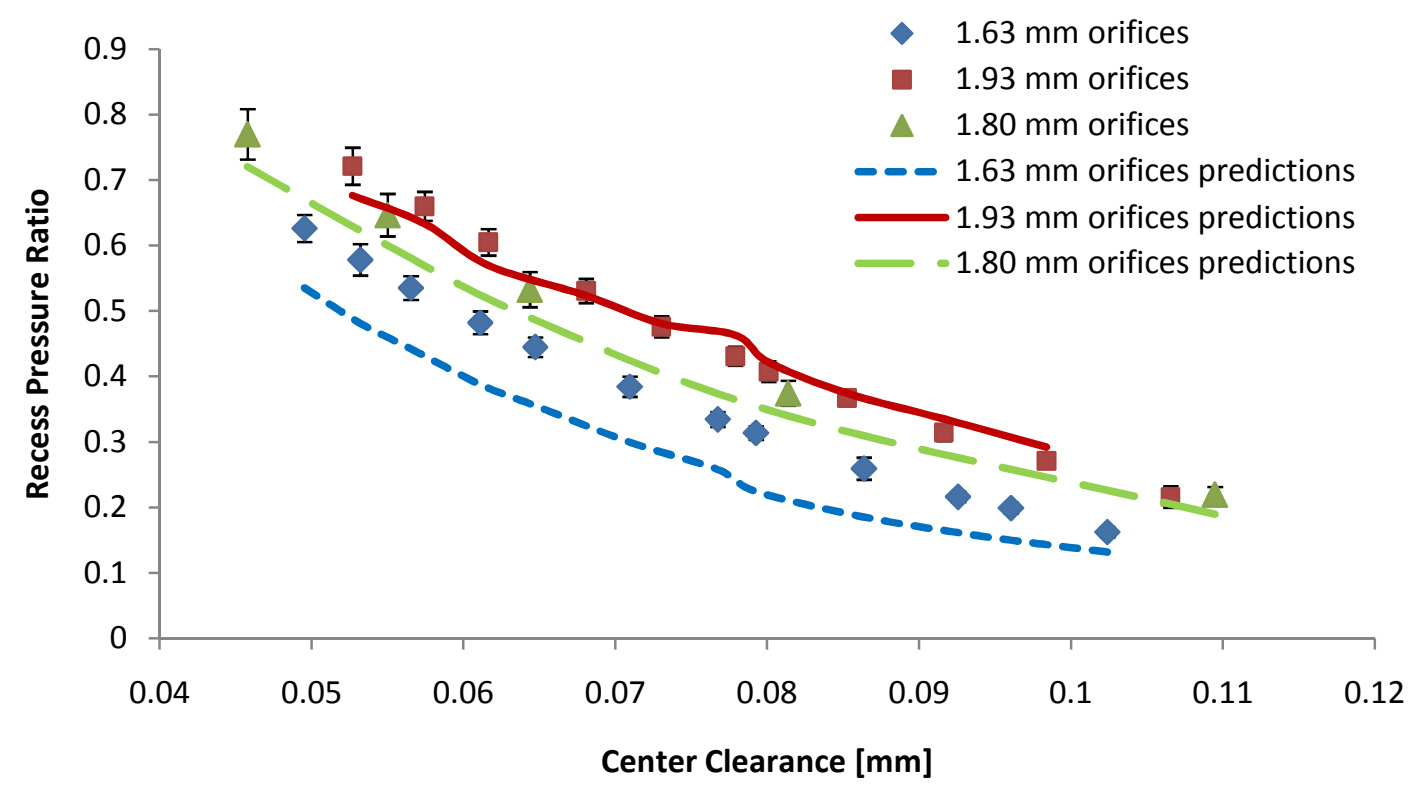

Figure F-5: Measured and predicted [3] recess pressure ratio versus clearance at 10.34 bar supply and 0 rpm

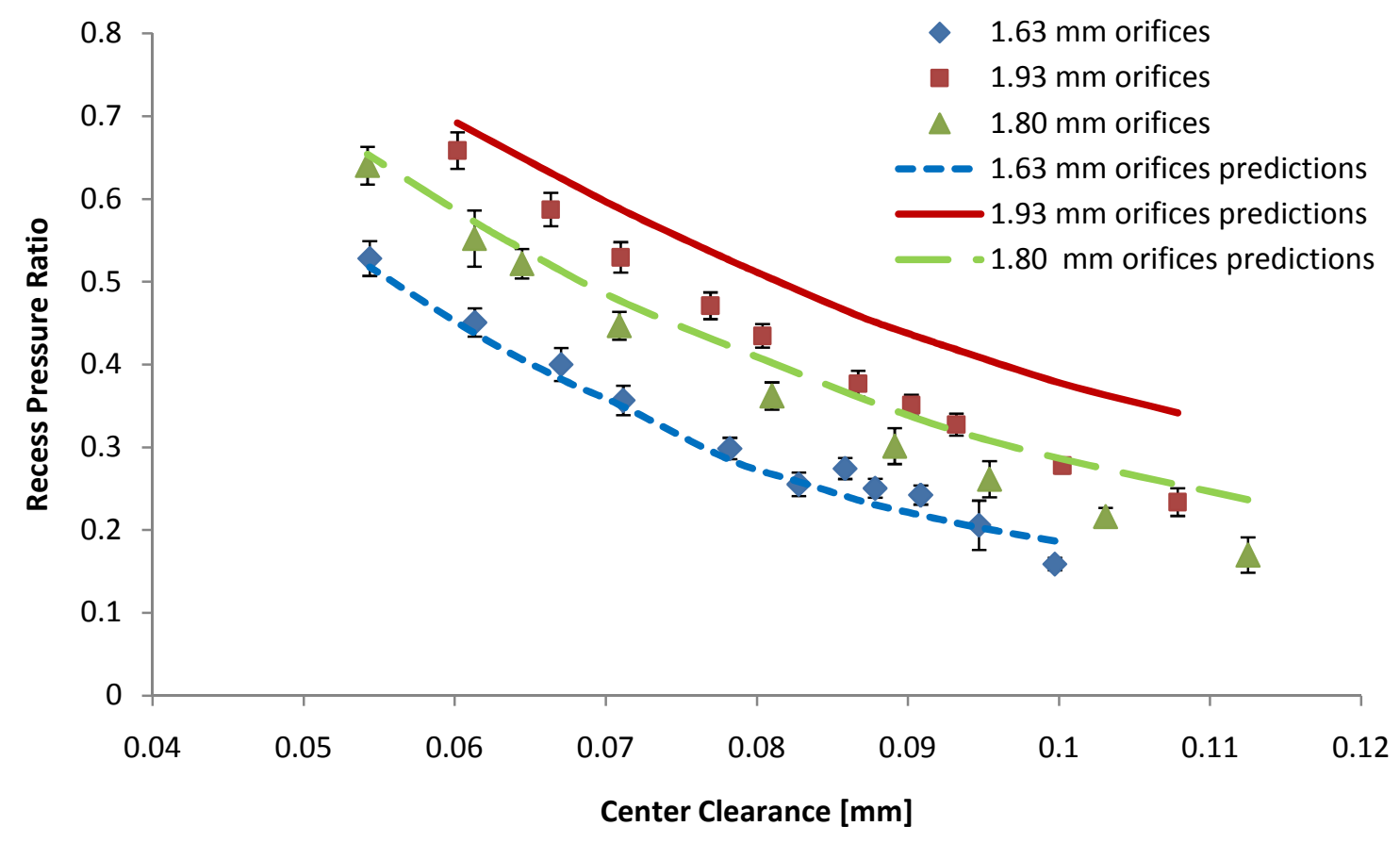

Figure F-6: Measured and predicted [3] recess pressure ratio versus clearance at 10.34 bar supply and $7.5 \mathrm{krpm}$ 


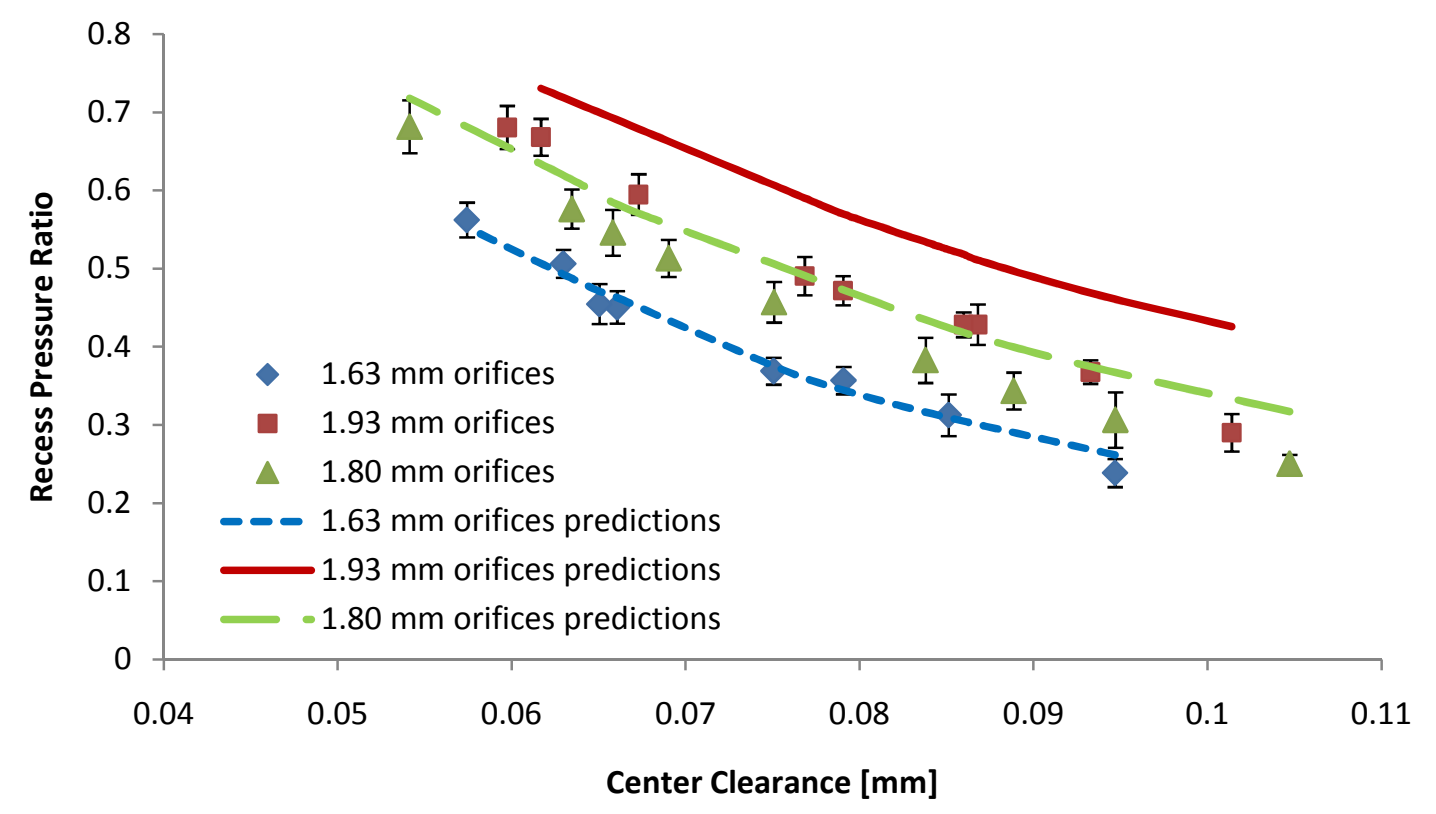

Figure F-7: Measured and predicted [3] recess pressure ratio versus clearance at 10.34 bar supply and $12.5 \mathrm{krpm}$ - repeated for reference

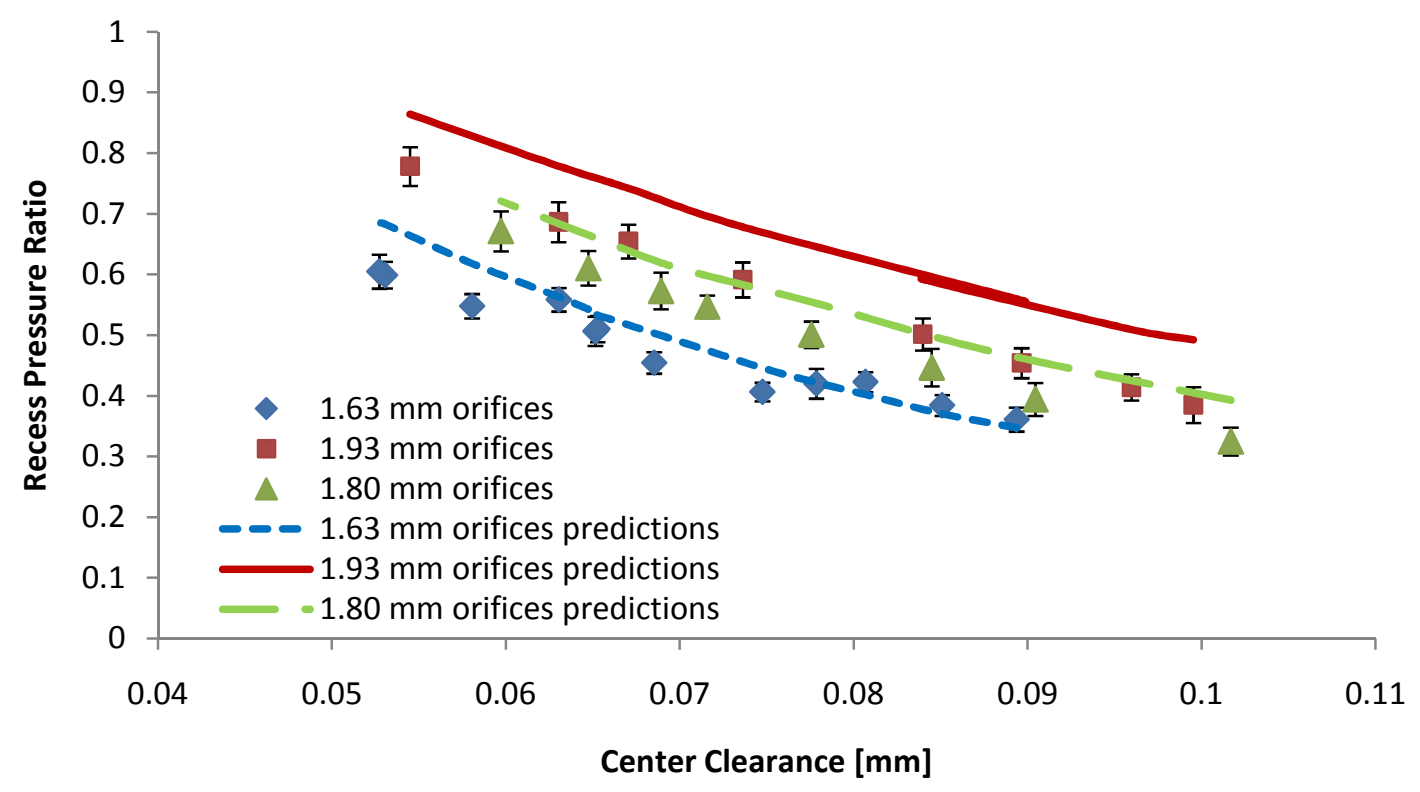

Figure F-8: Measured and predicted [3] recess pressure ratio versus clearance at 10.34 bar supply and $17.5 \mathrm{krpm}$ 


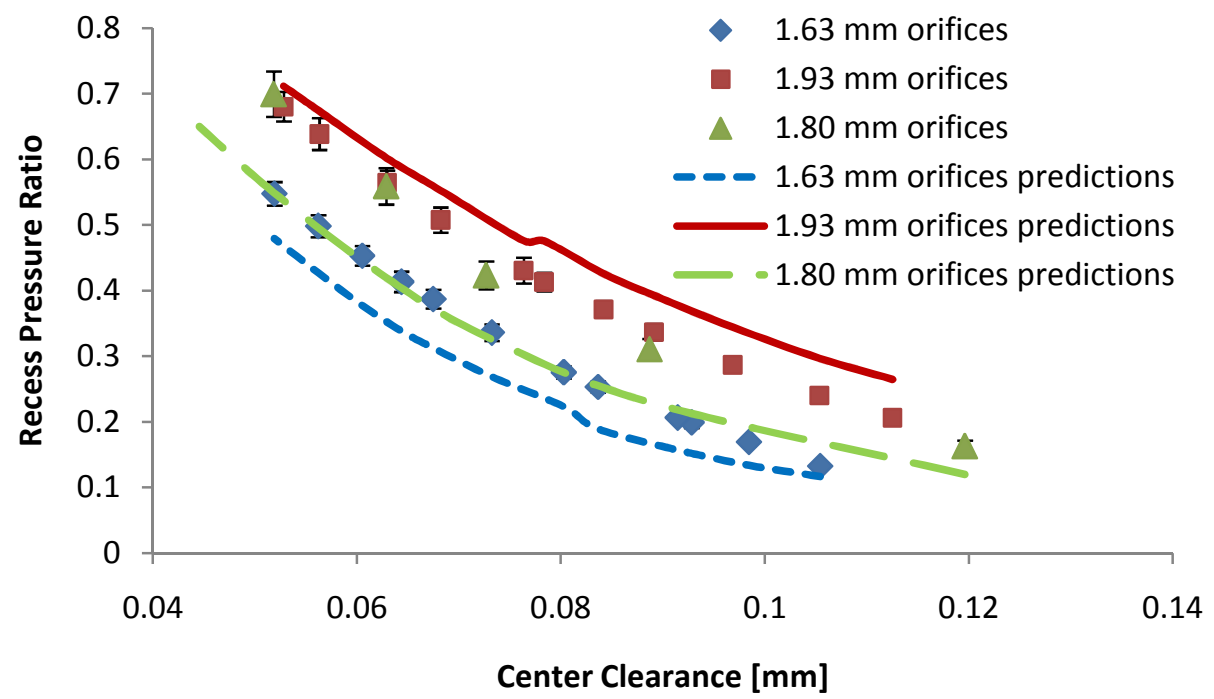

Figure F-9: Measured and predicted [3] recess pressure ratio versus clearance at 17.24 bar supply and 0 rpm

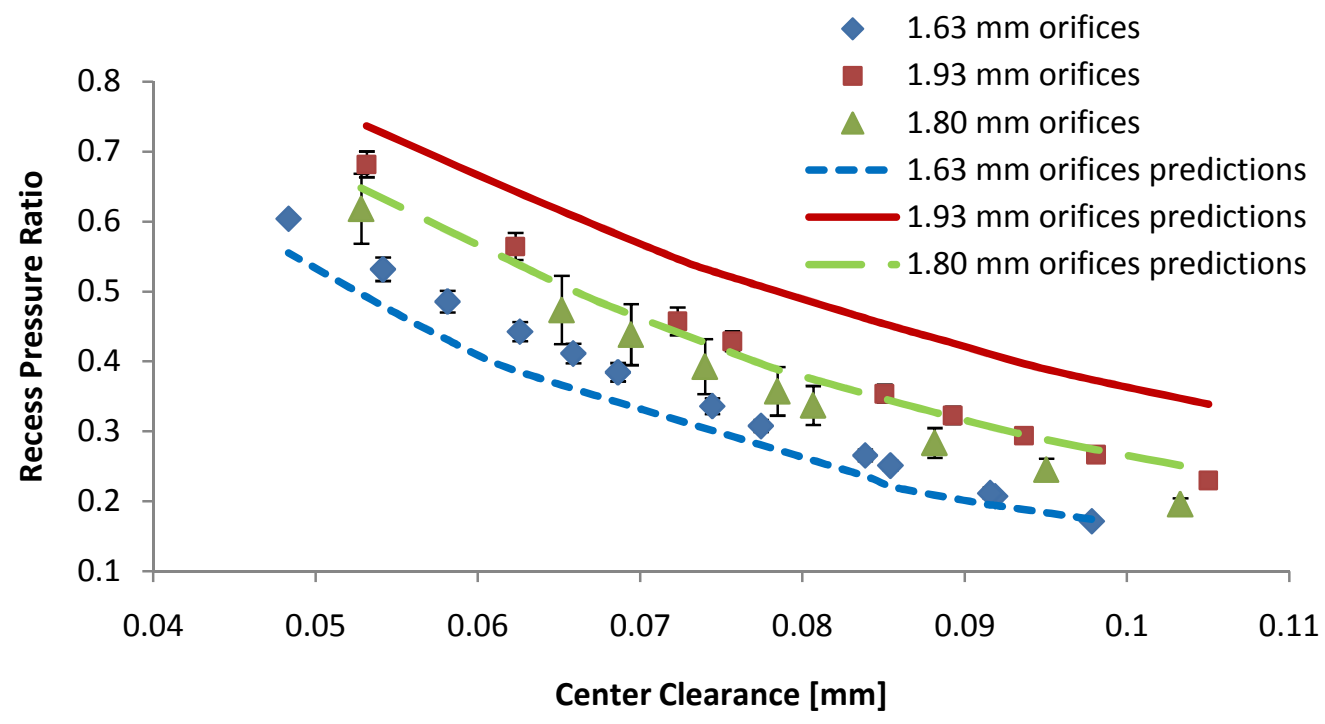

Figure F-10: Measured and predicted [3] recess pressure ratio versus clearance at 17.24 bar supply and $7.5 \mathrm{krpm}$ - repeated for reference 


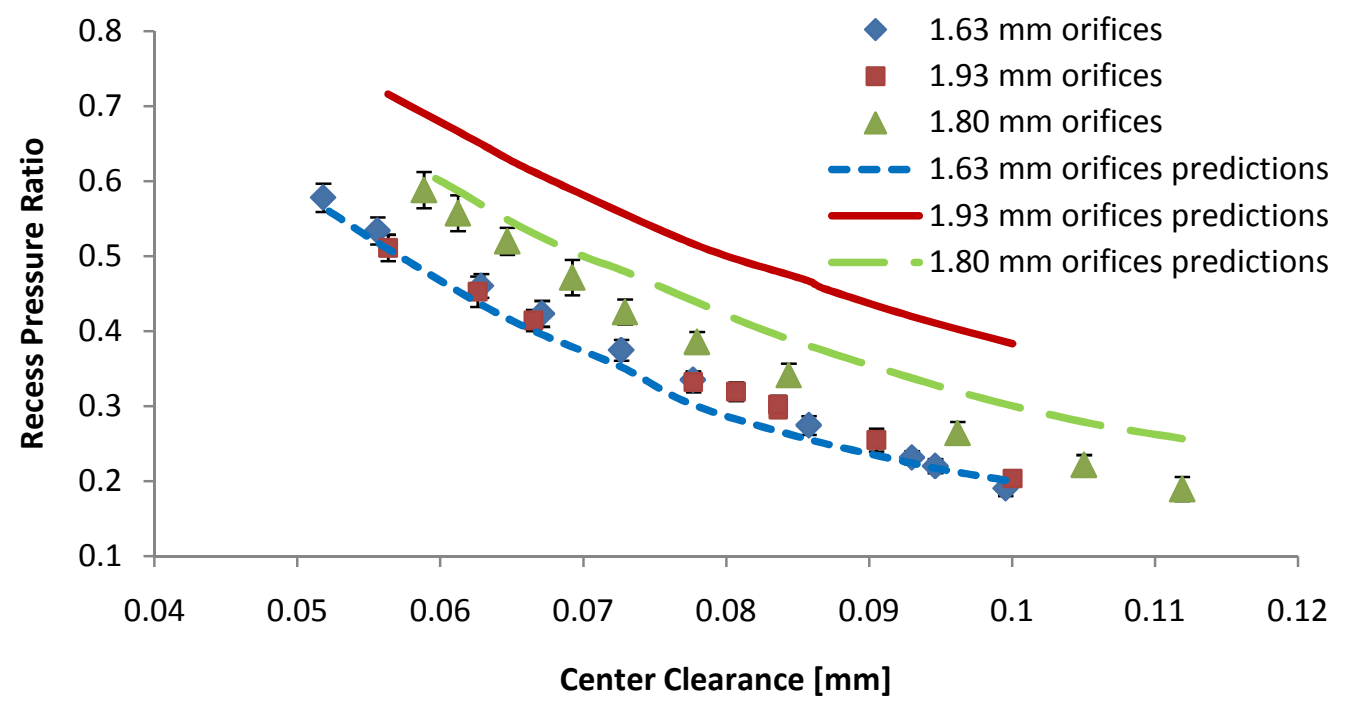

Figure F-11: Measured and predicted [3] recess pressure ratio versus clearance at 17.24 bar supply and $12.5 \mathrm{krpm}$ - repeated for reference

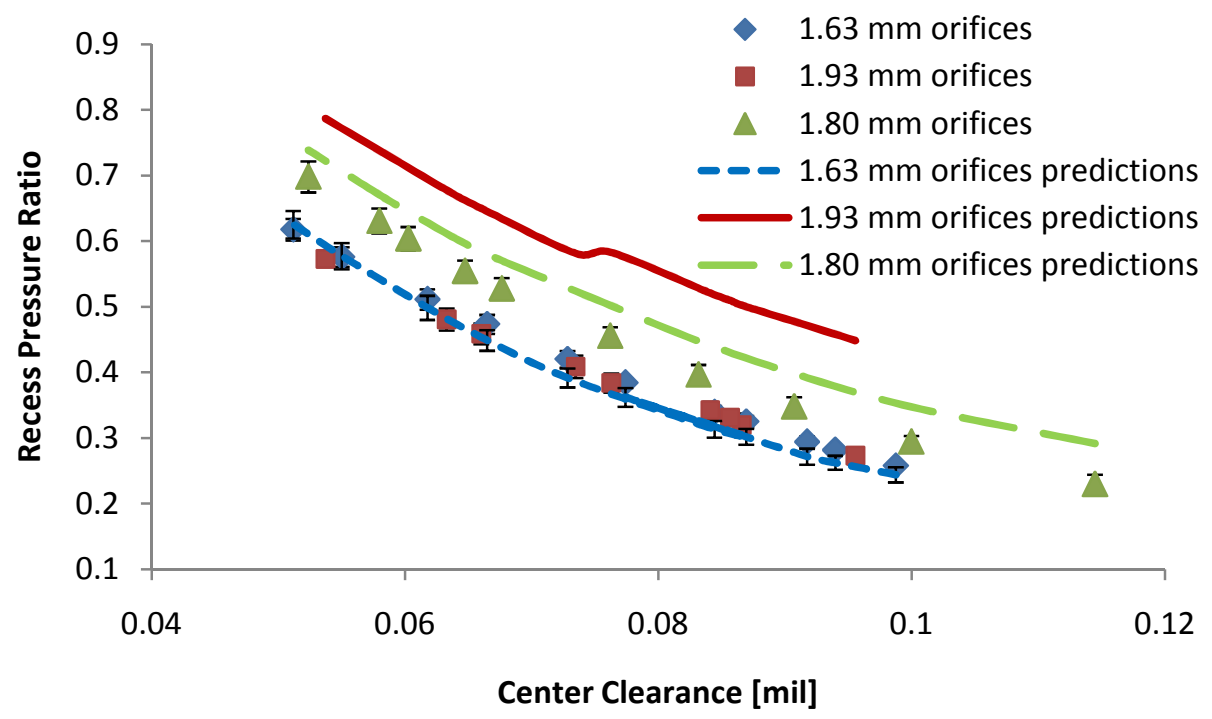

Figure F-12: Measured and predicted [3] recess pressure ratio versus clearance at 17.24 bar supply and $17.5 \mathrm{krpm}$ 


\section{APPENDIX G}

INNER RADIUS EXHAUST FLOW RATE FIGURES

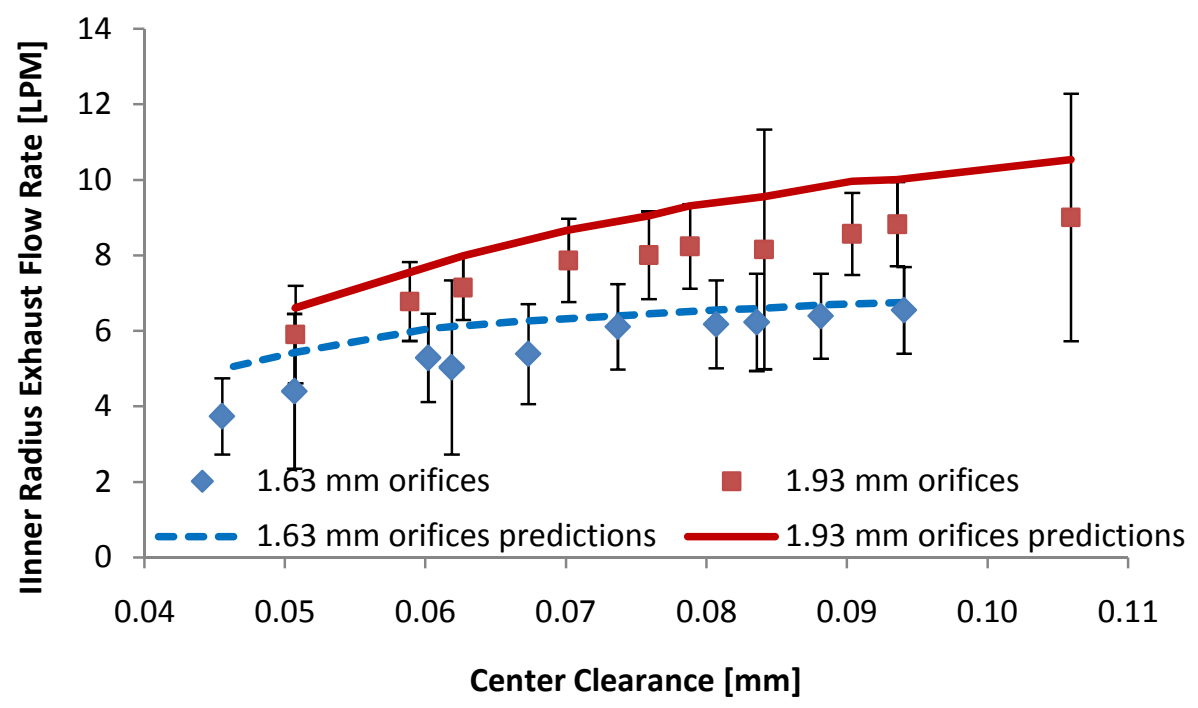

Figure G-1: Measured and predicted [3] inner radius exhaust flow rate versus center clearance at 5.17 bar and $0 \mathrm{rpm}$ - repeated for reference

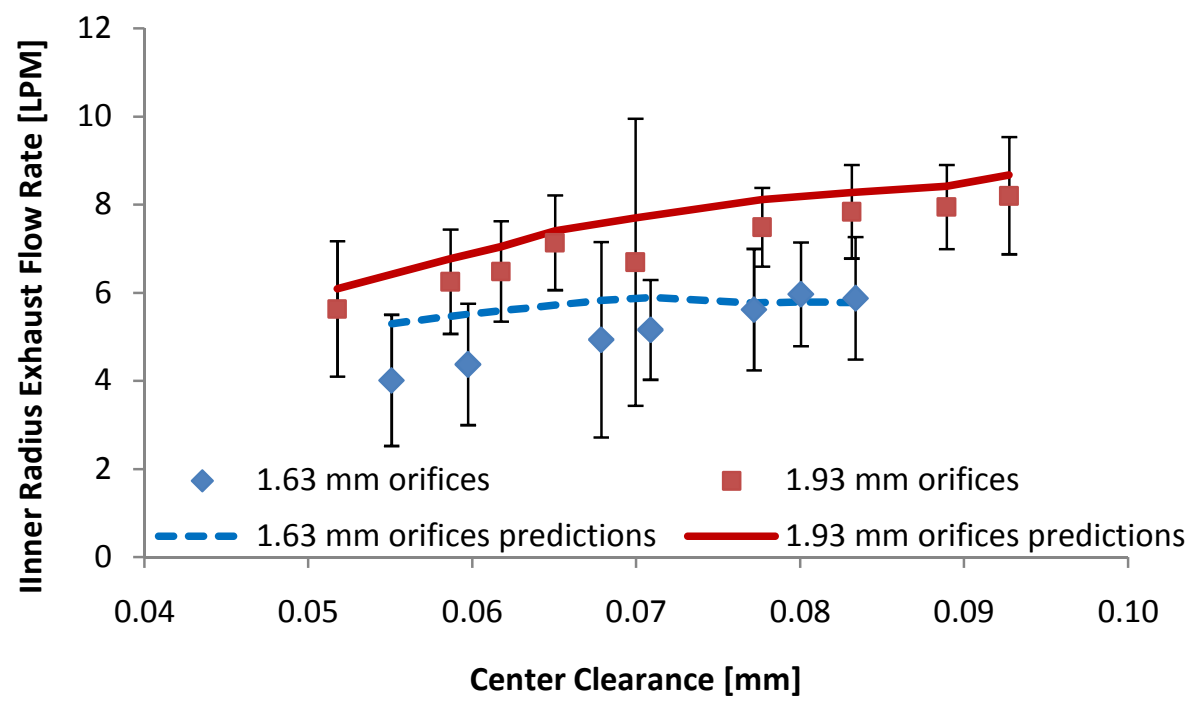

Figure G-2: Measured and predicted [3] inner radius exhaust flow rate versus center clearance at 5.17 bar and $7.5 \mathrm{krpm}$ 


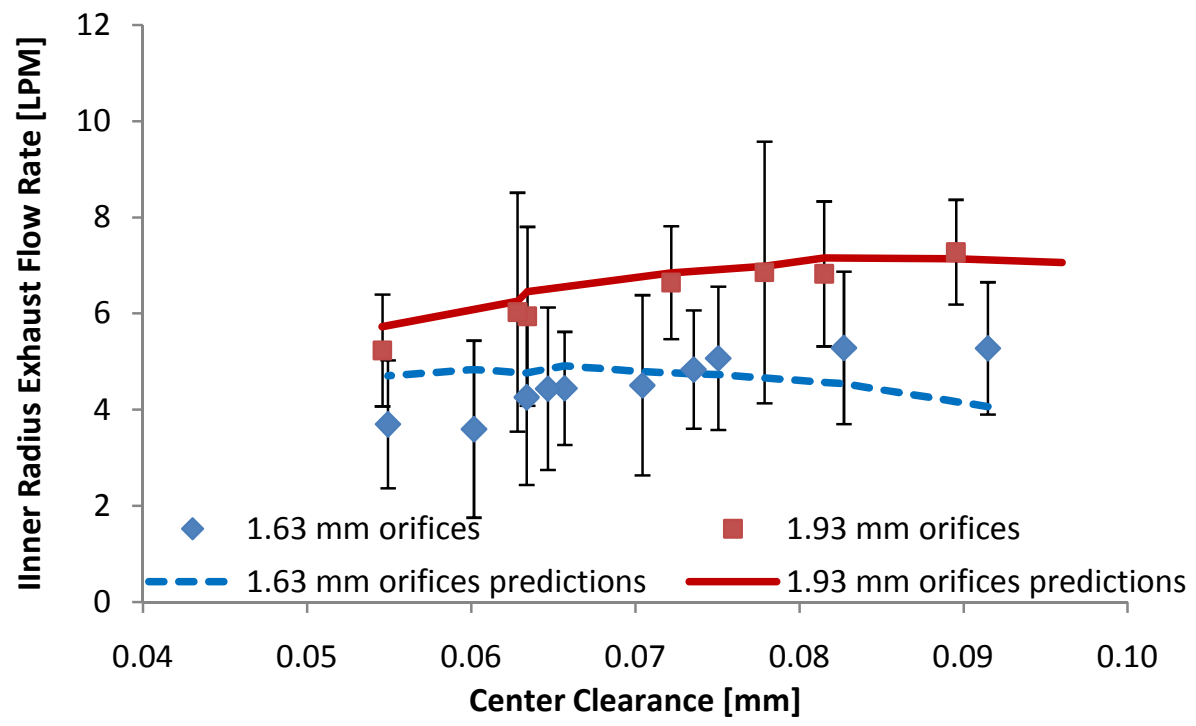

Figure G-3: Measured and predicted [3] inner radius exhaust flow rate versus center clearance at 5.17 bar and $12.5 \mathrm{krpm}$

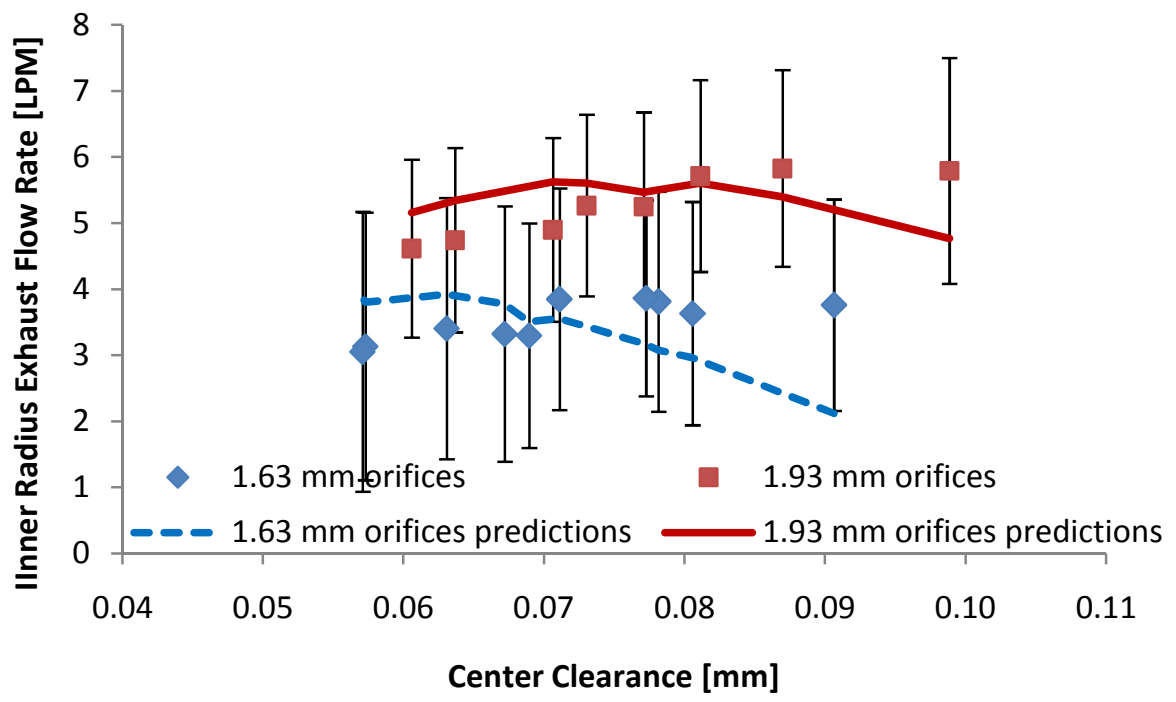

Figure G-4: Measured and predicted [3] inner radius exhaust flow rate versus center clearance at 5.17 bar and $17.5 \mathrm{krpm}$ - repeated for reference 


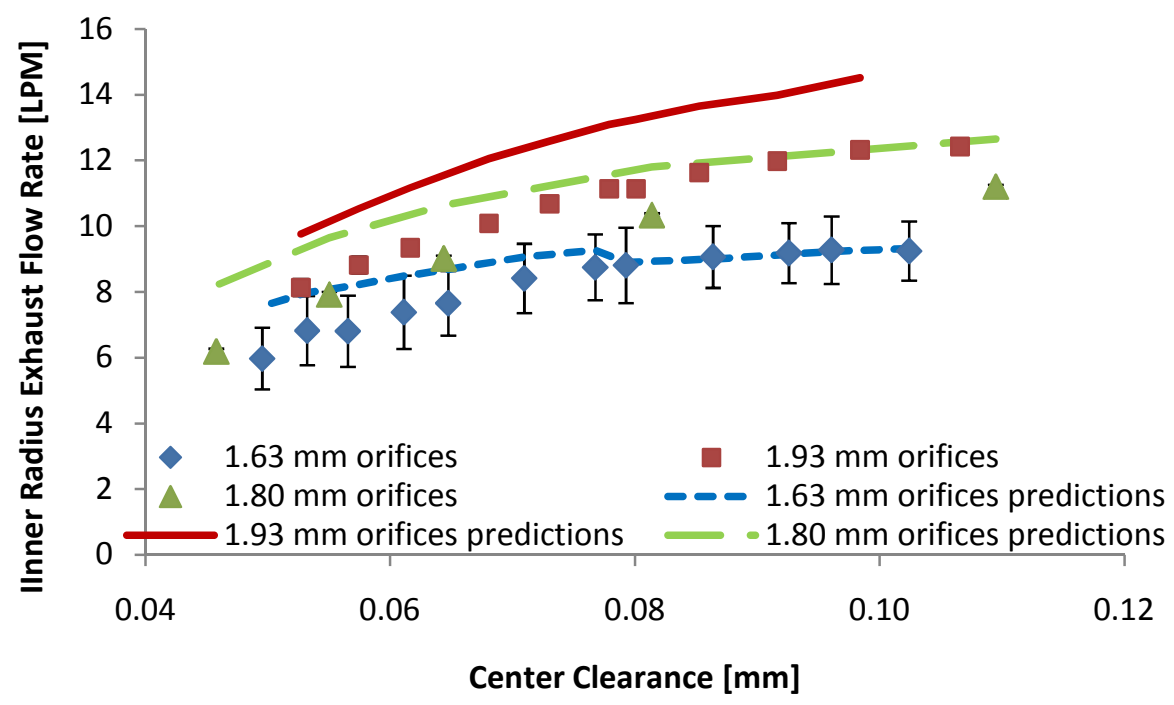

Figure G-5: Measured and predicted [3] inner radius exhaust flow rate versus center clearance at 10.34 bar and 0 rpm

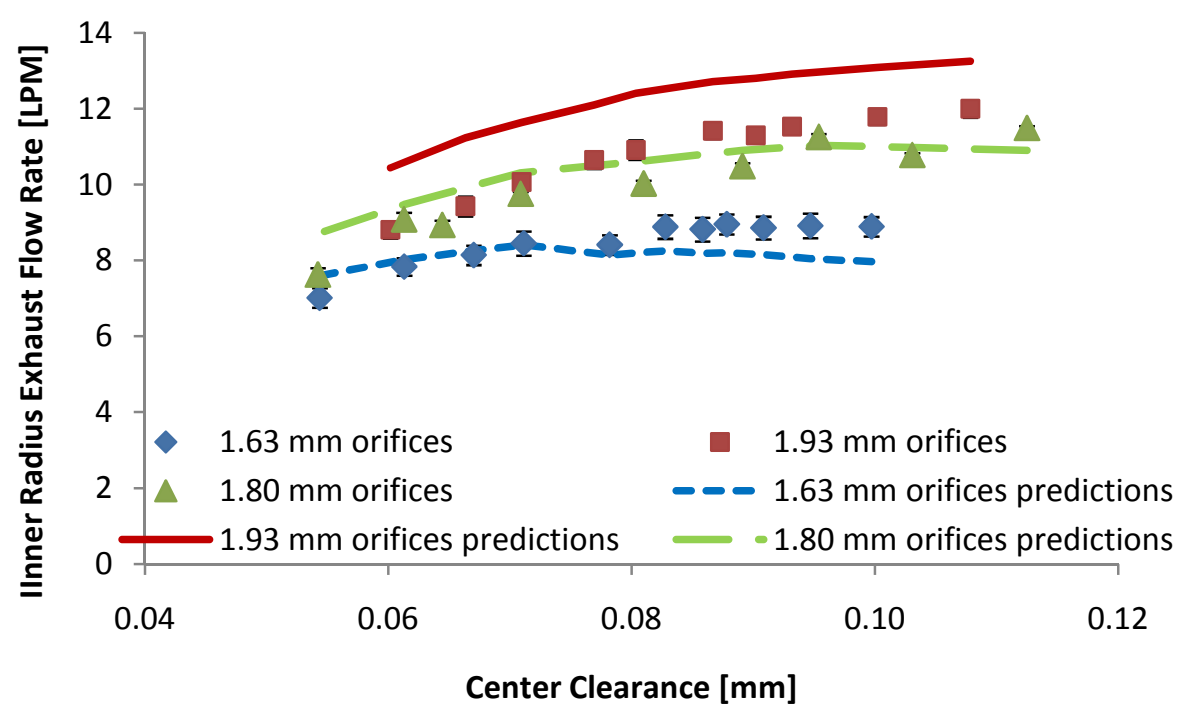

Figure G-6: Measured and predicted [3] inner radius exhaust flow rate versus center clearance at 10.34 bar and $7.5 \mathrm{krpm}$ 


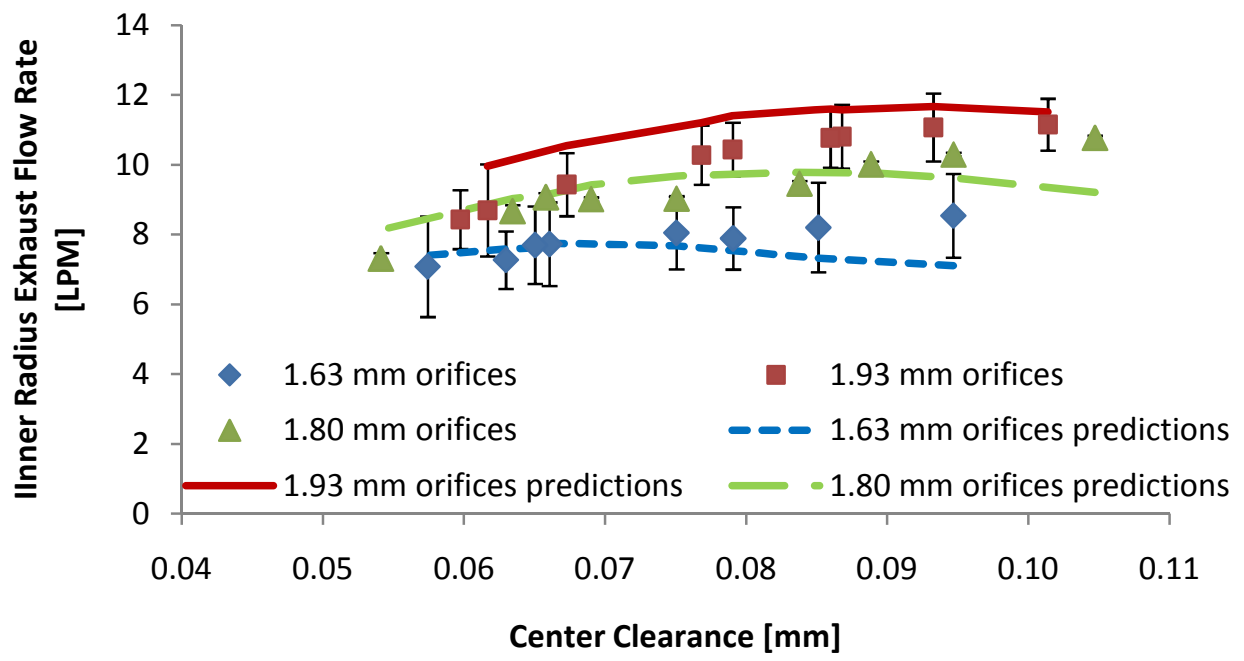

Figure G-7: Measured and predicted [3] inner radius exhaust flow rate versus center clearance at 10.34 bar and $12.5 \mathrm{krpm}$ - repeated for reference

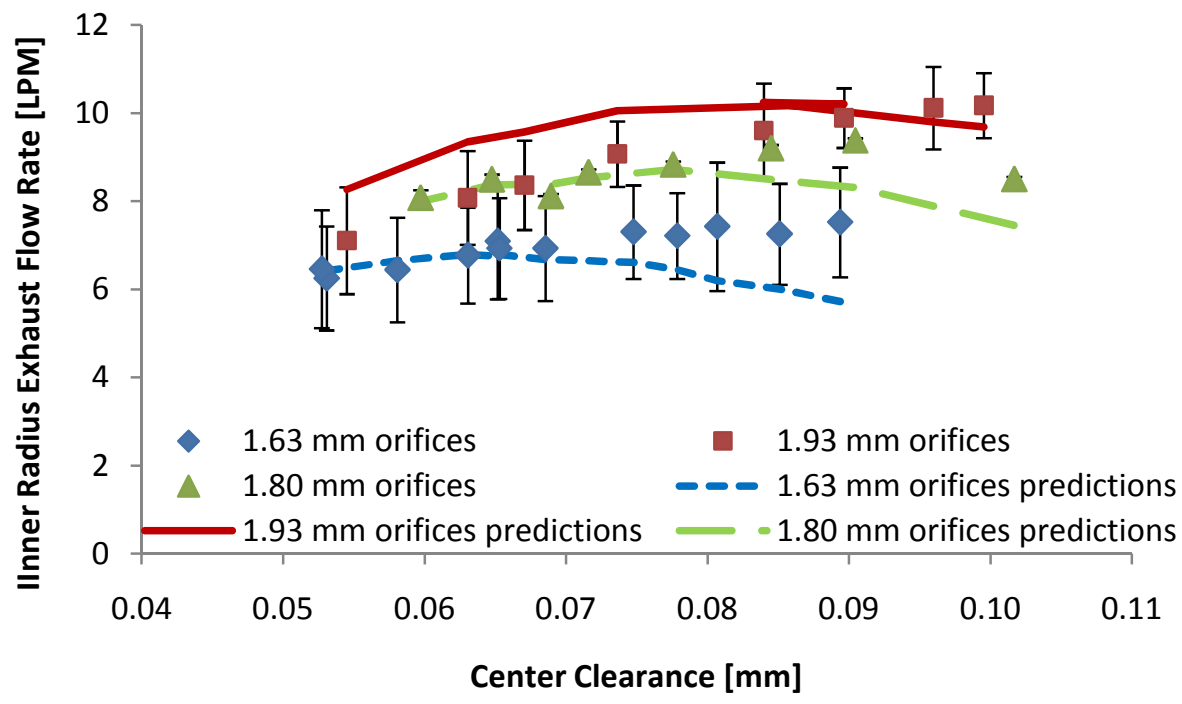

Figure G-8: Measured and predicted [3] inner radius exhaust flow rate versus center clearance at 10.34 bar and $17.5 \mathrm{krpm}$ 


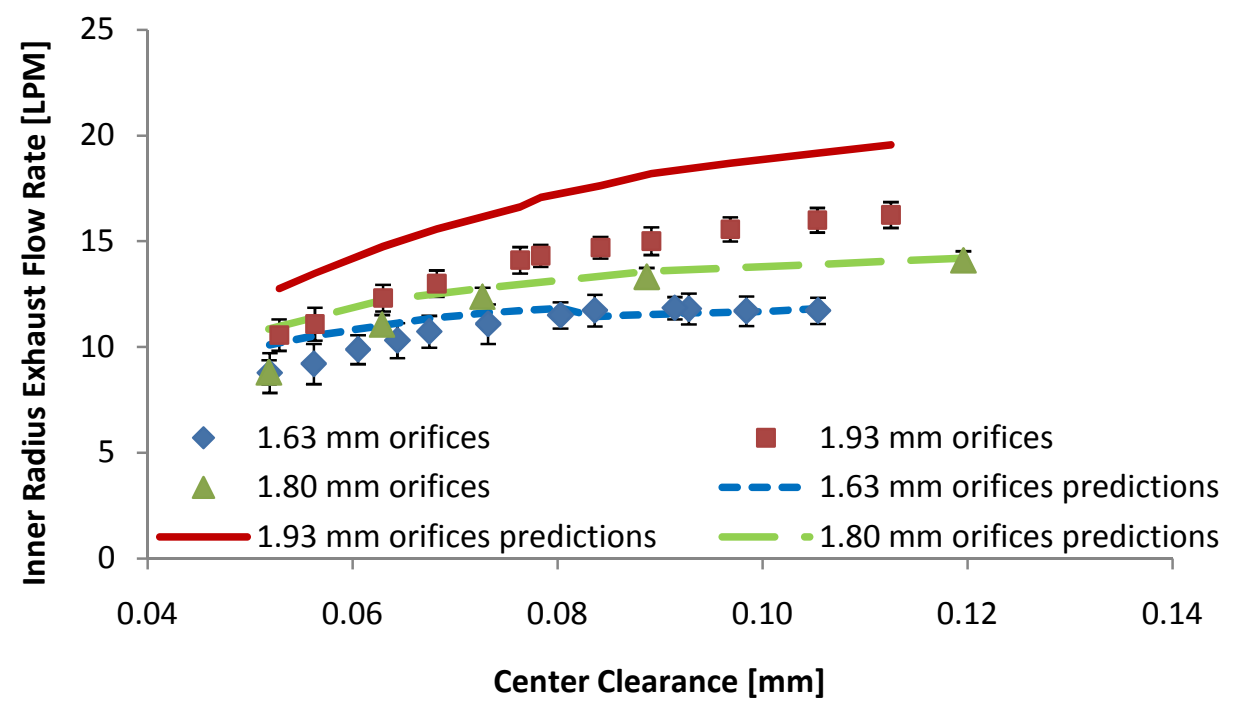

Figure G-9: Measured and predicted [3] inner radius exhaust flow rate versus center clearance at 17.24 bar and 0 rpm

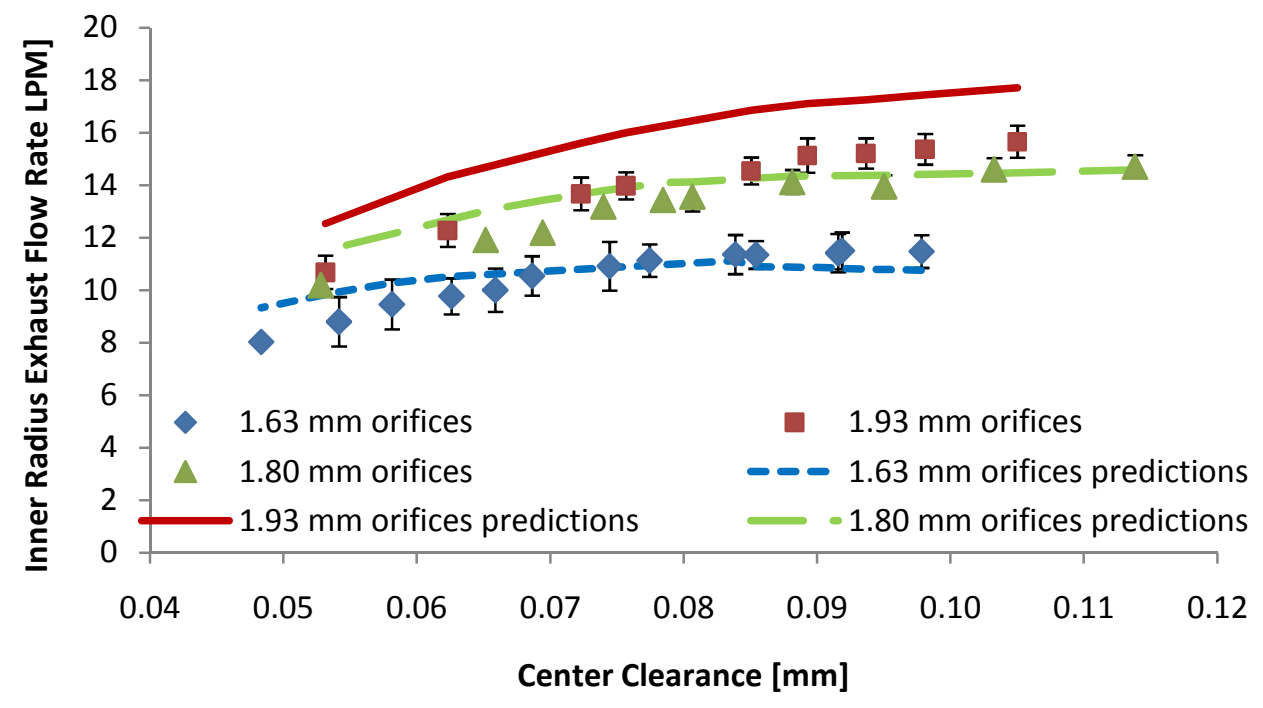

Figure G-10: Measured and predicted [3] inner radius exhaust flow rate versus center clearance at 17.24 bar and $7.5 \mathrm{krpm}$ 


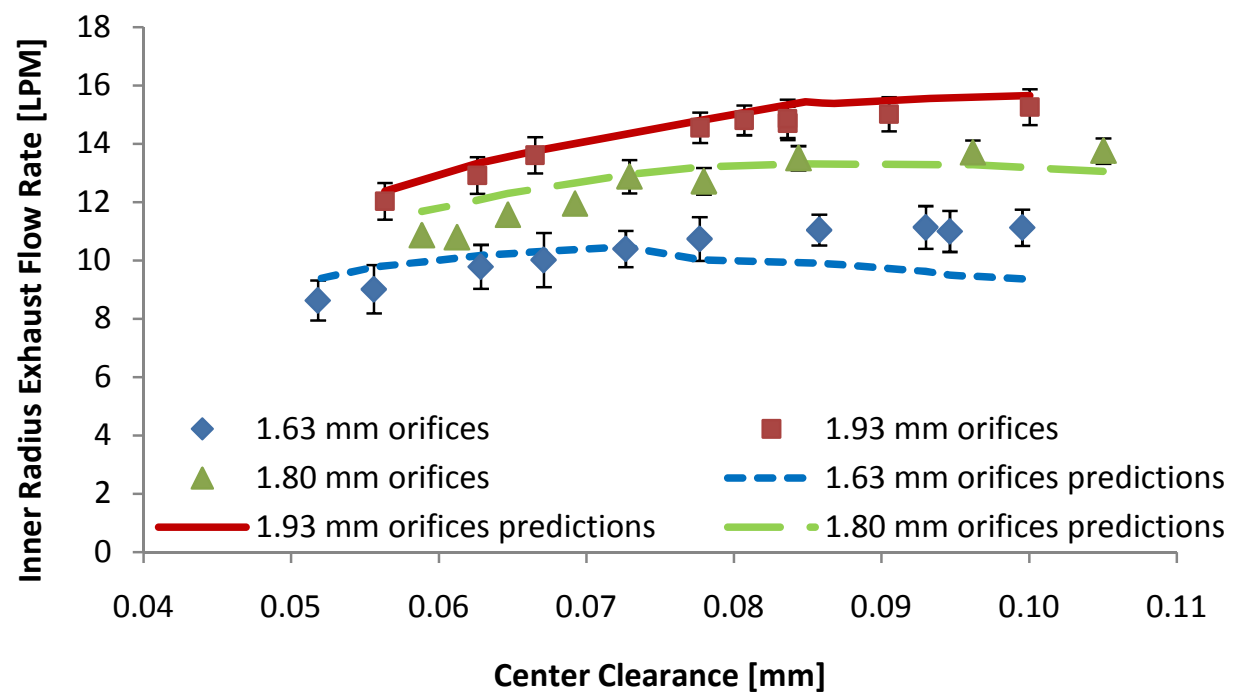

Figure G-11: Measured and predicted [3] inner radius exhaust flow rate versus center clearance at $\mathbf{1 7 . 2 4}$ bar and $12.5 \mathrm{krpm}$ - repeated for reference

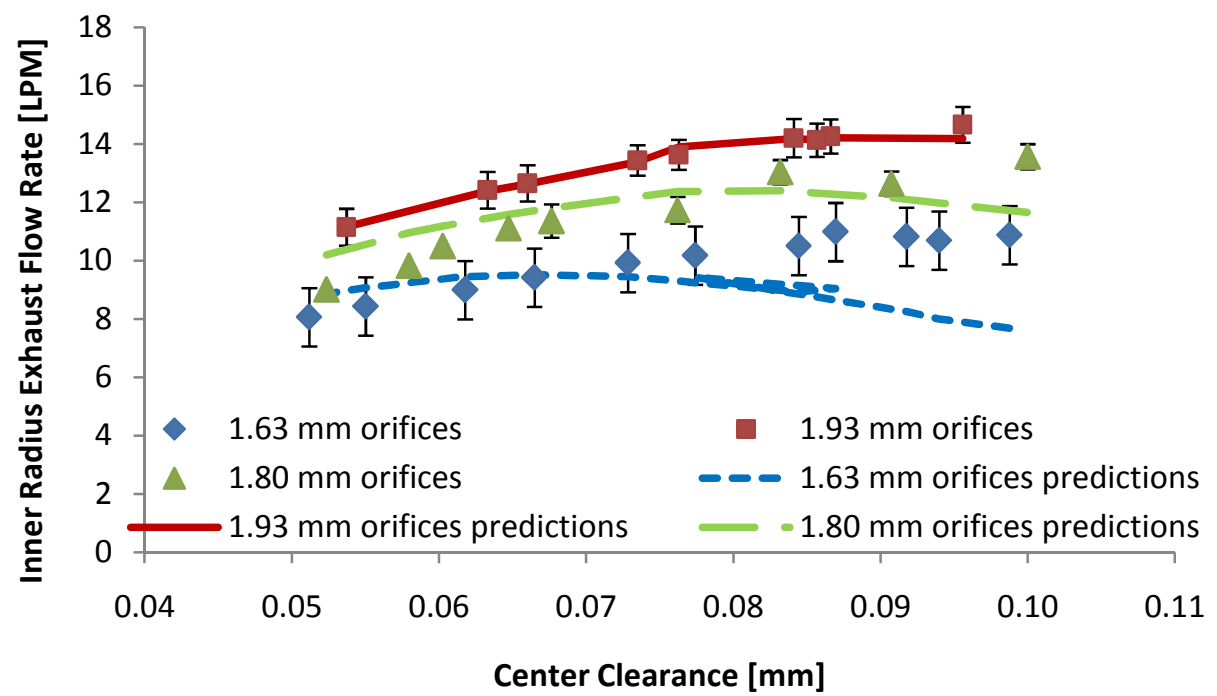

Figure G-12: Measured and predicted [3] inner radius exhaust flow rate versus center clearance at 17.24 bar and $17.5 \mathrm{krpm}$ 


\section{APPENDIX H}

\section{CENTER CLEARANCE FIGURES}

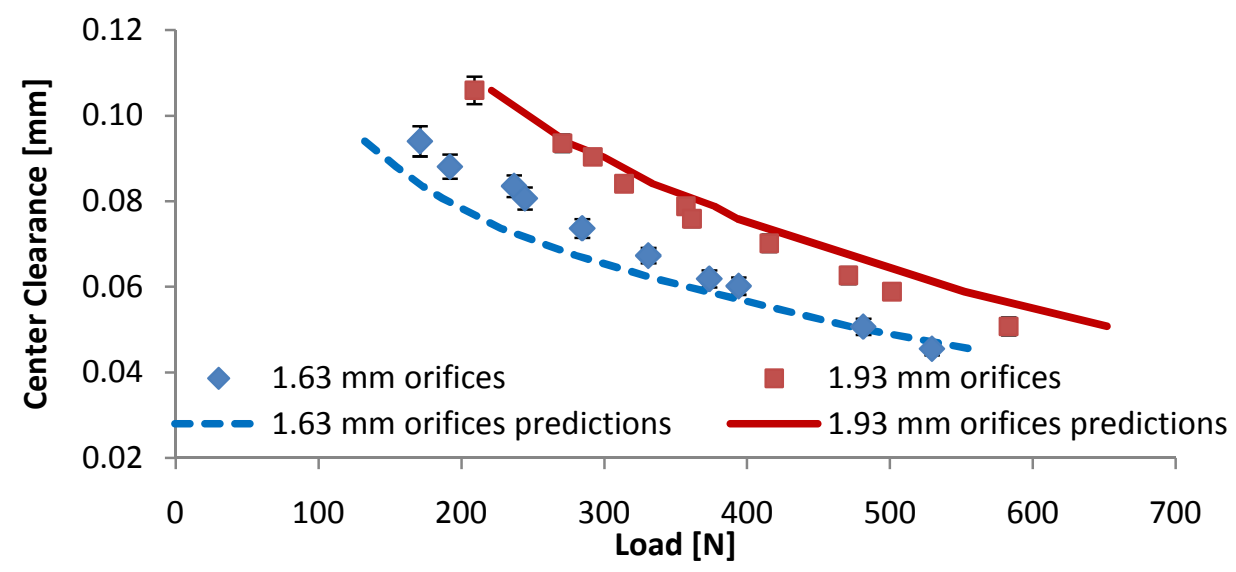

Figure H-1: Measured and predicted [3] center clearance versus load at 5.17 bar supply and $0 \mathrm{rpm}$ - repeated for reference

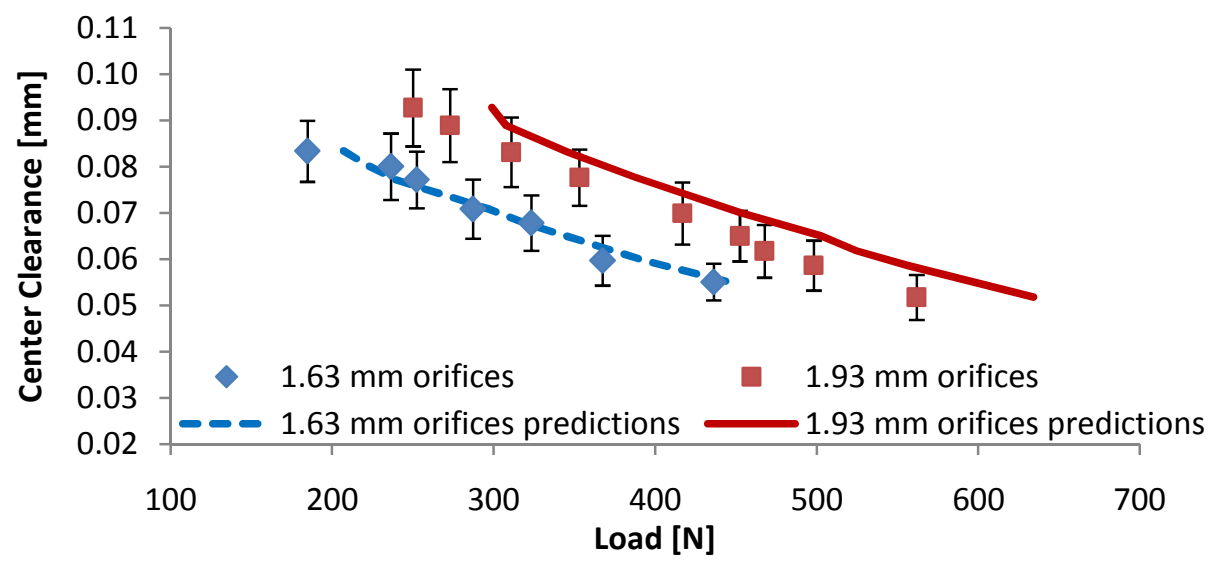

Figure H-2: Measured and predicted [3] center clearance versus load at 5.17 bar supply and $7.5 \mathrm{krpm}$ 


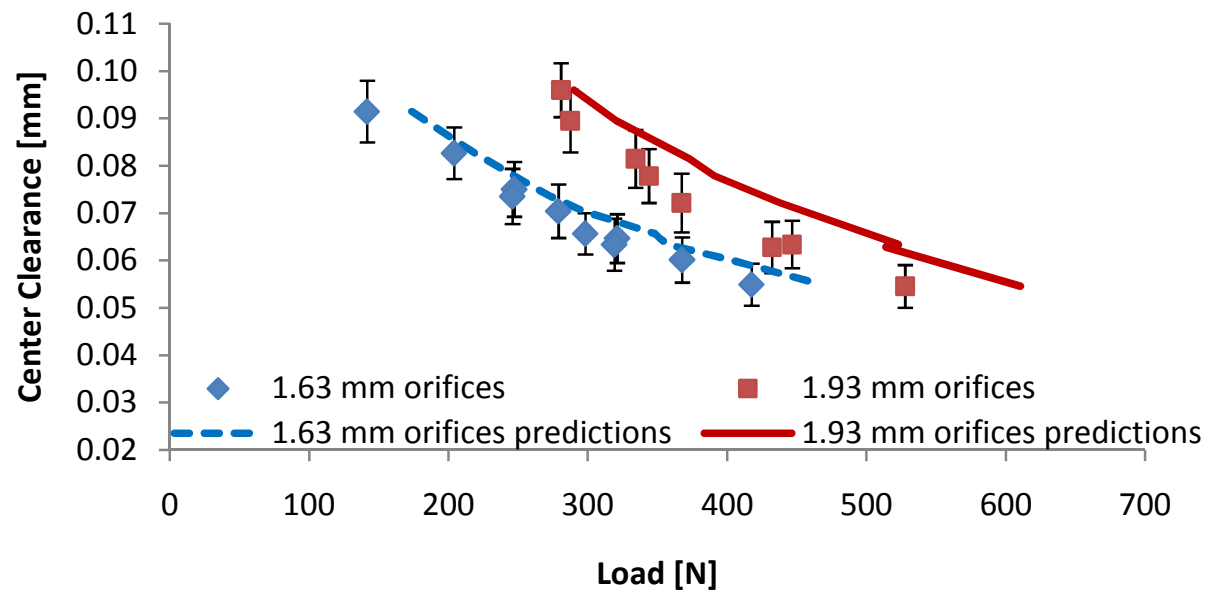

Figure H-3: Measured and predicted [3] center clearance versus load at 5.17 bar supply and $12.5 \mathrm{krpm}$

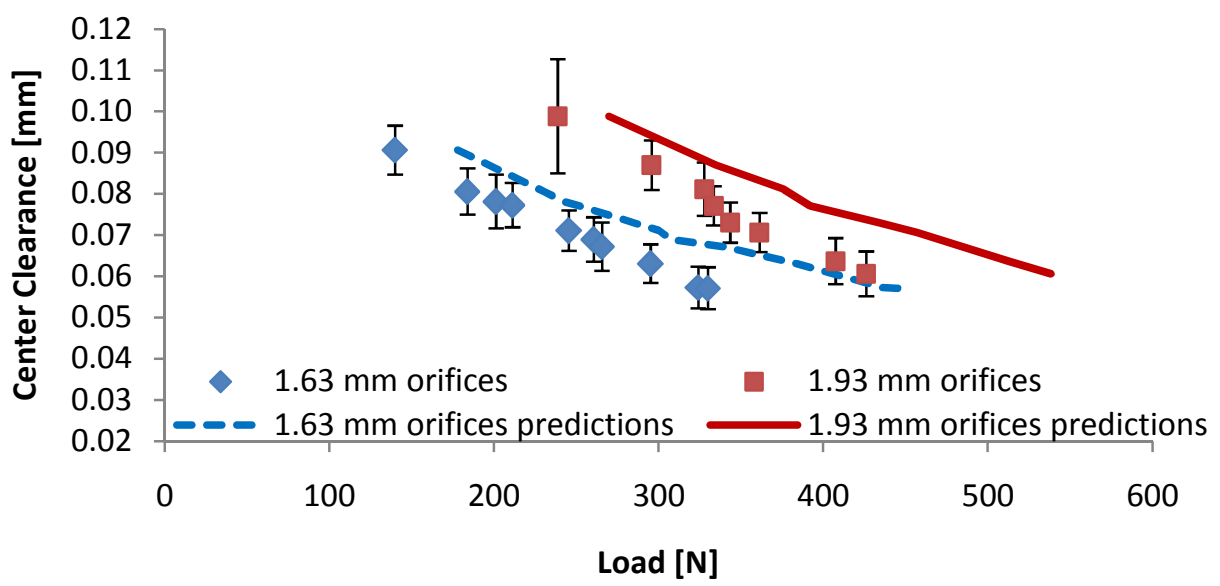

Figure H-4: Measured and predicted [3] center clearance versus load at 5.17 bar supply and $17.5 \mathrm{krpm}$ 


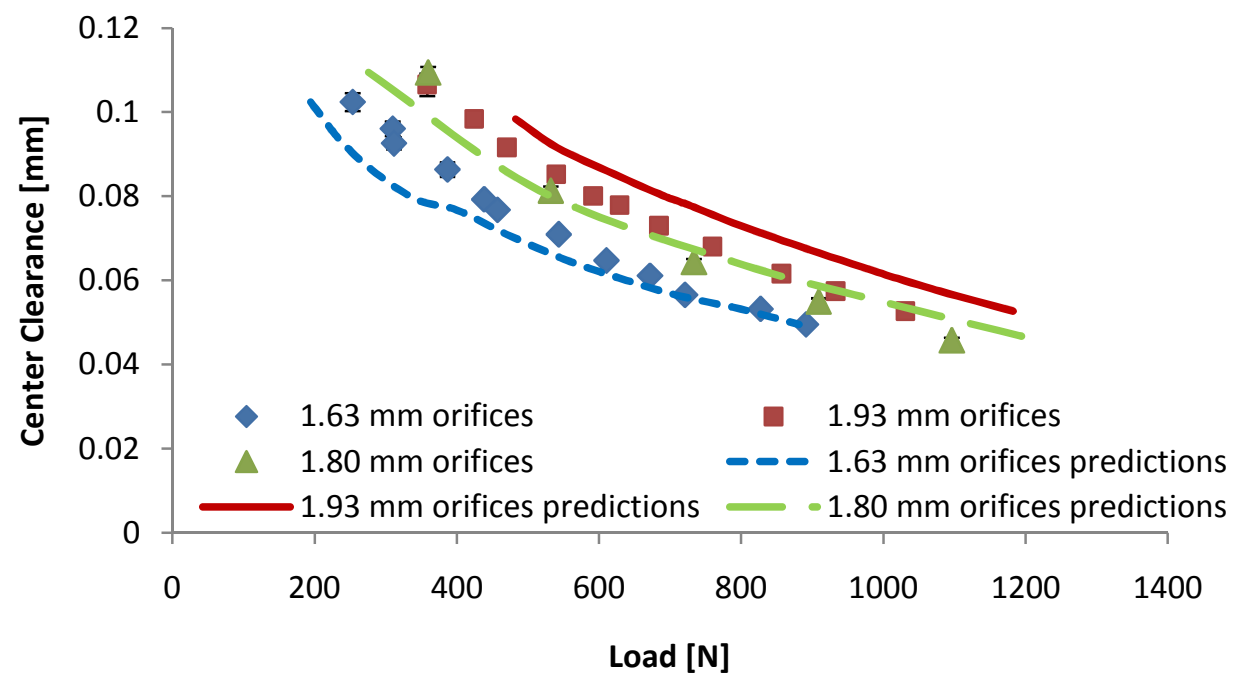

Figure H-5: Measured and predicted [3] center clearance versus load at 10.34 bar supply and 0 rpm

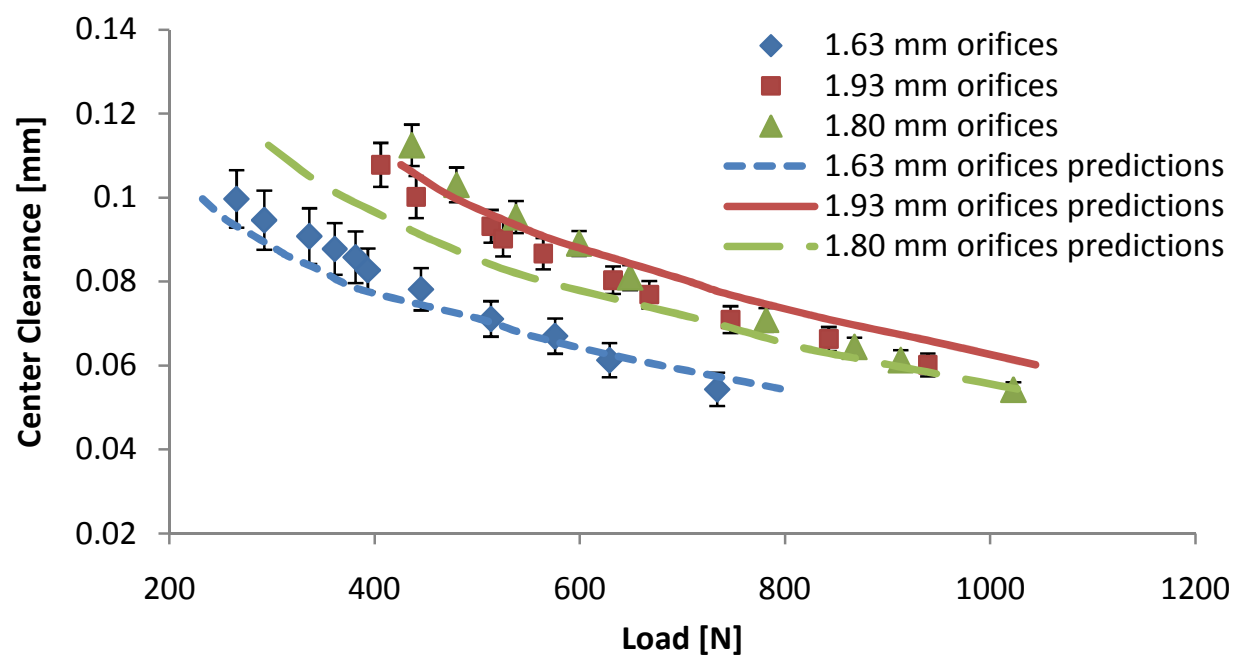

Figure H-6: Measured and predicted [3] center clearance versus load at 10.34 bar supply and $7.5 \mathrm{krpm}$ - repeated for reference 


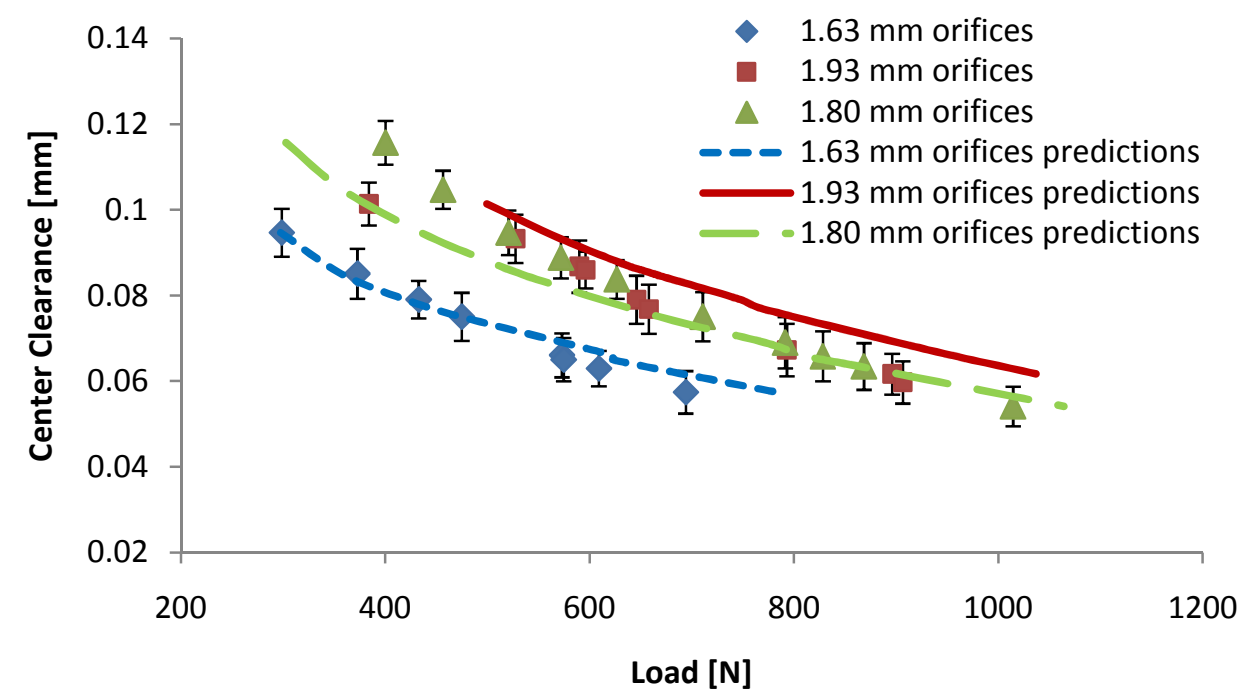

Figure H-7: Measured and predicted [3] center clearance versus load at 10.34 bar supply and $12.5 \mathrm{krpm}$

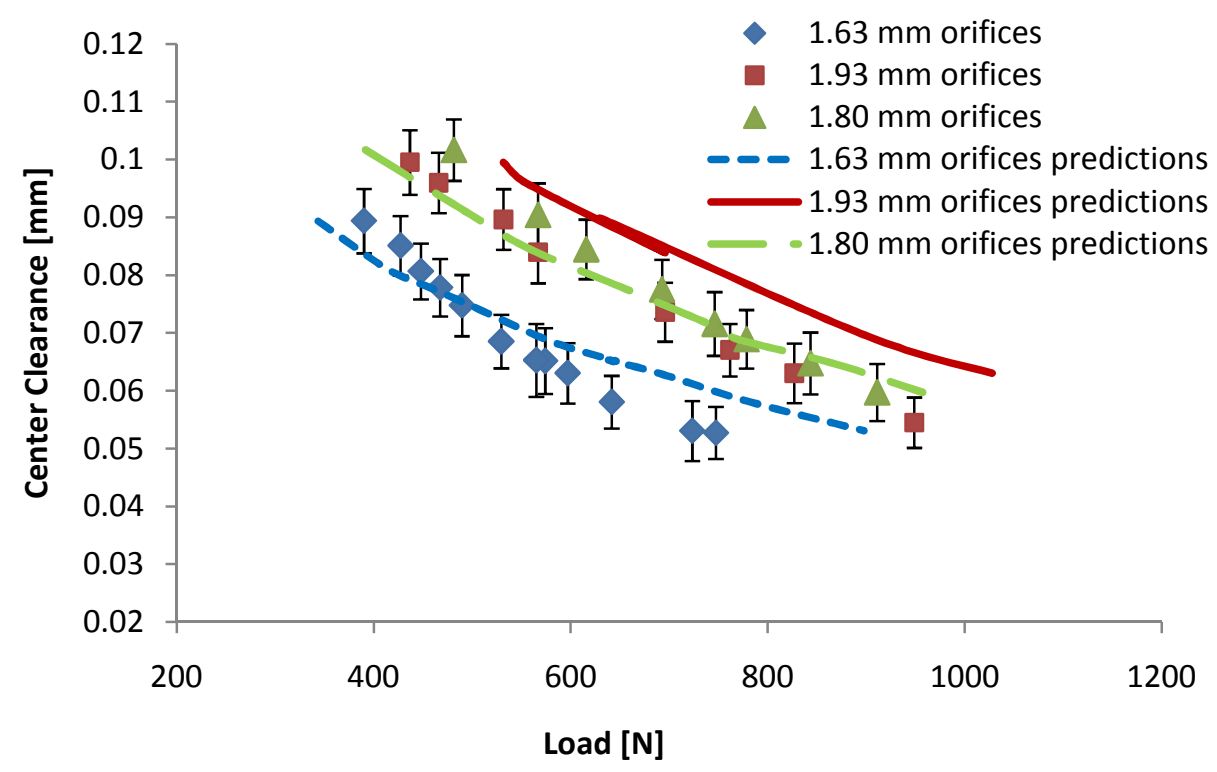

Figure H-8: Measured and predicted [3] center clearance versus load at 10.34 bar supply and $17.5 \mathrm{krpm}$ 


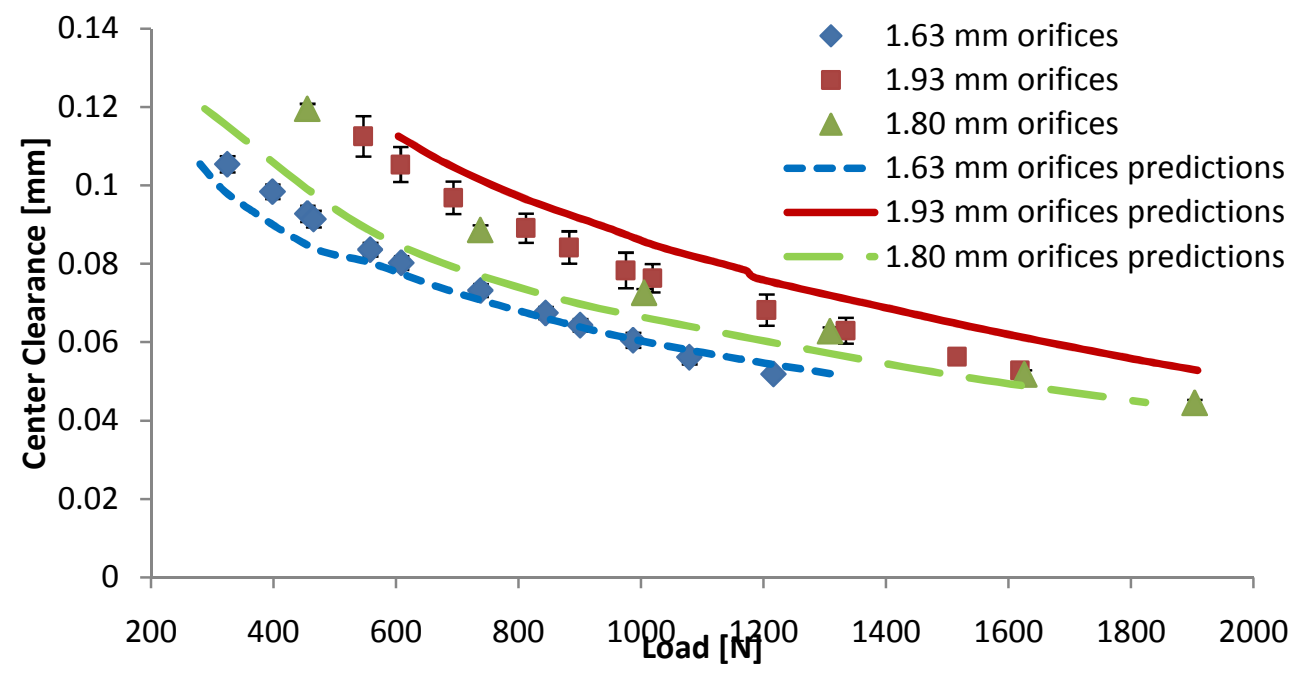

Figure H-9: Measured and predicted [3] center clearance versus load at $\mathbf{1 7 . 2 4}$ bar supply and 0 rpm

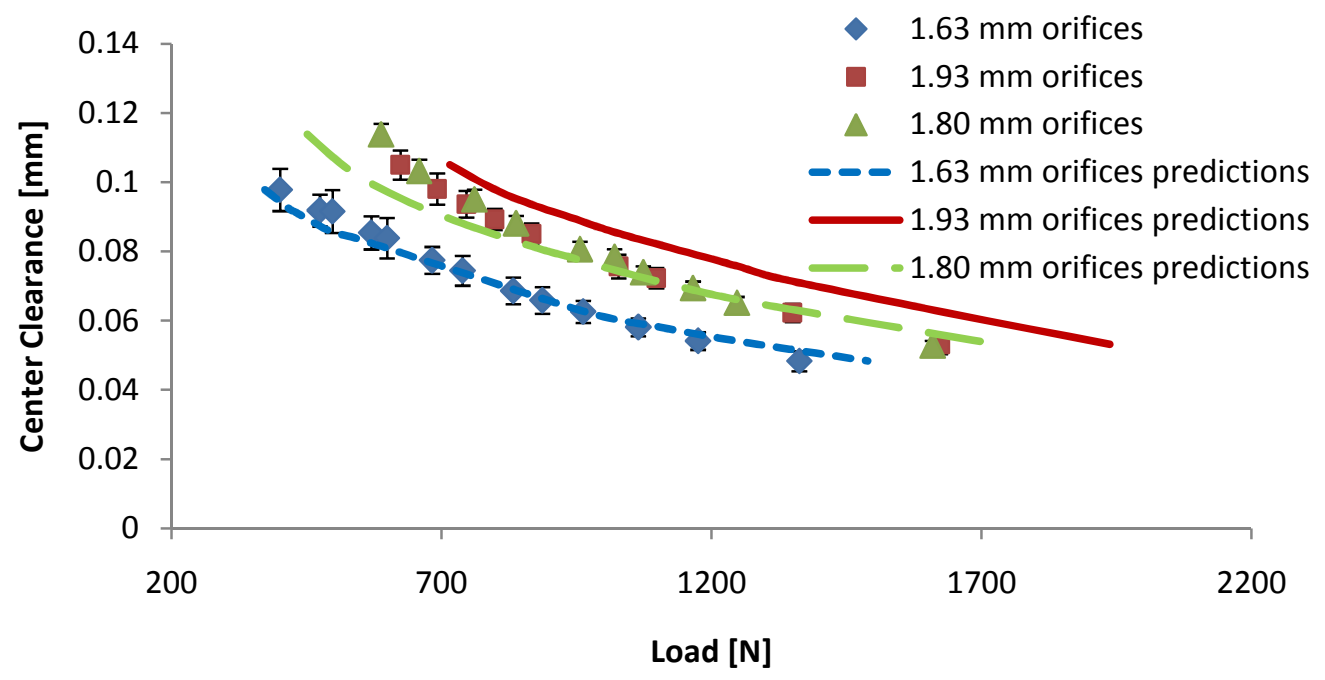

Figure H-10: Measured and predicted [3] center clearance versus load at 17.24 bar supply and $7.5 \mathrm{krpm}$ - repeated fore reference 


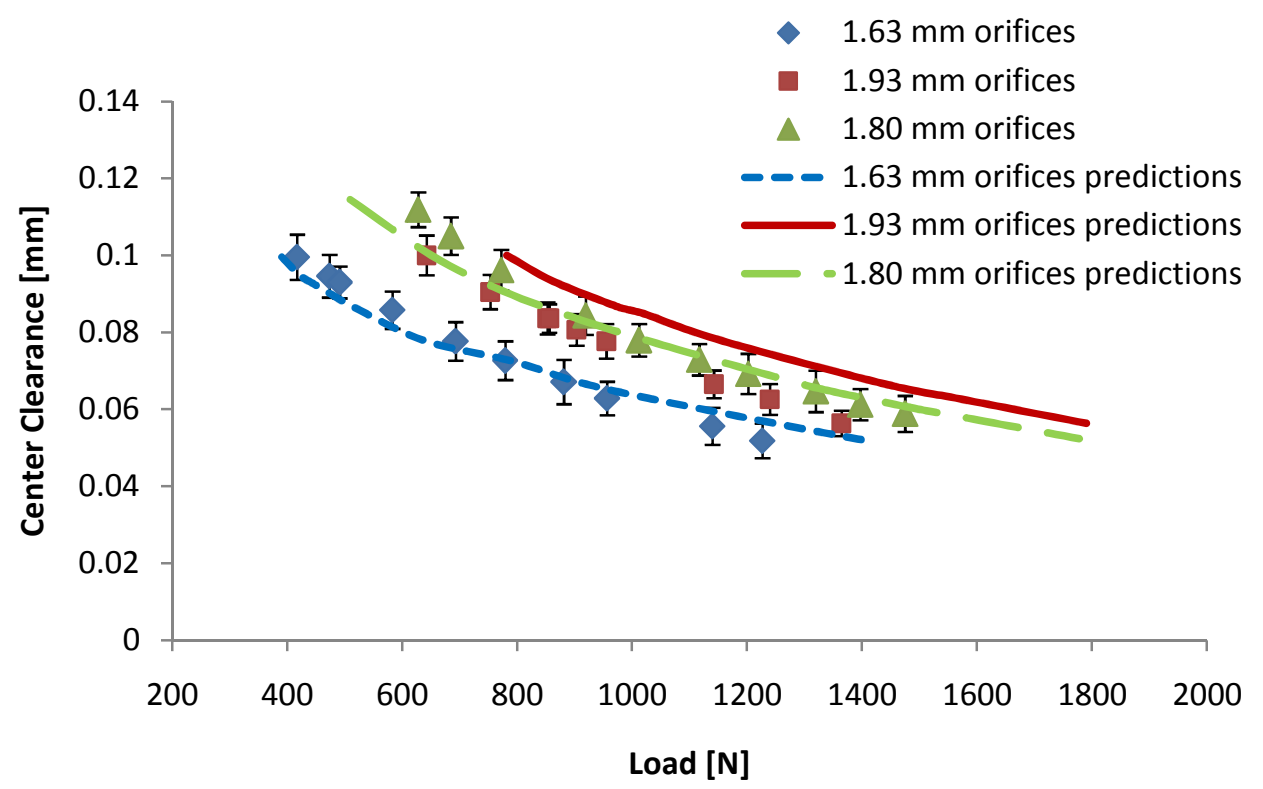

Figure H-11: Measured and predicted [3] center clearance versus load at $\mathbf{1 7 . 2 4}$ bar supply and $12.5 \mathrm{krpm}$

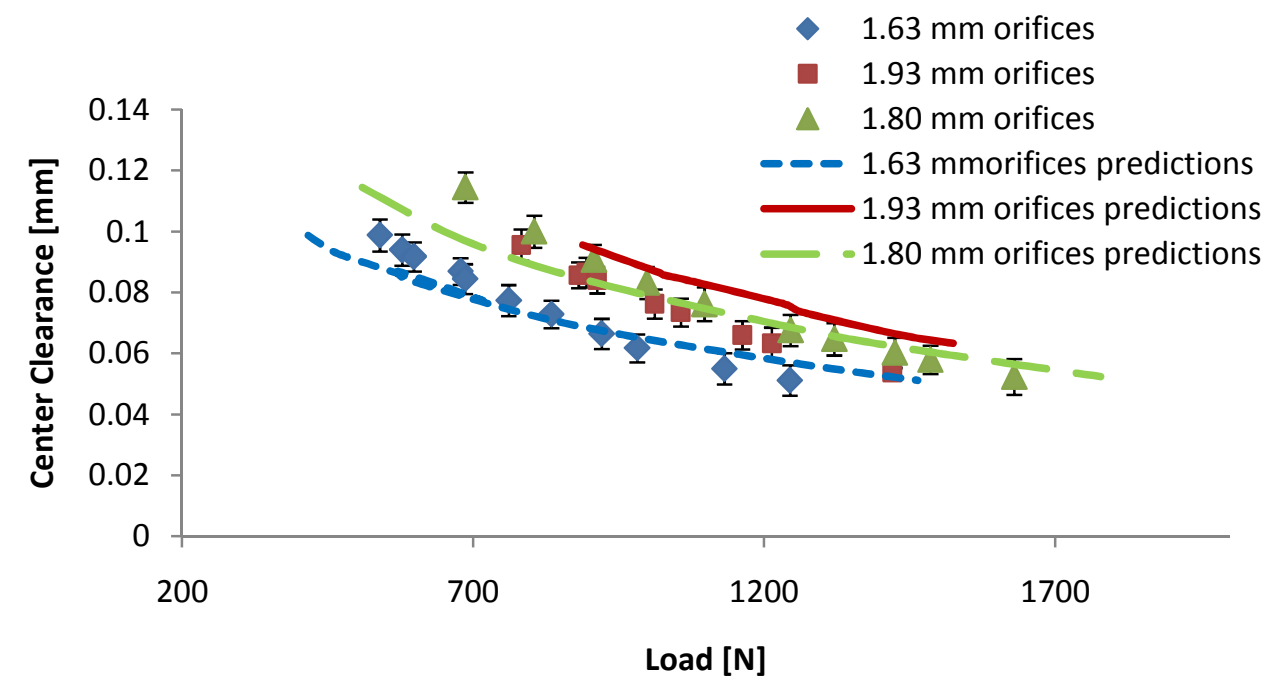

Figure H-12: Measured and predicted [3] center clearance versus load at $\mathbf{1 7 . 2 4}$ bar supply and $17.5 \mathrm{krpm}$ 


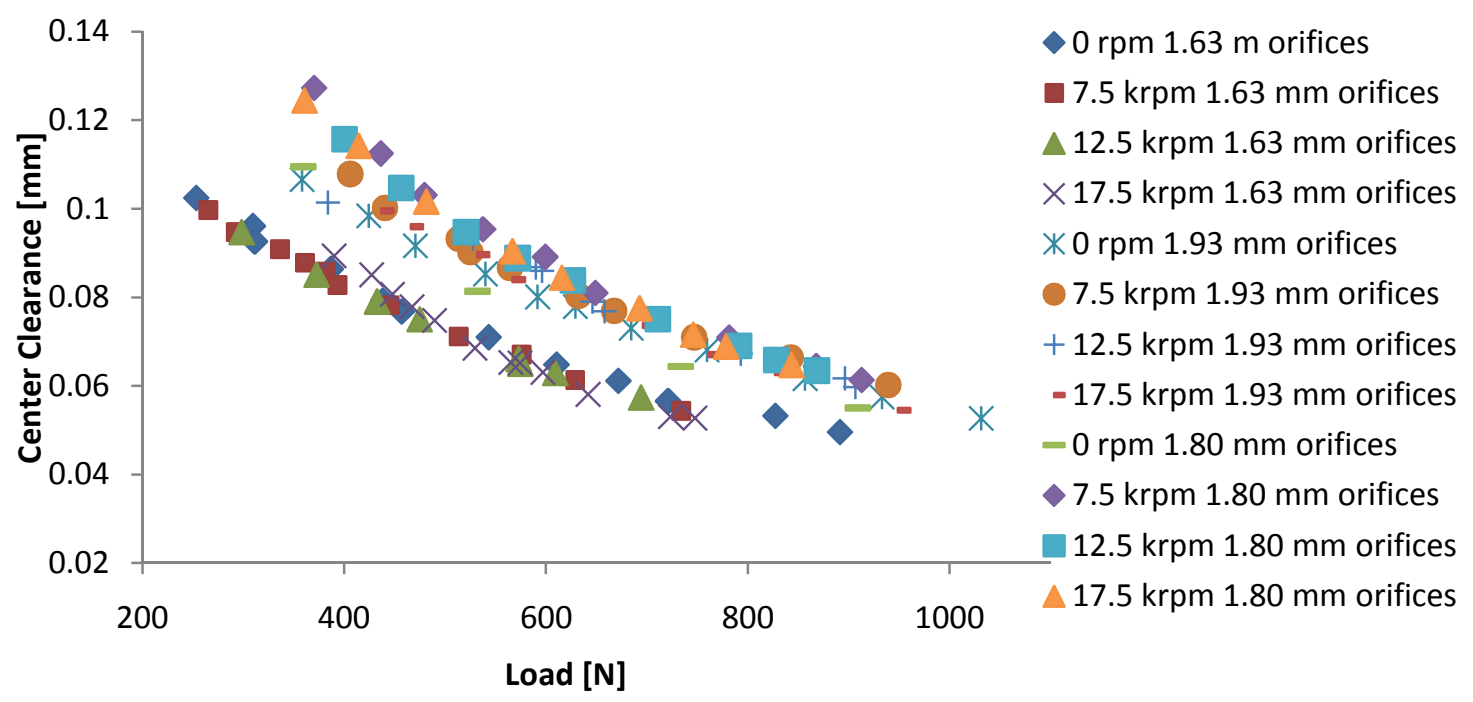

Figure H-13: Center clearance versus load at 10.34 bar supply and all speeds for all three orifice diameters

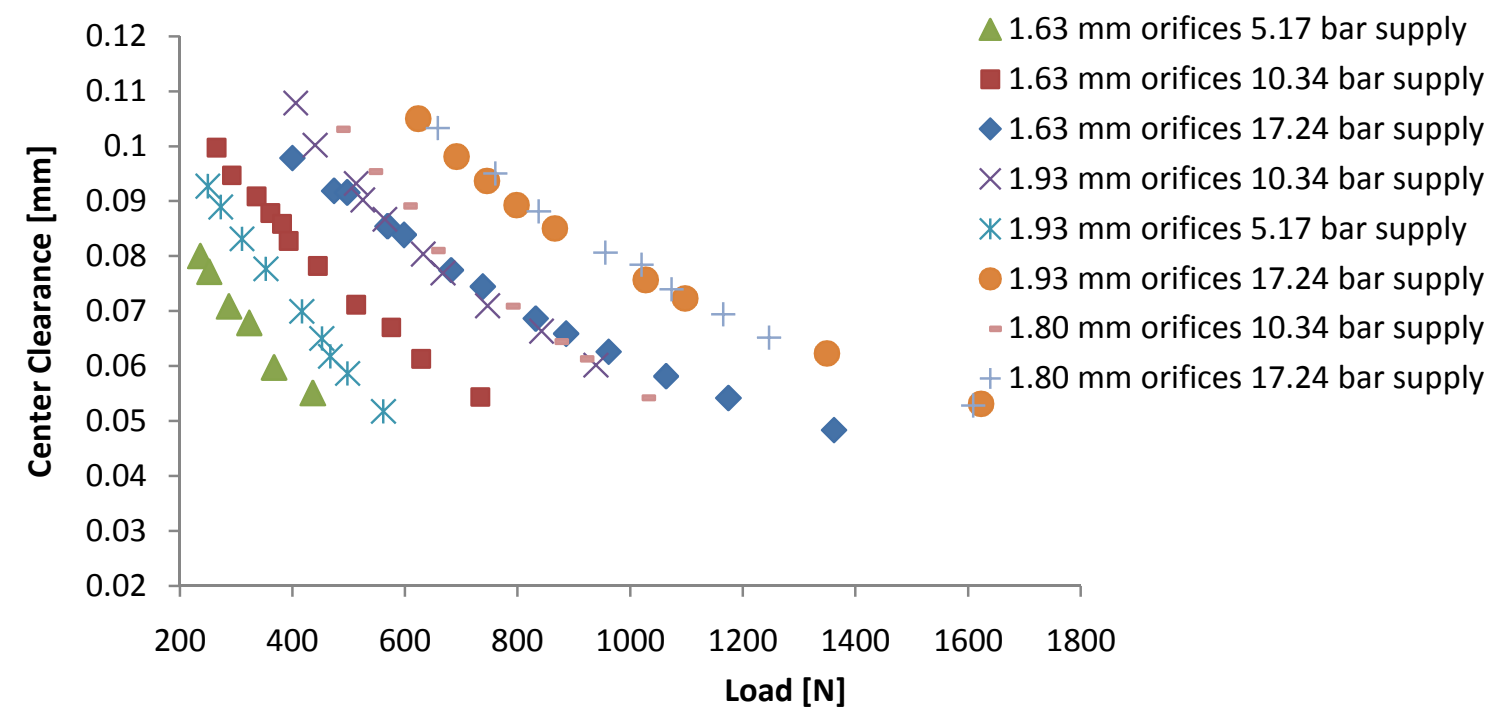

Figure H-14: Center Clearance versus load at $7.5 \mathrm{krpm}$ and all supply pressures for all three orifice diameters 


\section{APPENDIX I}

\section{ESTIMATED AXIAL STIFFNESS FIGURES}

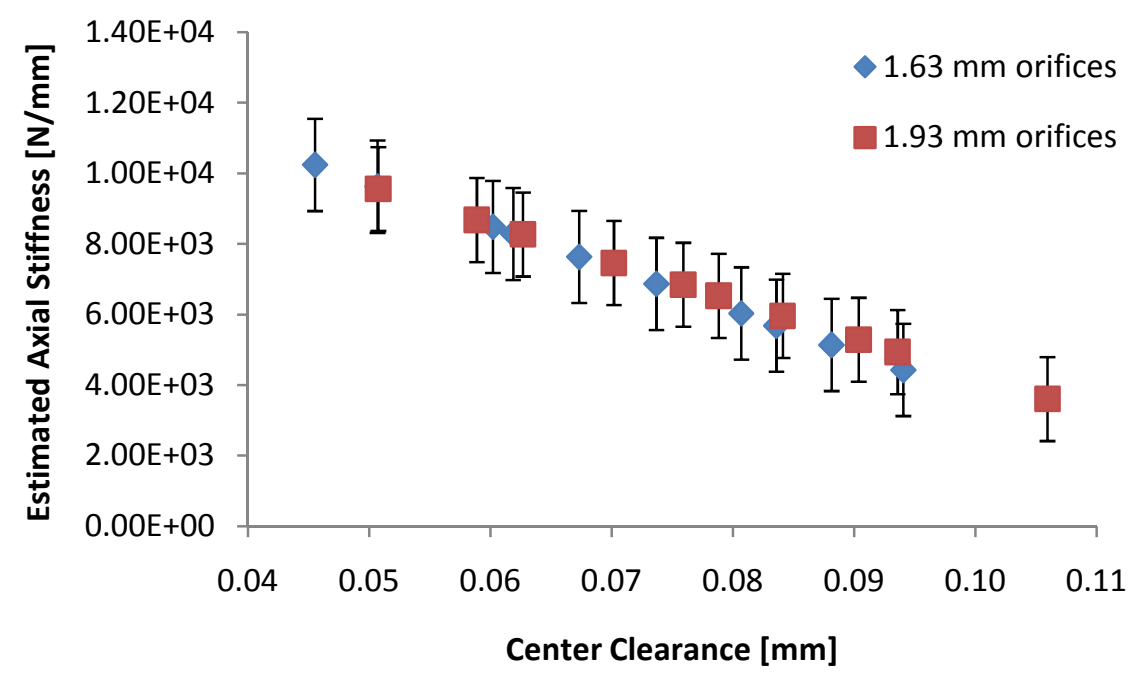

Figure I-1: Estimated axial stiffness versus clearance at 5.17 bar and 0 rpm repeated for reference

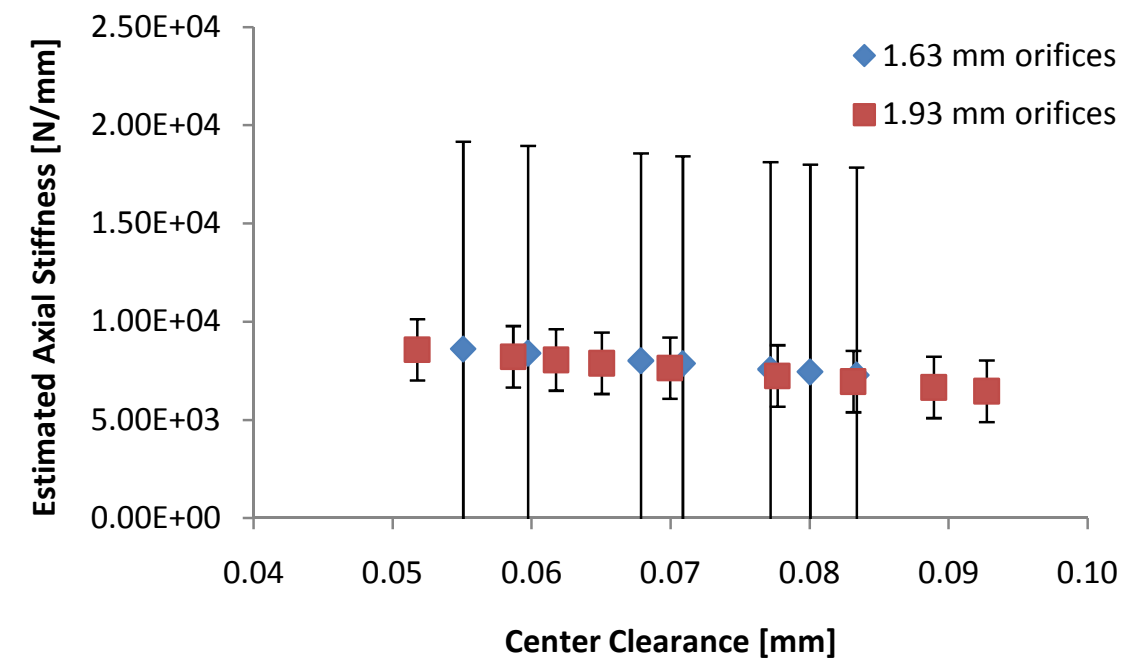

Figure I-2: Estimated axial stiffness versus clearance at 5.17 bar and $7.5 \mathrm{krpm}$ 


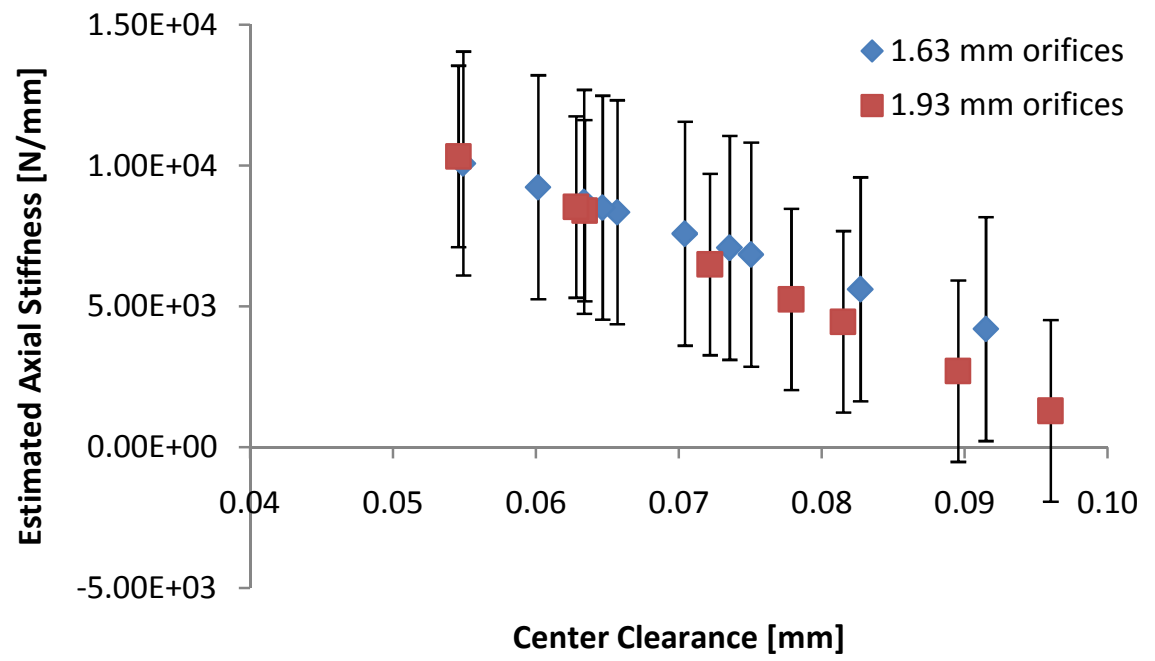

Figure I-3: Estimated axial stiffness versus clearance at 5.17 bar and $12.5 \mathrm{krpm}$

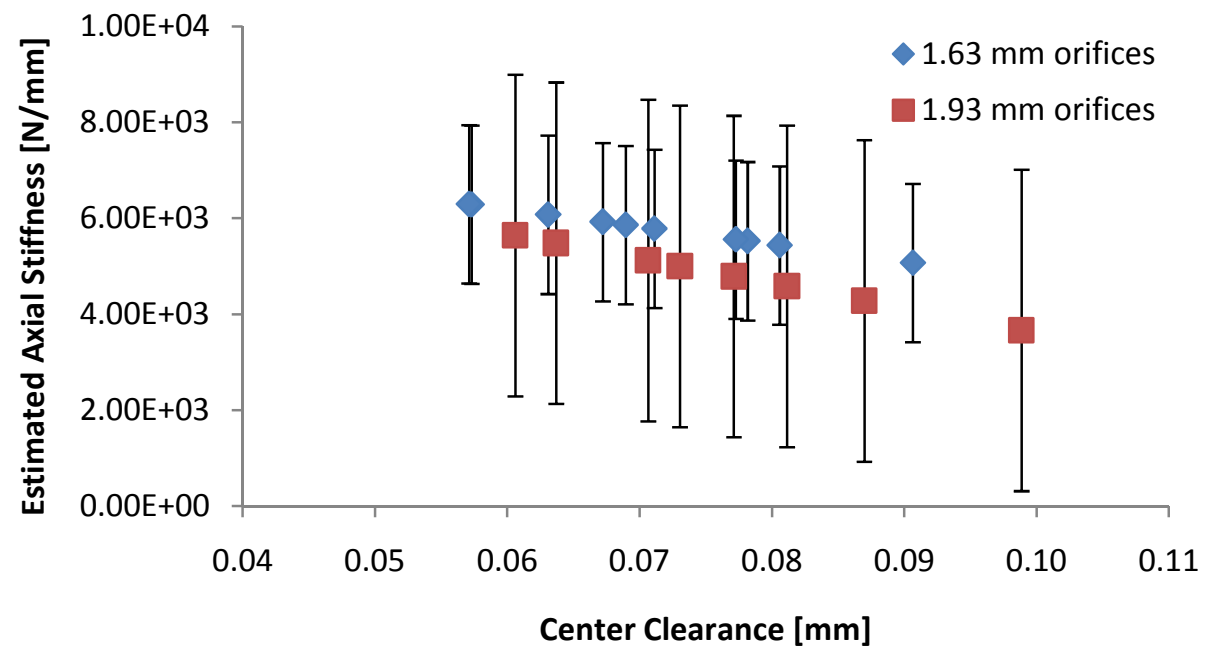

Figure I-4: Estimated axial stiffness versus clearance at 5.17 bar and $17.5 \mathrm{krpm}$ 


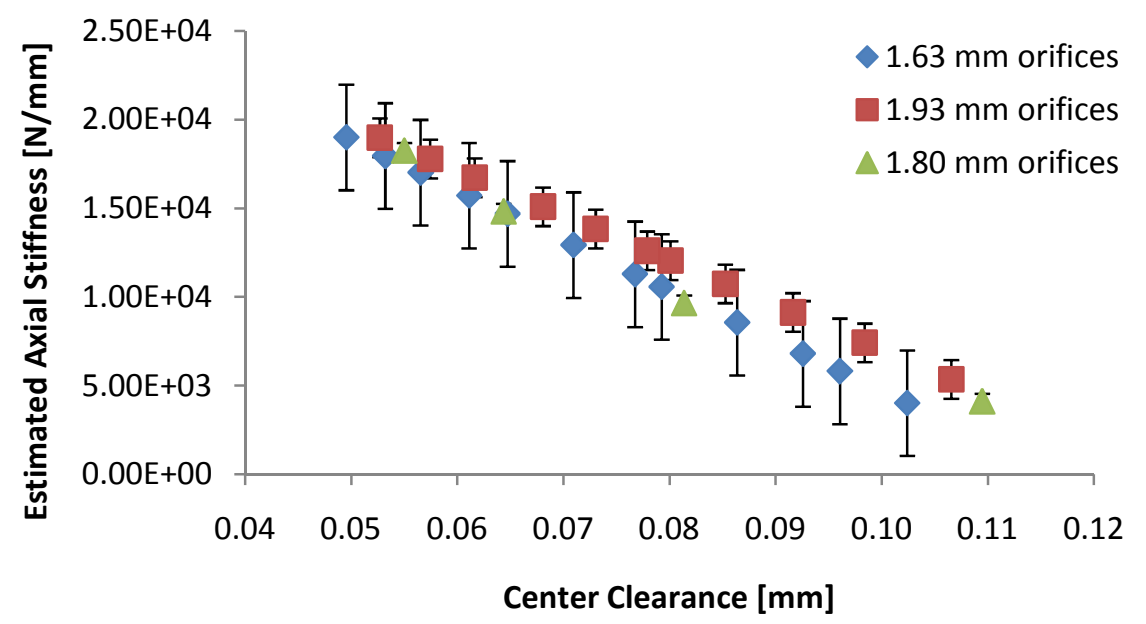

Figure I-5: Estimated axial stiffness versus clearance at 10.34 bar and 0 rpm

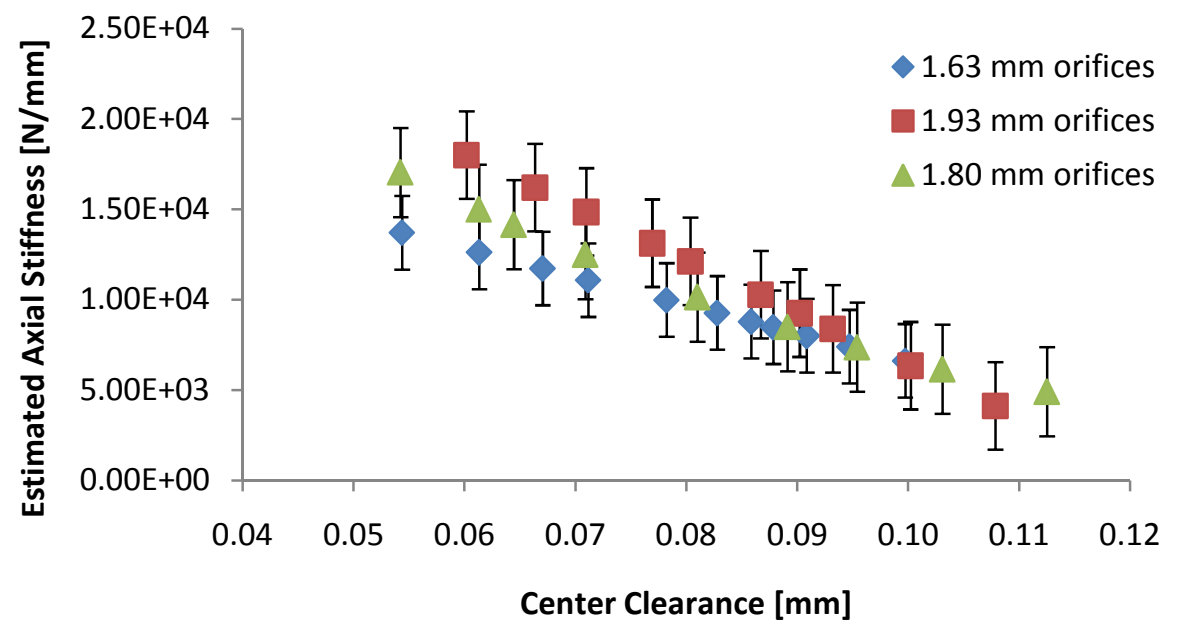

Figure I-6: Estimated axial stiffness versus clearance at 10.34 bar and $7.5 \mathrm{krpm}$ 


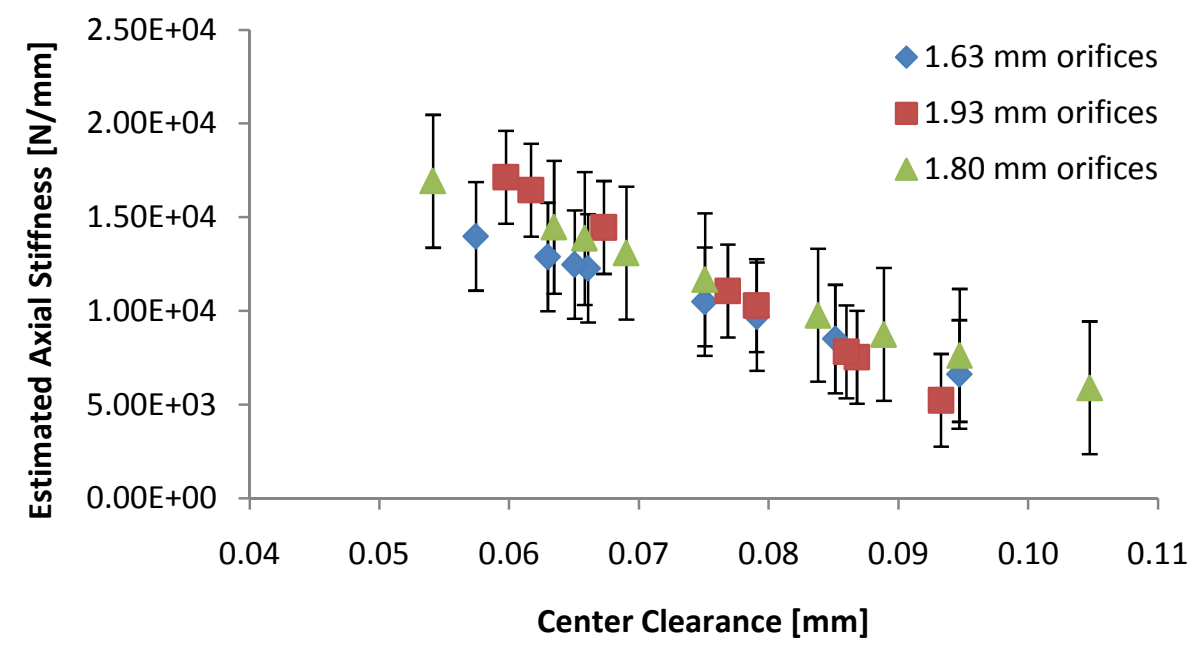

Figure I-7: Estimated axial stiffness versus clearance at 10.34 bar and $12.5 \mathrm{krpm}$

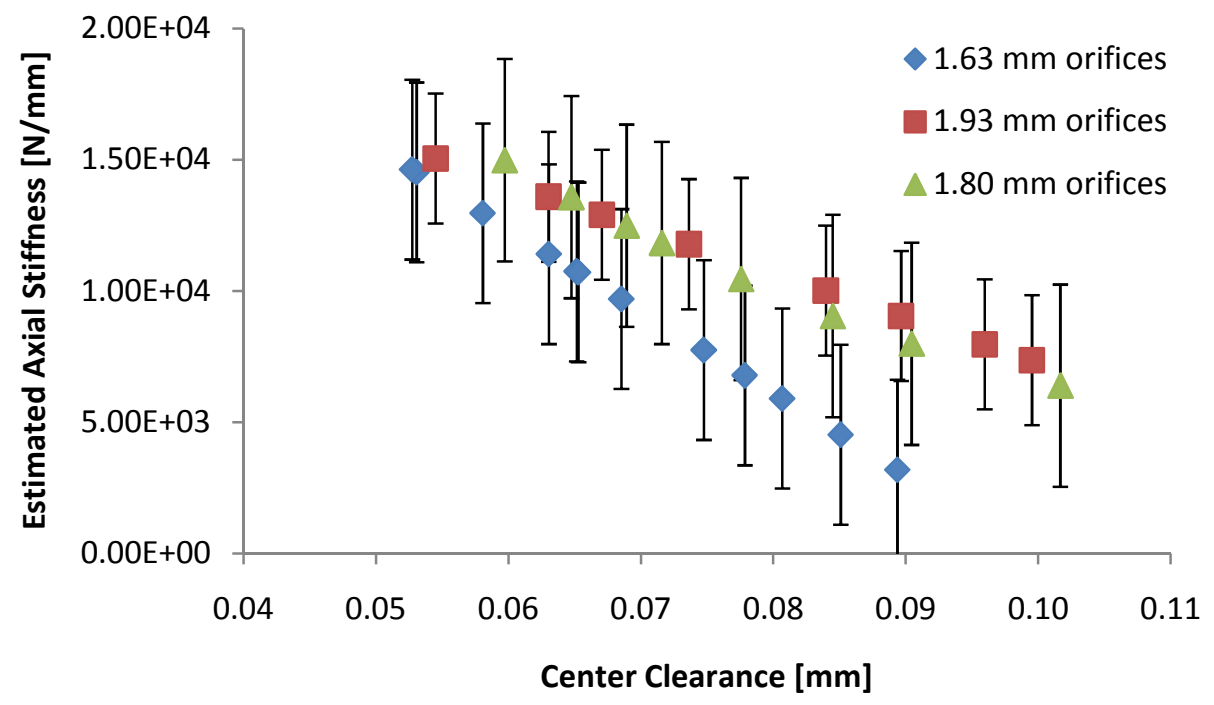

Figure I-8: Estimated axial stiffness versus clearance at 10.34 bar and $17.5 \mathrm{krpm}$ 


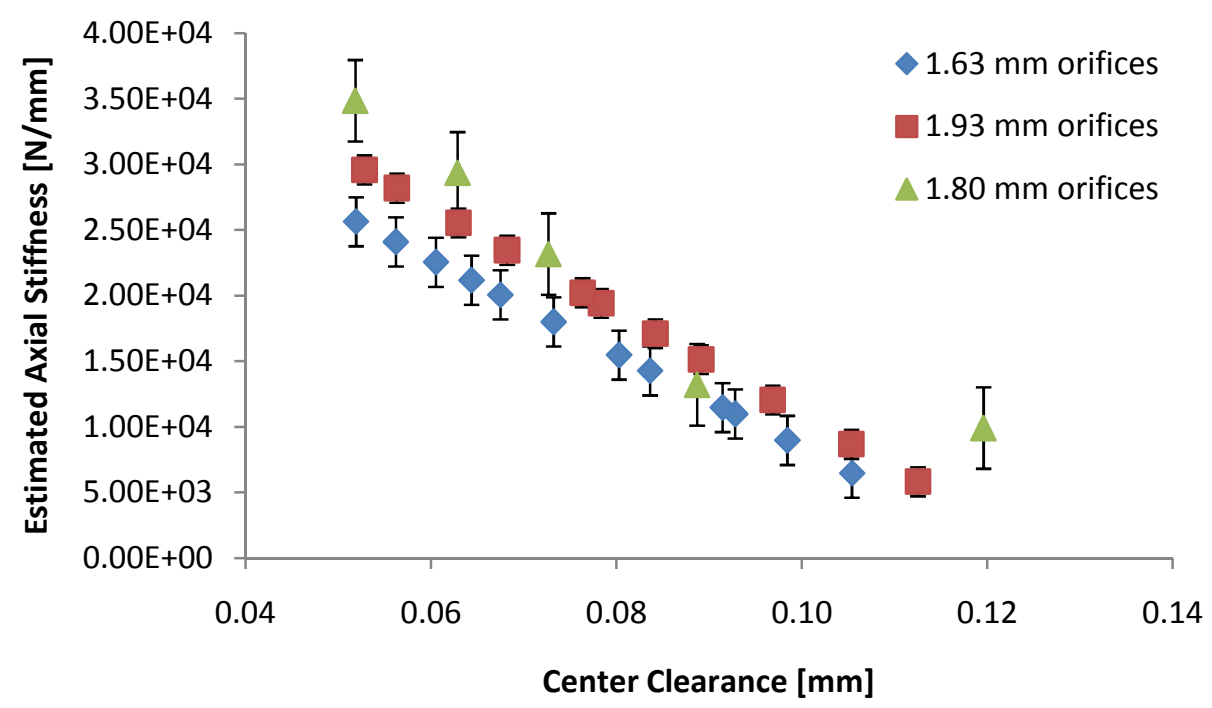

Figure I-9: Estimated axial stiffness versus clearance at 17.24 bar and 0 rpm

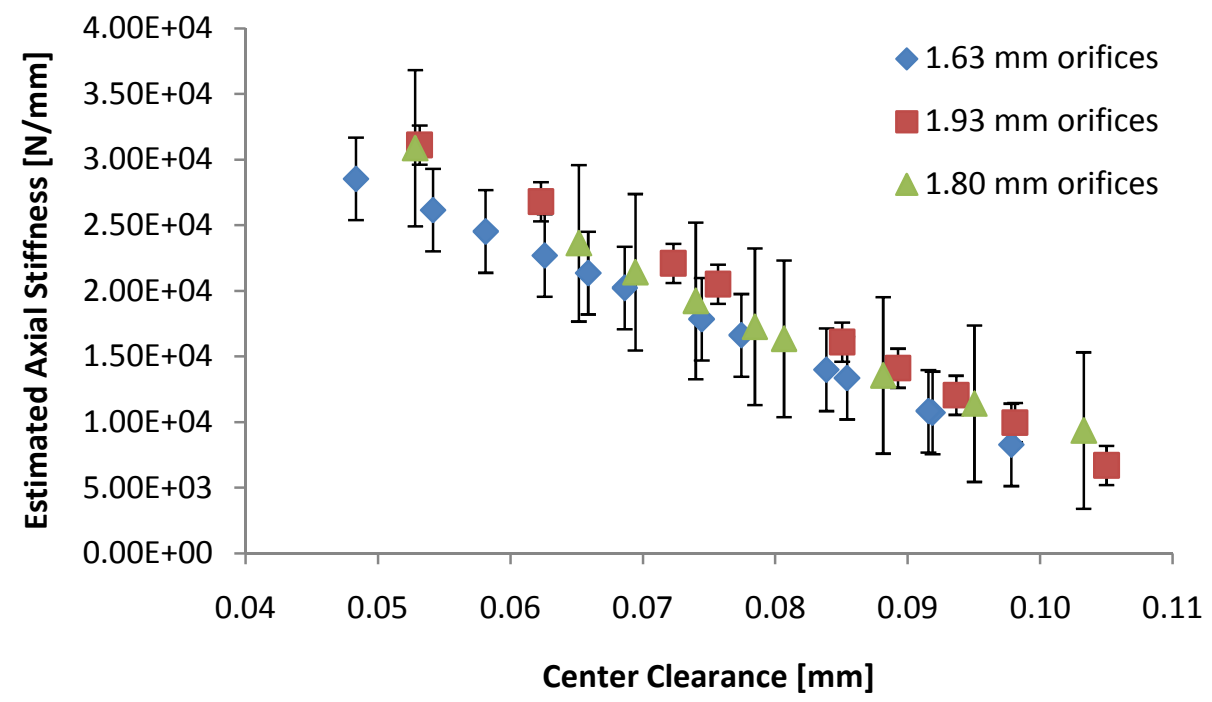

Figure I-10: Estimated axial stiffness versus clearance at 17.24 bar and $7.5 \mathrm{krpm}$ repeated for reference 


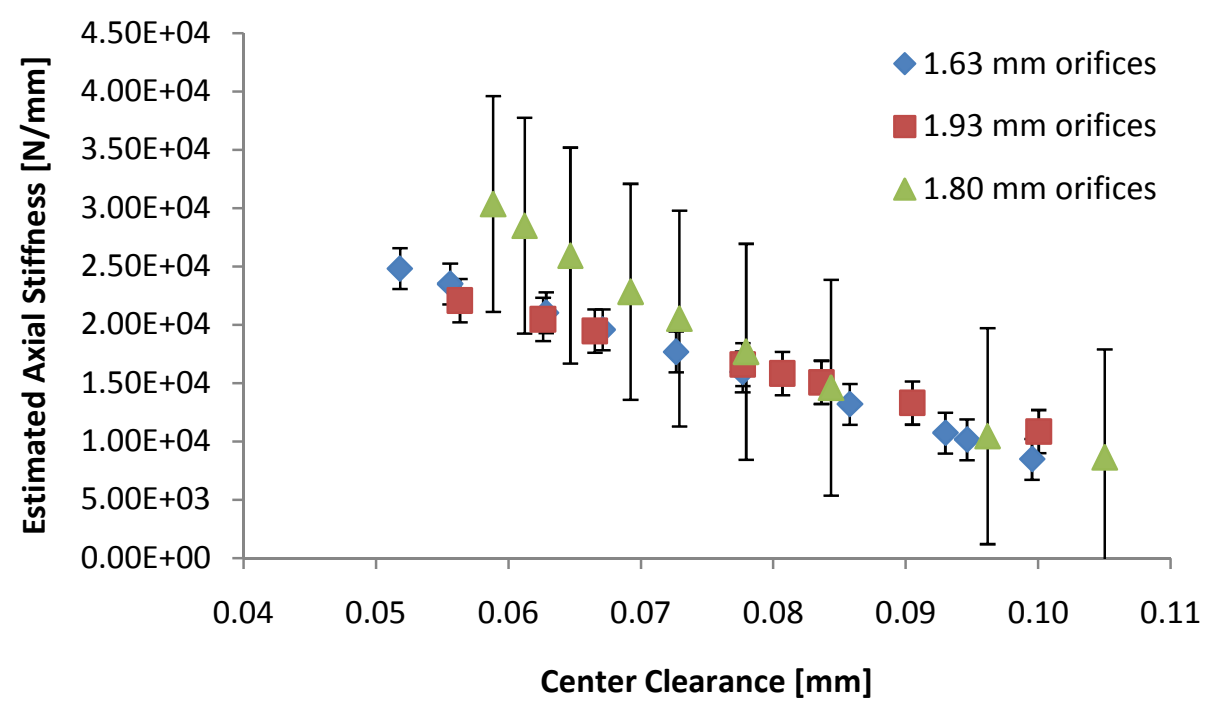

Figure I-11: Estimated axial stiffness versus clearance at 17.24 bar and $12.5 \mathrm{krpm}$

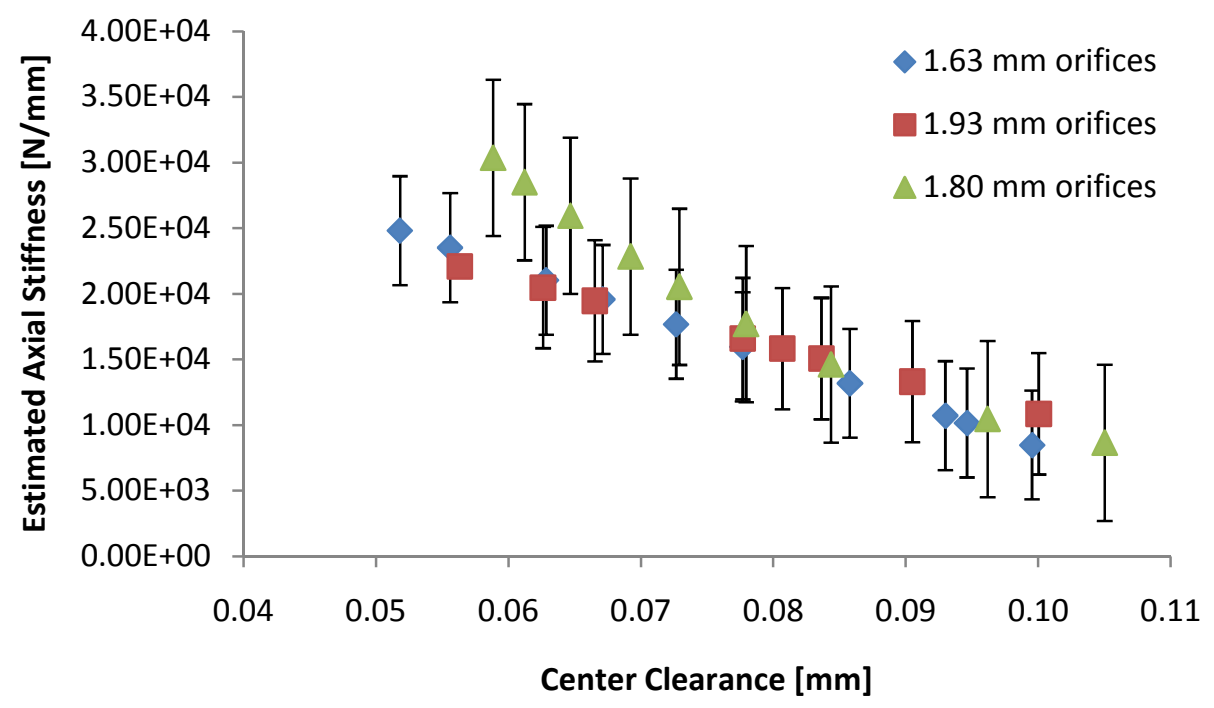

Figure I-12: Estimated axial stiffness versus clearance at 17.24 bar and $17.5 \mathrm{krpm}$ 


\section{VITA}

Name: $\quad$ Paul Robert Esser

Address: $\quad 7045$ Killarney,

Beaumont, TX 77706

Email Address: paul.r.esser@gmail.com

Education: $\quad$ B.S., Engineering - Mechanical Engineering, Texas Christian University, 2006

M.S., Mechanical Engineering, Texas A\&M University, 2010 